International Scientific-Technical and Production Journal

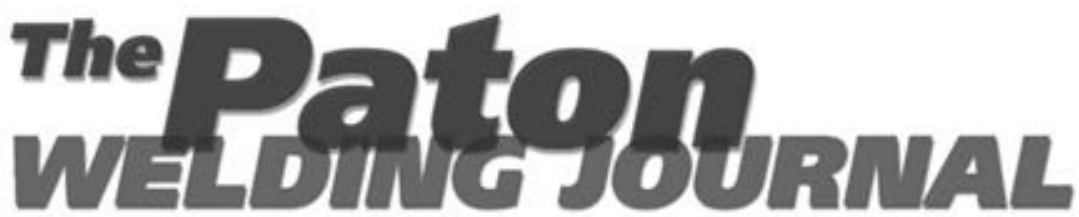

May 2014 No.5

Published since 2000

English translation of the monthly «Avtomaticheskaya Svarka» (Automatic Welding) journal published in Russian since 1948

\section{Editor-in-Chief B.E.Paton EDITORIAL BOARD}

Yu.S. Borisov,

B.V. Khitrovskaya (exec. secretary),

V.F. Khorunov, V.V. Knysh, I.V. Krivtsun,

S.I. Kuchuk-Yatsenko (vice-chief editor)

Yu.N. Lankin, V.N. Lipodaev (vice-chief editor), L.M. Lobanov, A.A. Mazur,

O.K. Nazarenko, I.K. Pokhodnya

V.D. Poznyakov, I.A. Ryabtsev, K.A. Yushchenko,

A.T. Zelnichenko (exec. director)

(Editorial Board Includes PWI Scientists)

\section{INTERNATIONAL EDITORIAL COUNCIL \\ N.P. Alyoshin}

N.E. Bauman MSTU, Moscow, Russia

V.G. Fartushny

Welding Society of Ukraine, Kiev, Ukraine Guan Qiao

Beijing Aeronautical Institute, China V.I. Lysak

Volgograd State Technical University, Russia B.E. Paton

PWI, Kiev, Ukraine

Ya. Pilarczyk

Weiding Institute, Gliwice, Poland U. Reisgen

Welding and Joining Institute, Aachen, Germany O.I. Steklov

Welding Society, Moscow, Russia

G.A. Turichin

St.-Petersburg State Polytechn. Univ., Russia M. Zinigrad

College of Judea \& Samaria, Ariel, Israel A.S. Zubchenko

OKB «Gidropress», Podolsk, Russia

Founders E.O. Paton Electric Welding Institute International Association «Welding» Publisher

International Association «Welding»

Translators

A.A. Fomin O.S. Kurochko,

I.N. Kutianova Editor

N.A. Dmitrieva

Electron galley

D.I. Sereda, T.Yu. Snegiryova

Address

E.O. Paton Electric Welding Institute International Association «Welding"

11, Bozhenko Str., 03680, Kyiv, Ukraine

, Boz (38044) 2006016,2008277

Tel.: (38044) 2006016,2008277

ax: (38044) 20082 77, 20081

www.patonpublishinghouse.com

State Registration Certificate KV 4790 of 09.01.2001 ISSN 0957-798X

Subscriptions

$\$ 348,12$ issues per year, air postage and packaging included. Back issues available. All rights reserved.

This publication and each of the articles contained herein are protected by copyright.

Permission to reproduce material contained in this

journal must be obtained in writing from the Publisher.

\section{CONTENTS}

\section{SCIENTIFIC AND TECHNICAL}

Poznyakov V.D., Markashova L.I., Maksimenko A.A., Berdnikova E.N., Alekseenko T.A. and Kasatkin S.B. Effect of cyclic load on microstructure and cold resistance of the 10G2FB steel HAZ metal

Khorunov V.F. and Lototsky P.N. Features of melting, structure and properties of $\mathrm{Ni}-\mathrm{Mn}-\mathrm{Cu}$ system nickel alloys

Babinets A.A., Ryabtsev I.A., Kondratiev I.A., Ryabtsev I.I. and Gordan G.N. Investigation of thermal resistance of deposited metal designed for restoration of mill rolls

Knysh V.V., Klochkov I.N., Pashulya M.P. and

Motrunich S.I. Increase of fatigue resistance of sheet welded joints of aluminum alloys using high-frequency peening

Fedorchuk V.E., Kushnaryova O.S., Alekseenko T.A. and Falchenko Yu.V. Peculiarities of alloying of weld metal of high-strength aluminium alloy welded joints with scandium

\section{INDUSTRIAL}

Shelyagin V.D., Orishich A.M., Khaskin V.Yu., Malikov

A.G. and Chajka A.A. Technological peculiarities of laser microplasma and hybrid laser-microplasma welding of aluminium alloys

But V.S. and Olejnik O.I. Development of technologies of repair by arc welding of operating main pipelines in Ukraine

Bryzgalin A.G. Assessment of effectiveness of residual stress lowering in circumferential joints of pipes after postweld explosion treatment

\section{NEWS}

The Evgeny Paton Prize Winners of 2013 


\title{
EFFECT OF CYCLIC LOAD ON MICROSTRUCTURE AND COLD RESISTANCE OF THE 10G2FB STEEL HAZ METAL
}

\author{
V.D. POZNYAKOV, L.I. MARKASHOVA, A.A. MAKSIMENKO, \\ E.N. BERDNIKOVA, T.A. ALEKSEENKO and S.B. KASATKIN \\ E.O. Paton Electric Welding Institute, NASU
}

11 Bozhenko Str., 03680, Kiev, Ukraine. E-mail: office@paton.kiev.ua

\begin{abstract}
Fatigue of structural materials is one of the main reasons of breakdown and failure of machines, mechanisms and engineering structures. Fatigue cracks in the welded joints are mainly nucleated in a HAZ, and process of their accumulation has long-term and phasic nature. Aim of the present work lies in investigation of effect of cyclic bending load on change of structure and properties of metal of HAZ in the welded joints of C490 strength class structural steel. Dynamics of accumulation of fatigue damages in the metal was investigated, and effect of cyclic load on cold resistance of the metal of HAZ in 10G2FB steel was estimated using model specimens, treated by welding thermal cycle. It is determined that formation of the fatigue cracks in welded joints as well as model specimens is proceeded by the processes of accumulation of fatigue damages in form of stable slip bands of different configuration as well as formation of extrusions and intrusions. The damages, accumulated in HAZ metal of low-alloy structural steels due to fatigue, promote embrittlement of the metal that results in reduction of its cold resistance. The results of investigations can be used as a basis for methods of testing of welded joints in metal structures of long-term operation as well as for taking the decisions on their strengthening or repair. 15 Ref., 9 Figures.
\end{abstract}

$\boldsymbol{K} \boldsymbol{e} \boldsymbol{y} \boldsymbol{w} \boldsymbol{O} \boldsymbol{r d} \boldsymbol{s}:$ arc welding, 10G2FB steel, welding thermal cycles, model specimens, heat-affected zone, cyclic bending load, structural changes, fatigue cracks, impact toughness

It is a well-known fact that one of the main reasons of breakdown and failure of machines, mechanisms and engineering structures is fatigue of structural materials [1], which results in formation of the fatigue cracks in separate part assemblies, having the greatest loading [2]. Typically, such assemblies in the welded joints are specific zones, which mainly include structural stress concentrators [2]. By now, number of accidents due to specified metal condition is still large, regardless the significant success in study of mechanisms of the fatigue processes and development of methods for increase of life duration of the welded metal structures. Therefore, specific practical interest is paid to investigation of the processes and reasons reducing life duration of the materials under service conditions, in particular, with regard to fatigue damage of the structures, which is evidenced by publications of the recent years [3-7].

The E.O. Paton Electric Welding Institute also carries out such works [8-11]. In particular, work [10] shows that accumulation of the fatigue damages and fatigue changes under conditions of cyclic bending load of the welded joints from low-alloy structural steel 09G2S are mainly localized in metal of HAZ and adjacent to it areas of the base metal. As a result, the metal becomes brittle and its cold resistance reduces by $20-40 \%$.

However, there are some difficulties in investigation of the reasons of fatigue damages directly on the welded joints. They are related with simultaneous effect of series of technological and structural conditions, among which the most important are inhomogeneity of structure and, respectively, properties of the metal in different zones of the welded joints varying in chemical and phase composition, as well as changes of welding modes, weld geometry, external load conditions etc. Eventually, a complex of structural, technological and external parameters promotes, particularly, appearance of significant errors in the results of investigations.

Considering complexity of the factors, promoting fatigue damages, a stepwise approach is taken for investigation of effect of cyclic load on the structure and, respectively, cold resistance of the HAZ metal of structural steel. It provides for successive study of conditions of damage accumulation in the welded joints (by making notches of different depth $\delta$ ), effect of rise of cyclic load (frequency, stress $\sigma_{-1}$ and increase of number of cycles $N$ ). At that, the whole complex of investigations was carried out only using model 
specimens that ensure consistency of chemical composition in examined zones of the welded joints, and process stability was provided by conditions of simulation of welding thermal cycle.

Materials and investigation procedures. The simulation of welding thermal cycles (heating and cooling in accordance with the modes which take place in HAZ metal of the real welded joints) using model specimens of $20 \times 20 \times 120 \mathrm{~mm}$ size (steel 10G2FB) was carried out on special unit of MSP-75 type, designed at the E.O. Paton Electric Welding Institute on the basis of machine for resistance welding. It allows simulation of real welding cycles through specimens heating using passing current and cooling by compressed air.

Heating rate of the specimens in simulation of welding cycles (specimens were heated to $1100{ }^{\circ} \mathrm{C}$ ) made $150{ }^{\circ} \mathrm{C} / \mathrm{s}$, and cooling rate in the range of $600-500{ }^{\circ} \mathrm{C}$ was $w_{6 / 5}=10{ }^{\circ} \mathrm{C} / \mathrm{s}$. After treatment of the specimens on welding thermal cycle for simulation of geometry stress concentrator, which is usually observed in the welded joints at weld to base metal transition, notches of $2 \mathrm{~mm}$ width and $1 \mathrm{~mm}$ rounded radius near its tip were made of the surface of $20 \times 20 \times$ $\times 60 \mathrm{~mm}$ size specimens. At that, notches of 1 , 3.5 and $7 \mathrm{~mm}$ were made on the specimens at initial stage of the investigations (in elaboration of the most optimum evaluation procedure) that allowed determining, which of the specimens would reflect real structural processes (slip sys- tems, cracks etc.), indicating accumulation of the damages taking place in the joints.

Fatigue testing of the model specimens was carried out on low-duty fatigue machine of UMM-1 type. The specimens were subjected to cyclic bending load with symmetric cycle at $35 \mathrm{~Hz}$ frequency and cycle stress $\sigma_{a}=120 \mathrm{MPa}$.

Structural changes under effect of different conditions of loading were studied using complex of the investigation methods, namely optical metallography (Versamet-2), analytical scanning electron microscopy (Philips SEM-515, Netherlands) and light electron microscopy (JEOL JEM-200CX, Japan) with accelerating voltage $200 \mathrm{kV}$.

Results of investigation. At the first stage, nature and distribution of slip systems on side surfaces of the specimens in corresponding zones of welding were investigated depending on number of load cycles as well as at change of notch depth, made for the purpose of simulation of geometry stress concentrator and, respectively, the conditions of crack formation in the welded joints in zone of weld to base metal transition.

Metallographic investigations showed that the fatigue cracks in specimens with $\delta=1 \mathrm{~mm}$ were formed after $2 \mathrm{mln} 500$ thou cycles of load $\left(0.45 N / N_{\text {fr }}\right.$, Figure 1, $\left.a\right)$.

Increase of number of load cycles rises an intensity of fatigue damages of the surface of model specimens that indicates increase of amount of stable slip bands as well as appearance of extru-

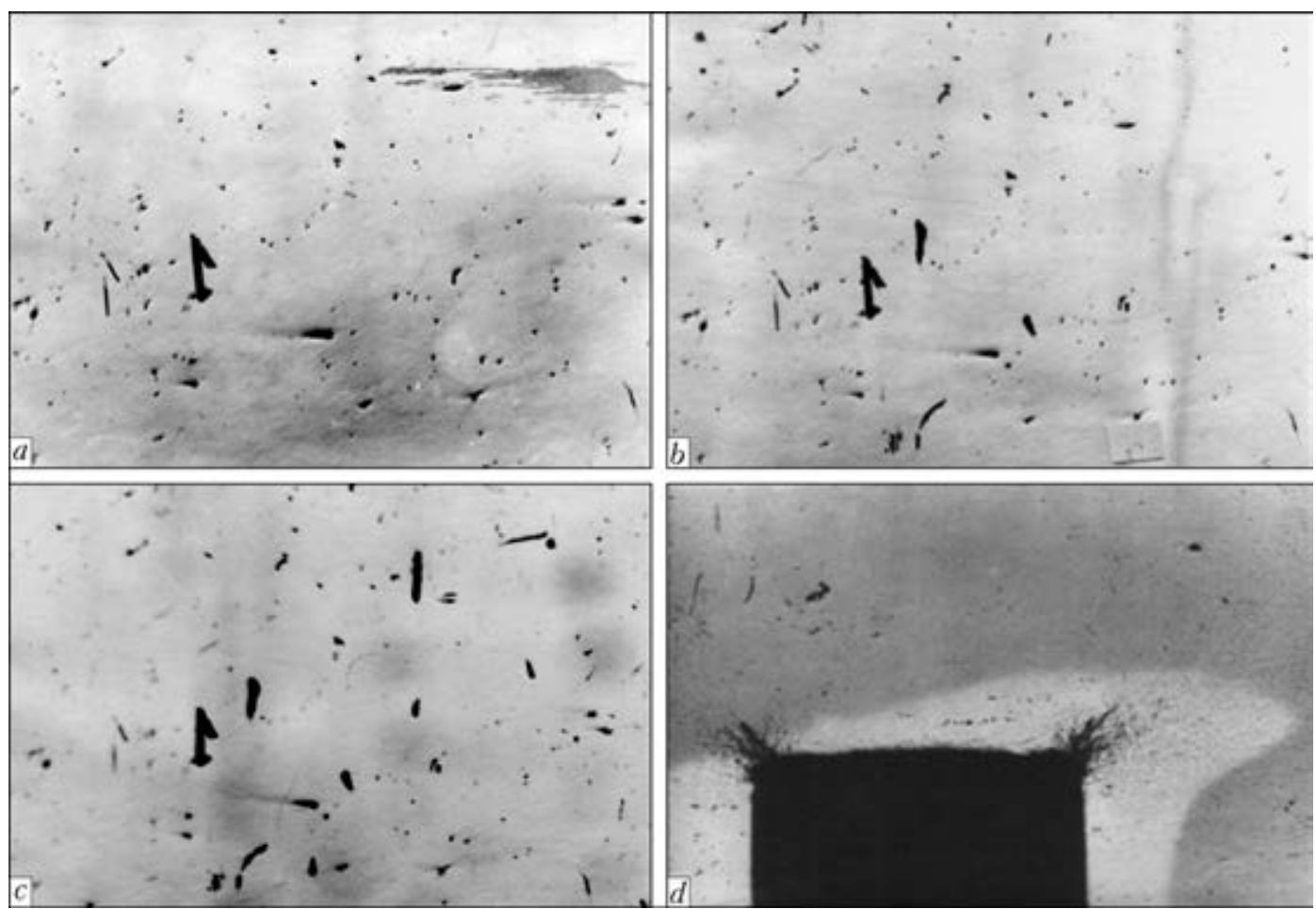

Figure 1. Macrostructure $(a-c-\times 50 ; d-\times 30)$ of steel 10G2FB model specimens with different notch depth after cyclic load: $a-0.45 N / N_{\mathrm{fr}}, \delta=1 \mathrm{~mm} ; b-0.70 \mathrm{~N} / N_{\mathrm{fr}}, \delta=1 \mathrm{~mm} ; c-0.80 \mathrm{~N} / N_{\mathrm{fr}}, \delta=1 \mathrm{~mm} ; d-N_{\mathrm{fr}}, \delta=3.5 \mathrm{~mm}$ 
sions and intrusions. Moreover, further loading becomes structurally evident through growth of dimensions of stable slip bands, complication of their configuration as well as increase of distribution frequency of slip bands on the surface of model specimens $\left(0.70 \mathrm{~N} / \mathrm{N}_{\mathrm{fr}}, 0.80 \mathrm{~N} / \mathrm{N}_{\mathrm{fr}}\right)(\mathrm{Fi}-$ gure $1, b, c)$. At that, fatigue damages and structural changes in the HAZ metal of specimens developed, as a rule, in certain zones and had local nature. The greatest number of the stable slip bands was observed in central (axial) part of the specimen that, apparently, is caused by high level of stresses acting in this zone in course of cyclic strain.

The similar structural changes, but at earlier stages of cyclic bending load were observed in the specimens with $\delta=3.5 \mathrm{~mm}$. The fatigue cracks in these specimens were already formed after $N=$ $=21,000$ cycles of load (Figure 1, $d$ ), proceeded by significant changes in structure of the HAZ metal under notch. Beginning of formation of the stable slip bands in examined specimens was observed after 5000 cycles of load and further increase of number of load cycles promoted growth of density of the stable slip bands.

Completely another situation was observed near the surface of specimens with $\delta=7 \mathrm{~mm}$. The fatigue cracks in these specimens have already formed after 4500 cycles of load, nucleation of such type of the cracks takes place immediately under notch and without noticeable (at optical investigations) changes in metal structure.

It is determined, considering the results of investigation of structures with different notch depth, that $\delta=3.5 \mathrm{~mm}$ is the optimum specimen

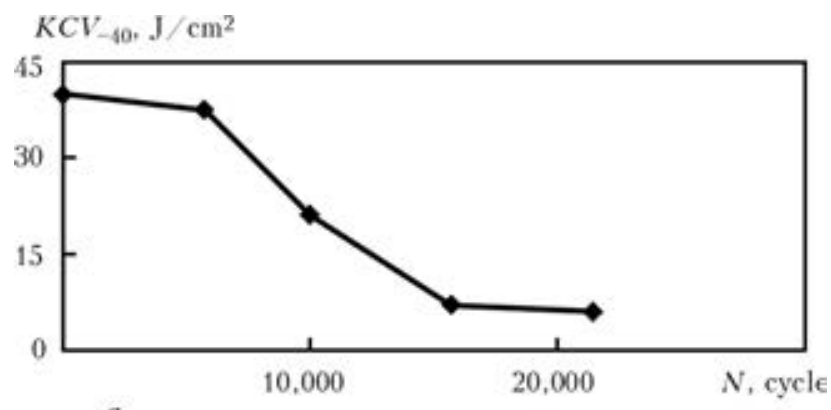

$a$

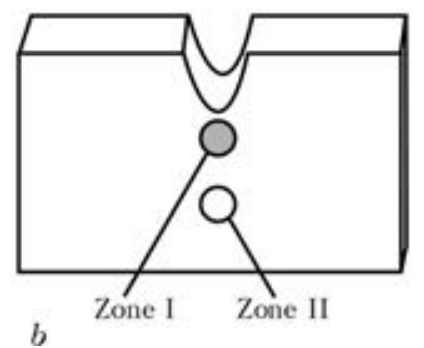

Figure 2. Effect of cyclic load on impact toughness of steel 10G2FB model specimens $(a)$, and scheme of specimen with indication of examined zones $(b)$ notch. This allows reproducing all structural changes accompanying the processes, which are studied in the welded joints, as well as accelerating the procedure of specimen preparation to further examination.

For this purpose, first of all, effect of the level (number) of cyclic load on nature of plastic strain, formation of fatigue cracks and cold resistance were investigated on the model specimens (particularly with $\delta \sim 3.5 \mathrm{~mm}$ ) treated on welding thermal cycle after cyclic load under cycle stress $120 \mathrm{MPa}$. Loading at $N=21,000$ results in development of $2 \mathrm{~mm}$ fatigue crack from notch tip with plastic strain zone, which indicate that these number of cycles is critical one and loading to $N=7000,11,000$ and 15,000 makes $33.3,53.2$ and $71.4 \%$ of critical load, respectively.

Impact bending tests of standard specimens with sharp Charpy notch, cut from model specimens after all cyclic loads with notch $(\delta$ $\sim 3.5 \mathrm{~mm}$ ) tip orientation in area of plastic strain zone, were carried out in parallel. At that, according to [10] reduction of indices of critical stress intensity factor $K_{1 c}$ and critical crack opening in HAZ metal takes place at negative temperatures, therefore, the tests of specified specimens were carried out at $-40{ }^{\circ} \mathrm{C}$. As can be seen from Figure 2, $a$, the values of impact toughness in the initial condition after treatment on welding thermal cycle, as well as cyclic load to 7000 in tested specimens, were sufficiently similar (37$40 \mathrm{~J} / \mathrm{cm}^{2}$ ). Increase of load cycles promotes irregularity of such uniformity. Cold resistance of model specimens reduces gradually to 18$22 \mathrm{~J} / \mathrm{cm}^{2}$ after 11,000 cycles and to $7-8$ and $4.5-6 \mathrm{~J} / \mathrm{cm}^{2}$ after 15,000 and 21,000 load cycles, respectively. Thus, impact toughness of the specimens from steel 10G2FB reduces 1.8, 4.9 and 7.5 times under given conditions of cyclic load in comparison with initial conditions $(N=0)$.

The second stage of work lied in structural examinations, aim of which was determination of the initial structure before loading under conditions of growth of cyclic load as well as determination of peculiarities of structural changes, accompanying crack formation.

Change of structural composition, first of all, phase constituents, dimension of their grains, microhardness, as well as such parameters of fine structure as dimensions of subgrains, width of laths, density and distribution of dislocations in the model specimens were examined in two specific zones, namely I - under notch (zone of maximum loading), and II - in the center of specimen (see Figure 2, b)

Initial structure condition. Structure of metal in the specimens treated on welding thermal cycle, but did not subjected to cyclic load (initial 

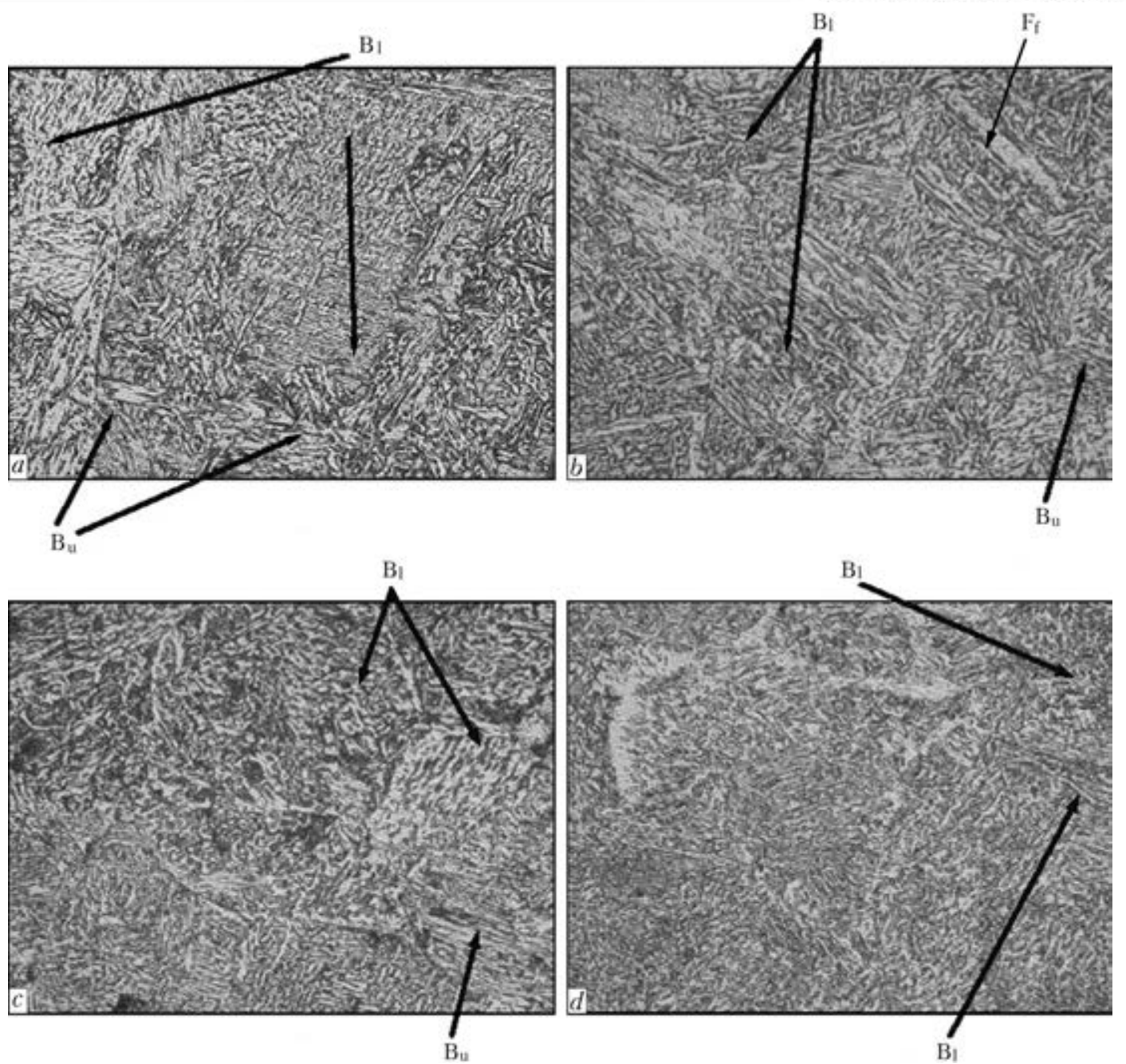

Figure 3. Microstructure $(\times 500)$ of metal of steel 10G2FB model specimens in HAZ overheating area in initial condition $(a, b)$ and after 21,000 cycles of load $(c, d)$ under notch $(a, c)$ and in the specimen center $(b, d)$

condition), was investigated. The structure under notch (zone I) as well as in the center of specimen (zone II) is represented by upper bainite $\left(\mathrm{B}_{\mathrm{u}}\right)$, lower bainite $\left(\mathrm{B}_{1}\right)$ and ferrite fringes $\left(\mathrm{F}_{\mathrm{f}}\right)(\mathrm{Fi}-$ gure $3, a, b)$. In zone I dimension of upper bainite grain $D_{\mathrm{g}}$ lies in the range of $100-250 \mu \mathrm{m}(\mathrm{Fi}-$ gure $4, a)$. Dimension of lower bainite grain changes from 80 to $180 \mu \mathrm{m}$ and width of ferrite fringes is from 5 to $10 \mu \mathrm{m}$. Microhardness $H \mathrm{~V}$ of upper bainite takes $2370-2470 \mathrm{MPa}$ range and that for lower bainite is $2630-2830 \mathrm{MPa}$.

Metal structure similar on phase composition (in initial condition) was formed in the center of specimen, but it has somewhat another parameters and microhardness. Rise of dimensions of grain of structural constituents, namely upper bainite by $16 \%$ (to $130-290 \mu \mathrm{m}$ ) and lower bainite by $26 \%$ (to $120-230 \mu \mathrm{m}$ ) is observed in zone II in contrast with zone I, whereas their microhradness reduces by $5 \%$ (Figure $4, c$ ). Dimension of ferrite fringes in these zones remains the same.

Investigation of fine metal structure in zones I and II at initial condition using transmission mi- croscopy determined (Figures $4, b, d ; 5, a, b$ ) that width of lath $h_{1}$ for upper bainite reduces in zone I in comparison with corresponding parameters in zone II by $13 \%$ and makes $h_{1} \sim 0.5-1.8 \mu \mathrm{m}$, i.e. dimensions of dislocation substructure $d_{\mathrm{s}}$ also reduces, mainly with substructures of lower bainite in zone I (almost 1.4 times reduction to $\sim 0.5-0.8 \mu \mathrm{m}$ dimension). As for values of insidevolume dislocation density $\rho$, then, concerning different structural constituents (and for $B_{u}$ and $B_{1}$ ) lager increase of dislocation density is typical for zone I, i.e. for zone with maximum loading (Figure $4, b$ ). It is typically that volume dislocation density rises to lager extent in lower bainite structures, for which $\rho \sim 5-7 \cdot 10^{10} \mathrm{~cm}^{-2}$, and $\rho \sim(3-5) \cdot 10^{10} \mathrm{~cm}^{-2}$ for upper bainite.

Cyclic load. Transformation of structural constituents takes place in the process of further cyclic load of the examined metal directly under notch (zone I). In comparison with initial condition, reduction of the dimension of upper bainite grain is observed on average by 4, 11 and $20 \%$ after $7000,15,000$ and 21,000 cycles of load, 

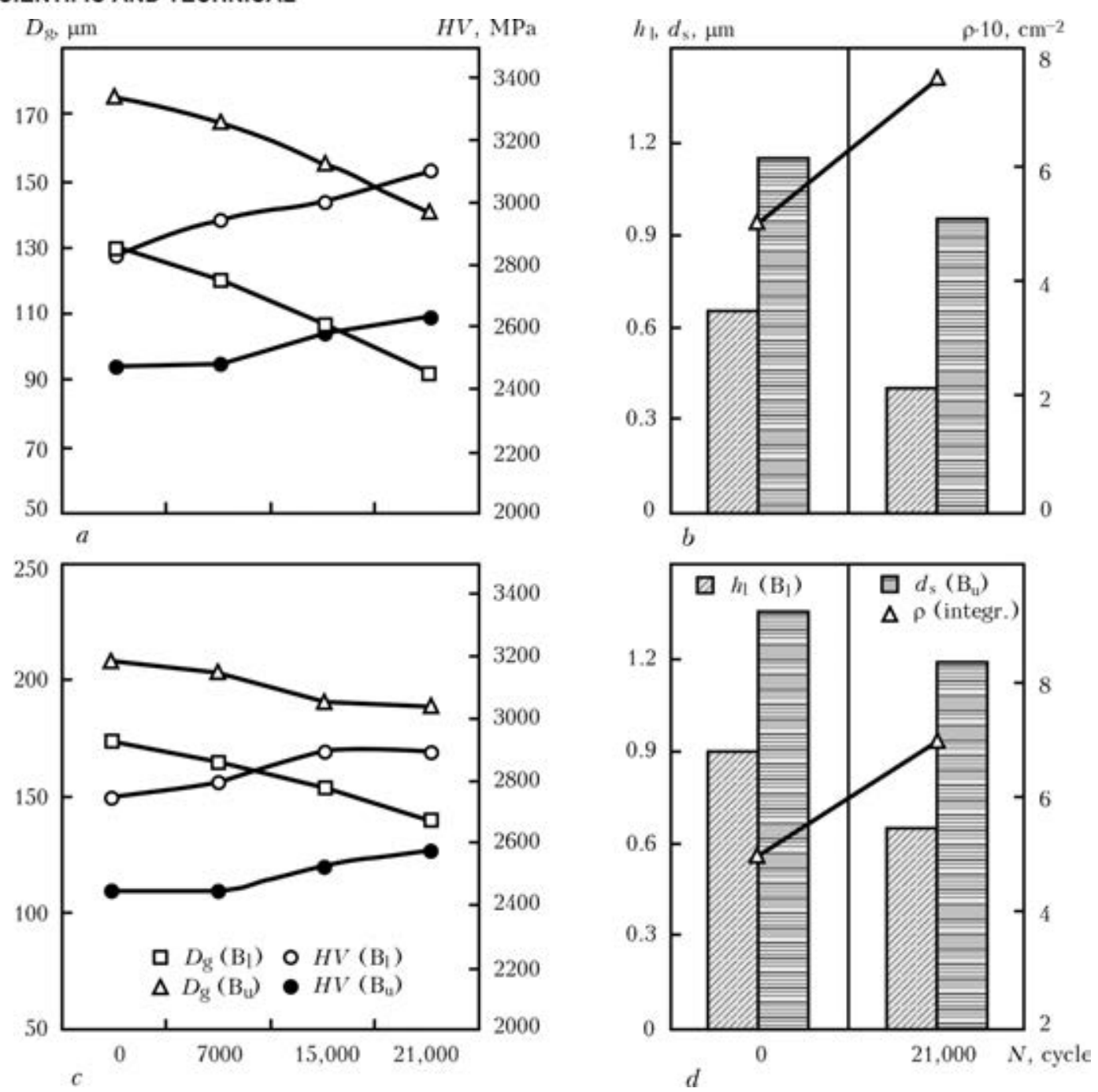

Figure 4. Dependence of average grain size and maximum values of microhardness $(a, c)$, lath width and dislocation density $(b, d)$ in structural constituents of metal of steel 10G2FB model specimens under notch $(a, b)$ and in the center specimen $(c, d)$ on number of load cycles

respectively (Figure 4, $a$ ). Similarly, 8, 18 and $30 \%$ decrease of the dimensions of lower bainite grains takes place. At that, width of ferrite fringes remains the same.

Values of microhardness for upper bainite structures are, virtually, at the level of initial ones (without cyclic load) (2360-2500 MPa) at minimum number of load cycles at the level of around 7000, whereas they are somewhat higher (up to 2570-2940 MPa) for lower bainite. Inhomogeneity of the microhardness indices of indicated structural constituents $\left(\mathrm{B}_{\mathrm{u}}, \mathrm{B}_{1}\right)$ are also observed at increase of number of load cycles to $N \sim 15,000$ and this tendency is preserved ( $\mathrm{Fi}-$ gure $4, a, c)$ with maximum number of load cycles (up to 21,000).

Examination of changes of fine metal structure in zone I during deformation process determined that cyclic load (from initial to $N=21,000$ ) promotes reduction of the structure dimensions in comparison with initial one (1.6 times, i.e. by $38 \%)$ as well as decrease of the dimensions of upper bainite laths 1.2 times, i.e. by $17 \%$. Besides, approximately, 1.4 times increase (from $6 \cdot 10^{10}$ to $8.5 \cdot 10^{10} \mathrm{~cm}^{-2}$ ) (see Figure $4, b$ ) of total volume density of the dislocations takes place in wrought metal. At that, formation of intergranular dislocation substructure, i.e. fragmentation of structure (Figure 5, d) with clear subboundaries and higher scalar dislocation density $(\rho \sim$ $\sim(7-9) \cdot 10^{10} \mathrm{~cm}^{-2}$ ), is observed in the structures of lower bainite, that is higher of the corresponding values in the structures of upper bainite $\left(\rho \sim(5-8) \cdot 10^{10} \mathrm{~cm}^{-2}\right)$ (Figure 5, $\left.c\right)$.

Similar dependencies in transformation of the structural constituents, taking place as a result of effect of external cyclic bending load, is observed in the metal in specimen center (zone II). It was also found in this case that increase of number of load cycles promotes reduction of grain dimensions of upper and lower bainite in the following order, namely by 3 and $6 \%$ after 7000 cycles, by 8 and $11 \%$ after 15,000 and by 10 and $20 \%$ after 21,000 cycles, respectively. Micro- 

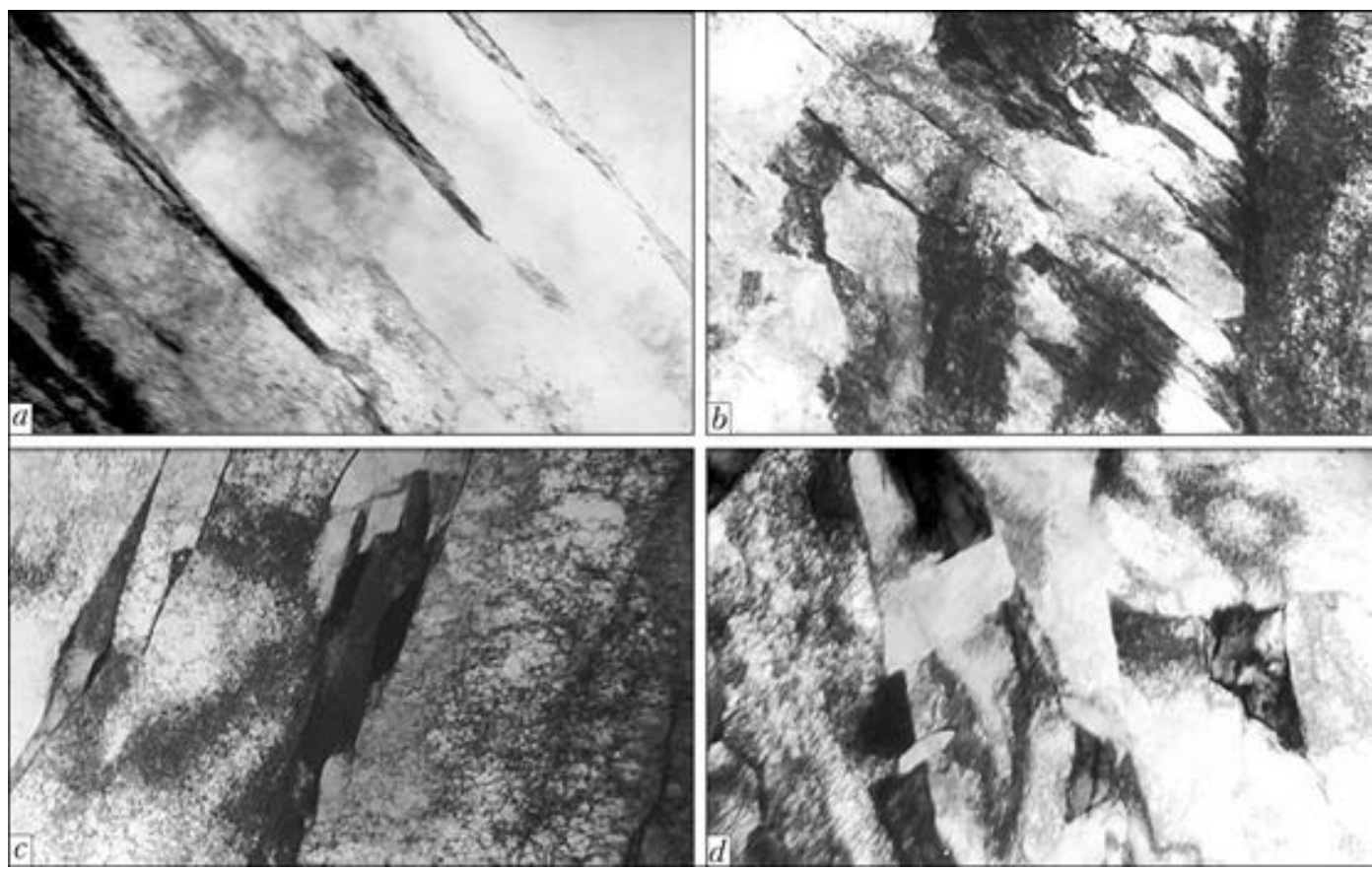

Figure 5. Microstructure $(\times 1500)$ of metal of steel 10G2FB model specimens in initial condition $(a, b)$ and after 21,000 cycles of load $(c, d)$ in zone I: $a, c$ - laths of upper bainite; $b, d$ - fragments of lower bainite

hardness of the structural constituents in zone II shows increase for upper and lower bainite (see Figure $4, c$ ) with rise of number of cycles.

More detailed transmission examinations of zone II fine structure showed that width of laths of upper bainite at $N=21,000$ reduces 1.1 times (by $11 \%$ ) in comparison with initial condition, and dimensions of fragments of lower bainite decreases, approximately, 1.4 times, i.e. by $27 \%$. Total volume density of dislocations in given zone also rises from $4 \cdot 10^{10}$ to $6.5 \cdot 10^{10} \mathrm{~cm}^{-2}$, i.e. 1.5 times.

It is interesting to note that the greatest dislocation density is observed along the boundaries of upper bainite laths in zone I. It rises up to $2.5 \cdot 10^{11} \mathrm{~cm}^{-2}$ in separate zones after $21,000 \mathrm{cy}$ cles, that results in appearance of clear zones of deformation localizing and, obviously, is one of the main reasons of crack formation (Figure 6).

Performed complex of experimental investigations was used for estimation of differential effect of structural parameters of HAZ metal of 10G2FB steel deformed under cyclic load on change of main service characteristics of examined specimens, i.e. static strength, fracture toughness and crack resistance. Analytical estimation of integral value of yield strength $\Sigma \sigma_{\mathrm{y}}$ was carried out using equation, including known dependencies of Hall-Petch, Orowan and others:

$$
\Sigma \sigma_{\mathrm{y}}=\Delta \sigma_{0}+\Delta \sigma_{\mathrm{s} . \mathrm{s}}+\Delta \sigma_{\mathrm{g}}+\Delta \sigma_{\mathrm{s}}+\Delta \sigma_{\mathrm{d}}+\Delta \sigma_{\mathrm{d} . \mathrm{s}}
$$

where $\Delta \sigma_{0}$ is the resistance of metal lattice to movement of free dislocations; $\Delta \sigma_{\text {s.s }}$ is the strengthening of solid solution with alloying elements; $\Delta \sigma_{\mathrm{g}}, \Delta \sigma_{\mathrm{s}}$ is the strengthening due to change of value of grain and subgrain; $\Delta \sigma_{d}$ is the dislocation strengthening; $\Delta \sigma_{\mathrm{d} . \mathrm{s}}$ is the dispersion strengthening. The examples of calculation are given in works [12, 13].

It is shown as a results of analytical estimation of metal yield strength (Figure 7), that $\sigma_{\mathrm{y}} \sim$ $\sim 541 \mathrm{MPa}$ in initial condition in zone II after treatment on welding thermal cycle. In zone I this index is little bit higher $\left(\sigma_{\mathrm{y}} \sim 644 \mathrm{MPa}\right)$ that can be related with more intensive deformation of metal during notch performance. Yield strength of metal increases as a result of cyclic load (after 21,000 cycles) in zone I, as well as in zone II by $16-20 \%$ to 671 and $771 \mathrm{MPa}$, respectively. The main contribution in rise of $\sigma_{\mathrm{y}}$ integral value makes strengthening due to refining of substructure $\left(\Delta \sigma_{\mathrm{s}} \sim 243-283 \mathrm{MPa}\right)$, mainly

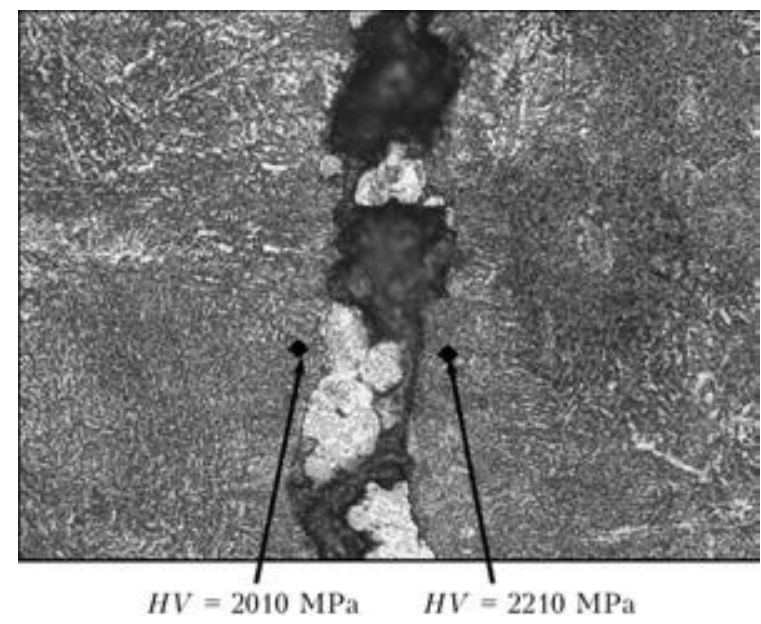

Figure 6. Fatigue crack $(\times 320)$ formed in the specimen under notch (zone I) after 21,000 cycles of load 


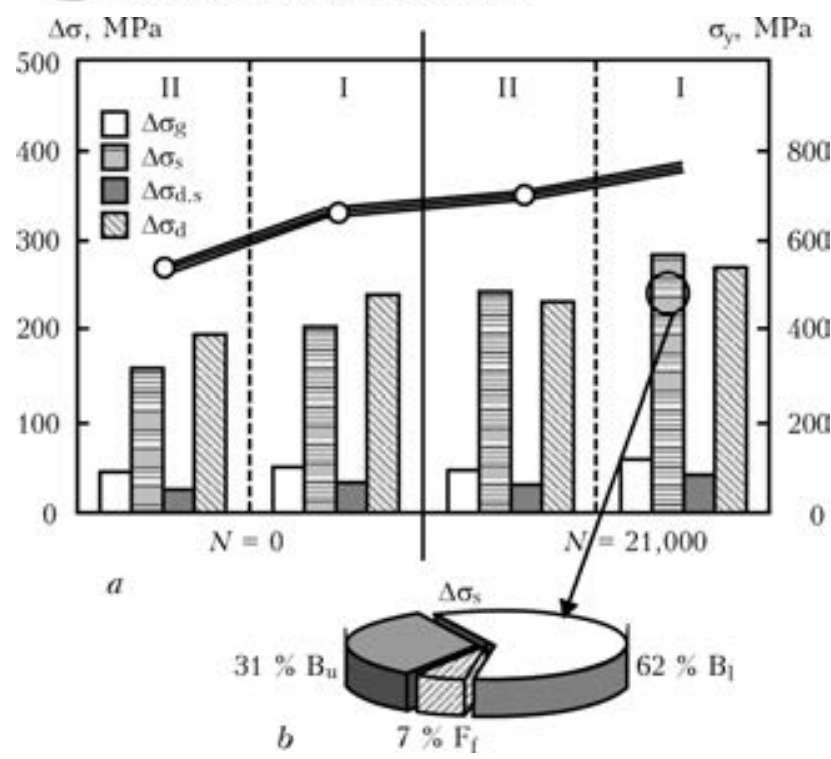

Figure 7. Contribution of separate structural parameters in integral strengthening $(a)$ and structural constituents in substructure strengthening $(b)$ of metal of steel $10 \mathrm{G} 2 \mathrm{FB}$ model specimens in initial condition and after 21,000 cycles of load

in the structures of lower bainite (up to $\Delta \sigma_{\mathrm{s}} \sim$ 159-188 $\mathrm{MPa}$ ) as well as dislocation strengthening structures (up to $\Delta \sigma_{\mathrm{d}} \sim 230-270 \mathrm{MPa}$ ). Grain structure $\left(\Delta \sigma_{\mathrm{g}} \sim 47-57 \mathrm{MPa}\right)$ and dispersion strengthening $\left(\Delta \sigma_{\text {d.s }} \sim 31-41 \mathrm{MPa}\right)$ have the minimum effect on strengthening (Figure 7).

It should be noted that the calculated values of metal yield strength sufficiently well correlate with $\sigma_{\mathrm{v}}$ values, received in investigation of effect of cooling rate on structure and properties of $10 \mathrm{G} 2 \mathrm{FB}$ steel [2]. It was determined in course of these investigations that metal indices in HAZ overheating area lie in $550 \mathrm{MPa}$ level at $w_{6 / 5}=$ $=10{ }^{\circ} \mathrm{C} / \mathrm{s}$ cooling rate.

The value of critical stress intensity factor (index of fracture toughness) was determined

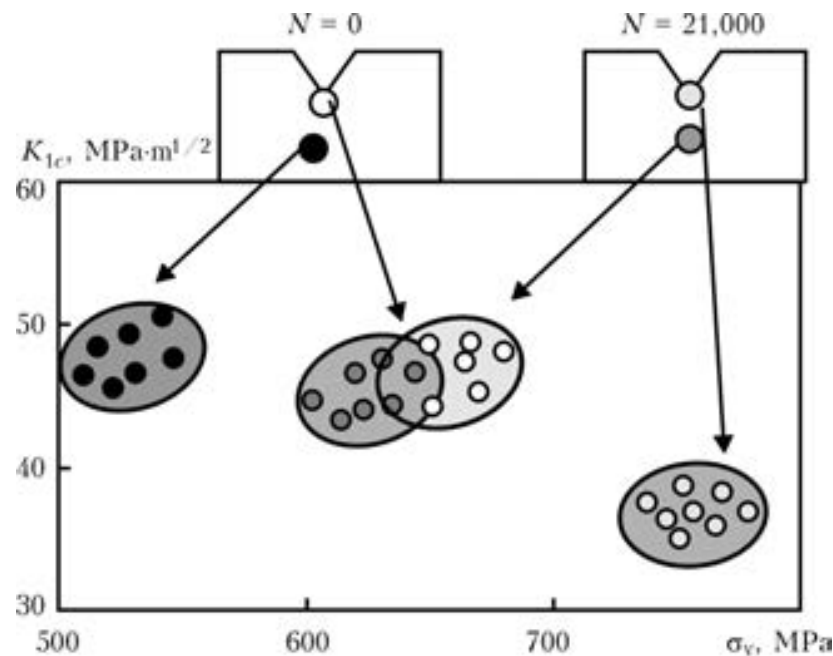

Figure 8. Relationship between yield strength $\sigma_{\mathrm{y}}$ and stress intensity factor $K_{1 c}$ of metal of steel $10 \mathrm{G} 2 \mathrm{FB}$ model specimens in initial condition and after 21,000 cycles of load in accordance with Krafft dependence, given in [14]:

$$
K_{1 c}=\left(2 E \sigma_{\mathrm{y}} \delta_{i}\right)^{-1 / 2},
$$

where $\delta_{i}$ is the crack tip opening, $\mathrm{mm}$, received on data of fractographic analysis of fractures; $E$ is the Young's modulus, MPa.

Analytical estimation of critical stress intensity factor verified a mechanism of reduction of $K_{1 c}$ indices, obtained as a result of testing of specimens of butt and T-welded joints, described in work [11]. The latter shows that the values of fracture toughness reduces from 47 initial condition to $35 \mathrm{MPa} \cdot \mathrm{m}^{1 / 2}$ after 21,000 cycles, i.e. 1.3 times (Figure 8), under notch. It is, obviously, related with general increase and inhomogeneous distribution of the dislocation density in upper bainite structures.

In addition to mentioned above analytical estimations of contribution of structures in change of strength and fracture toughness of the metal, effect of some structural factors on such process as crack formation and providing of crack resistance of examined welded joints operating under complex conditions of cyclic load was also determined. Estimations of the local internal stresses $\tau_{1 . \text { int }}$ in specific examined zones, considering dislocation density in typical structural constituents, were carried out using dependence, calculation of which is given in [15]:

$$
\tau_{1 . \text { int }}=\operatorname{Ebh} \rho /(\pi(1-v)) \text {, }
$$

where $b$ is the Burgers vector; $h$ is the foil thickness, $\mu \mathrm{m} ; \nu$ is the Poisson coefficient.

As examination of the dislocation structure showed, increase of number of cycles (up to $21,000)$ in examined areas of the metal, first of all, in zone I of the wrought metal, provides for formation of extended dislocation accumulations with high dislocation density (to $\rho \sim 2 \cdot 10^{11} \mathrm{~cm}^{-2}$ ) which, as a rule, are distributed along cementite intergrain boundaries of the upper bainite. The level of local internal stresses in indicated dislo-

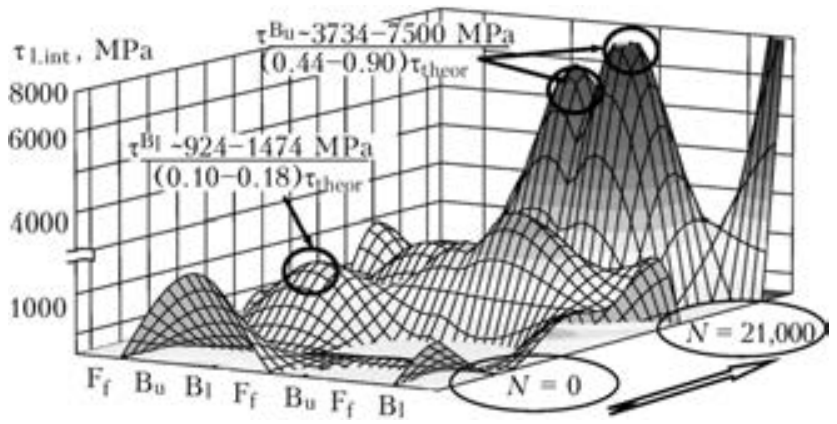

Figure 9. Calculated values of local internal stresses in different structural zones of metal of steel $10 \mathrm{G} 2 \mathrm{FB}$ model specimens in initial condition and after 21,000 cycles of load 
cation accumulations in some cases achieves around $3730-7500 \mathrm{MPa}\left((0.44-0.90) \tau_{\text {theor }}\right)$. This is an evidence of the fact that areas of the compact extended dislocation accumulations of specified type are the potential zones of nucleation and propagation of cracks (Figure 9). Another nature of the dislocation distribution under conditions of cyclic load is observed in the structures of lower bainite, where dislocation density makes approximately (7-9) $\cdot 10^{10} \mathrm{~cm}^{-2}$ at their uniform distribution in the internal lath volumes. This, respectively, results in redistribution and significant decrease of the level of local internal stresses to $924-1474 \mathrm{MPa}$, i.e. approximately, to $(0.10$ $0.18) \tau_{\text {theor }}$. The latter fact indicates that formation of the lower bainite structures in the HAZ metal of welded joints from 10G2FB steel provides for increase of their crack resistance and, respectively, safety of the metal structures, operating under complex load conditions.

\section{Conclusions}

1. Notch of $3.5 \mathrm{~mm}$ depth was taken as the optimum one in course of performance of experiments on HAZ metal of welded joints from highstrength steel 10G2FB under conditions of rise of cyclic fatigue load at parallel examination of structural changes in corresponding zones of metal. Larger notch depth $(7 \mathrm{~mm})$ promotes formation of the fatigue crack without obvious signs of accumulation of the fatigue damages. At reduction of notch depth $(1 \mathrm{~mm})$, duration of all processes, proceeding fatigue crack formation, significantly increase in time.

2. Formation of the fatigue cracks is accompanied by development of specific mechanisms of plastic strain, as well as accumulation of damages in form of stable slip bands of various configuration, extrusions and intrusions having significant effect on the welded joint properties.

3. Structural investigations determined that rise of number of load cycles (after 7000, 15,000 and 21,000, respectively) promotes decrease of grain dimensions of upper bainite by 4, 11 and $20 \%$, and also dimensions of lower bainite grains by 8,18 and $30 \%$, as well as dimensions of substructure (1.4-1.6 times) at increase of total dislocation density (1.4-1.5 times) in comparison with the initial condition.

4. Analytical estimations of effect of the structures formed in the process of cyclic load on indices of main service characteristics, i.e. strength, fracture toughness and crack resistance, were carried out based on complex examinations, including optic metallography, scanning and light electron microscopy. Increase of indices of HAZ metal yield strength by 16-20\% is observed with rise of number of bending load cycles, and the main contribution in improvement of the strength characteristics is introduced by substructure and dislocation strengthening. At that, fracture toughness reduces almost 1.3 times.

5 . Formation of the structures of lower bainite type promotes increase of crack resistance of the examined welded joints that is caused by development of complex conditions of loading typical for given type of fragmentation structures at uniform rise of the dislocation density that provide for decrease of the local internal stresses to $\left(0.10^{-}\right.$ $0.18) \tau_{\text {theor }}$ value.

1. (1990) Strength of welded joints under alternative loads. Ed. by V.I. Trufyakov. Kiev: Naukova Dumka.

2. Goritsky, V.M. (2004) Diagnostics of metals. Moscow: Metallurgizdat.

3. Lebedev, A.A., Makovetsky, I.V., Muzyka, N.P. et al. (2008) Study of processes of deformation and damage accumulation in 10GN2MFA steel under lowcycle loading. Problemy Prochnosti, 2, 2-25.

4. Byalonovich, A.V., Matokhnyuk, L.E. (2011) Study of fatigue damage accumulations in steels with application of Fourier transform of structure image. Ibid., 6. $136-145$.

5. Gorbachyov, L.A., Pogrebnyak, A.D. (2010) Formation of new phases, dark spots and slip bands in lowcarbon steel under cyclic deformation effect. Metallofizika i Nov. Tekhnologii, 32(1), 121-132.

6. Izotov, V.I., Pozdnyakov, V.A., Lukianenko, E.V. et al. (2010) Evolution of dislocation structure and formation of microcracks in fatigue of pearlitic-ferritic steel. Fizika Metallov $i$ Metallovedenie, 110(6), 624-627.

7. Kukarenko, V.A. (2009) Influence of submicroscopic structure on cyclic life of nickel-chrome dispersionhardening alloys. Ibid., 107(1), 101-108.

8. Knysh, V.V., Solovej, S.A., Kuzmenko, A.Z. (2011) Influence of preliminary cyclic loading on effectiveness of welded joint strengthening by high-frequency peening. The Paton Welding J., 10, 36-39.

9. Knysh, V.V., Solovej, S.A., Kuzmenko, A.Z. (2010) Improvement of cyclic fatigue life of welded joints with accumulated fatigue damage by high-frequency peening. Ibid., 10, 33-36.

10. Poznyakov, V.D., Dovzhenko, V.A., Kasatkin, S.B. et al. (2012) Microstructural features of fatigue damageability and methods to improve the fatigue life of welded joints from 09G2S steel. Ibid., 5, 26-30.

11. Zhdanov, S.L., Poznyakov, V.D., Maksimenko, A.A. et al. (2010) Structure and properties of arc-welded joints on steel 10G2FB. Ibid., 11, 8-12.

12. Markashova, L.I., Grigorenko, G.M., Poznyakov, V.D et al. (2009) Influence of thermal cycles of welding and external loading on structural-phase variations and properties of joints of $17 \mathrm{Kh} 2 \mathrm{M}$ steel. Ibid., 7, 18-25.

13. Markashova, L.I., Poznyakov, V.D., Alekseenko, T.A. et al. (2011)' Effect of alloying of the welds on structure and properties of welded joints on steel 17 Kh2M. Ibid., 4, 5-13.

14. Markashova, L.I., Poznyakov, V.D., Gaivoronskii, A.A. et al. (2012) Estimation of the strength and crack resistance of the metal of railway wheels after long-term operation. Materials Sci., 47(6), 799-806.

15. Markashova, L.I., Kushnaryova, O.S. (2013) Influence of structure on mechanical properties of weld metal of aluminium alloy joints of $\mathrm{Al}-\mathrm{Cu}-\mathrm{Li}$ system. PhizikoKhimich. Mekhanika Materialov, 5, 112-118.

Received 21.12.2013 


\title{
FEATURES OF MELTING, STRUCTURE AND PROPERTIES OF Ni-Mn-Cu SYSTEM NICKEL ALLOYS
}

\author{
V.F. KHORUNOV and P.N. LOTOTSKY \\ E.O. Paton Electric Welding Institute, NASU \\ 11 Bozhenko Str., 03680, Kiev, Ukraine. E-mail: office@paton.kiev.ua
}

\begin{abstract}
Influence of nickel alloy composition and method of melting on their structure and properties were studies. Melting was performed in argon and under a layer of flux. It is established that argon-arc melting of nickel alloys with high manganese content allows producing ingots of a more stable composition than in submerged-arc melting. It is noted that alloys of the considered system are prone to porosity. Increase of pouring temperature promotes reduction of porosity in ingots. Structure of ingots with different manganese content in as-cast condition, after annealing and rolling was studied. It was shown that at manganese content in the alloys of up to 25 wt.\%, it is possible to produce ingots of a higher strength and ductility, which lend themselves easily to forming. After rolling the alloys have the structure of fine-grained solid solution. Strength of such a metal reaches $900-950 \mathrm{MPa}$ at relative elongation of about $40 \%$. At greater manganese content the alloys become brittle as a result of formation of intermetallic phases in them. 8 Ref., 3 Tables, 7 Figures.
\end{abstract}

Key words: Ni-Mn-Cu system alloys, submergedarc and inert-gas arc melting, structure, mechanical properties of alloys, brazing, braze alloy

It is known that Fe-based structural materials usually have the structure of a solid solution, while braze alloys in their majority are eutectics, often having brittle phases in their composition. This contradiction is eliminated due to brazed joint design, brazing modes or some special techniques. Therefore, development of braze alloys based on solid solutions has been an urgent task for a number of years.

$\mathrm{Ni}-\mathrm{Mn}-\mathrm{Cu}$ system alloys have been quite well studied in many works [1-4]. Analysis of phase composition of this system alloys shows [1] that it has broad areas of alloys with solid solution structure with acceptable melting temperature for brazing corrosion-resistant steels. These are, mainly, Cu-based alloys. This system is the base for such well-known braze alloys as VPR-2, VPR-4, PM38ML, PM-17, P65, etc. [5, 6]. Nickel alloys of this system are not in such a good situation. Among widely accepted braze alloys we can mention US braze alloy $\mathrm{BNi}-8$, but it is eutectic with 7 wt.\% Si. In works [7, 8] alloys of this system were studied in the field of concentrations, wt.\%: $7-27 \mathrm{Mn}, 7-27 \mathrm{Cu}, 1-10 \mathrm{Si}$, Ni being the rest, in order to determine the possibility of producing eutectic alloys with a lower content of silicon. The most interesting results were obtained when studying alloys of $\mathrm{Ni}-24 \mathrm{Mn}-\mathrm{Cu}-\mathrm{Si}$ system.

(c) V.F. KHORUNOV and P.N. LOTOTSKY, 2014
Nonetheless, development of a braze alloy with solid solution structure is an attractive prospect, but it is very difficult to implement. The purpose of this work was to study the structure and properties of nickel alloys of $\mathrm{Ni}-\mathrm{Mn}-\mathrm{Cu}$ system, depending on composition and melting technology.

Analysis of the constructed respective constitutional diagram (Figure 1) shows that the regions of $\mathrm{NiMn}$ and $\mathrm{Ni}_{3} \mathrm{Mn}$ intermetallic phases have an extension in the three-component system up to a certain copper content. We have studied the structure and properties of the alloys, located in the near-boundary region (see Figure 1; Table 1). As is seen from the Table and presented diagrams, moving along the abscissa of 19 wt.\% $\mathrm{Cu}$, we must go over from alloys with solid solution structure to a structure with intermetallic compounds.

Melts were performed under a layer of cryolite. The alloy was poured into a cast iron mould, and then the possibility of ingot rolling was tried out and the microstructure was studied.

Microstructure of ingot 8 with low manganese content (20 wt.\%) is single-phase in the cast and annealed conditions (Figure 2, $a, b$ ). Intercrystalline boundaries are clean. With manganese increase up to 25 wt.\% (ingot 9), an eutectic component precipitates in interdendritic regions in the ingot center, and the structure becomes twophase (Figure 2,c). However, annealing at $950{ }^{\circ} \mathrm{C}$ restores the single-phase structure through the entire ingot volume (Figure $2, d$ ). The alloys can be rolled down to a rod with $14 \mathrm{~mm}$ side. 


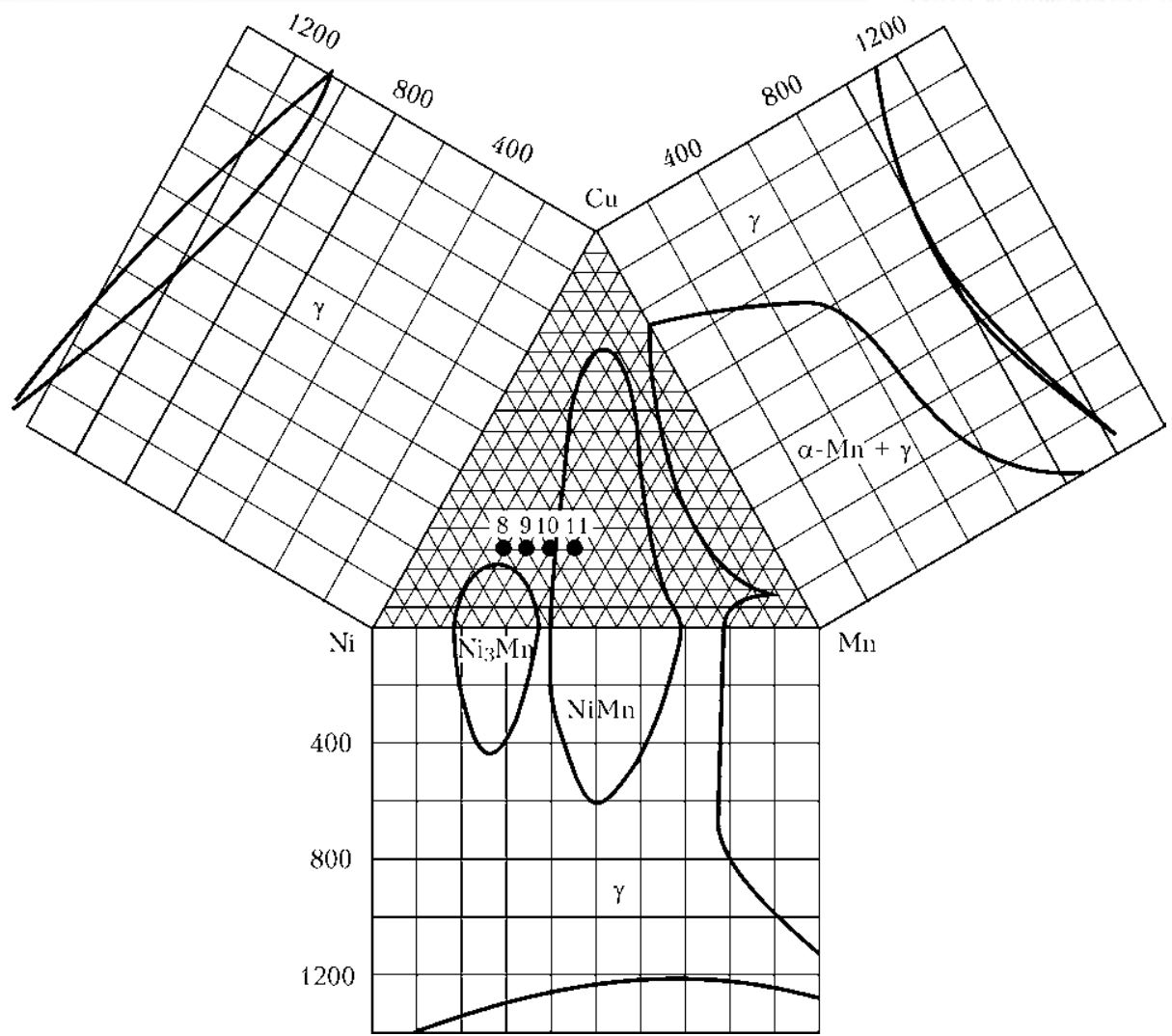

Figure 1. Phase areas in alloys of $\mathrm{Ni}-\mathrm{Mn}-\mathrm{Cu}$ system, compared to phase areas in binary systems [1]: 8-11 - number of ingot acc. to Table 1

Table 1. Composition and structure of the studied alloys

\begin{tabular}{|c|c|c|c|c|c|c|c|c|}
\hline \multirow{2}{*}{ Ingot number } & \multicolumn{5}{|c|}{ Composition, wt.\% } & \multirow{2}{*}{$\begin{array}{c}\text { Ingot weight, } \\
\text { kg }\end{array}$} & \multirow{2}{*}{$\begin{array}{l}\text { Second phase } \\
\text { quantity, \% }\end{array}$} & \multirow{2}{*}{ Porosity, \% } \\
\hline & $\mathrm{Ni}$ & $\mathrm{Mn}$ & $\mathrm{Cu}$ & $\mathrm{Si}$ & $\mathrm{Ce}$ & & & \\
\hline 8 & 60 & 20 & 19 & 0.9 & 0.2 & 5 & No & 18 \\
\hline 9 & 55 & 25 & 19 & 0.9 & 0.2 & 5 & 1.55 & 10 \\
\hline 10 & 50 & 30 & 19 & 0.9 & 0.2 & 5 & 7.3 & 9 \\
\hline 11 & 45 & 35 & 19 & 0.9 & 0.2 & 5 & 10.1 & 1 \\
\hline
\end{tabular}

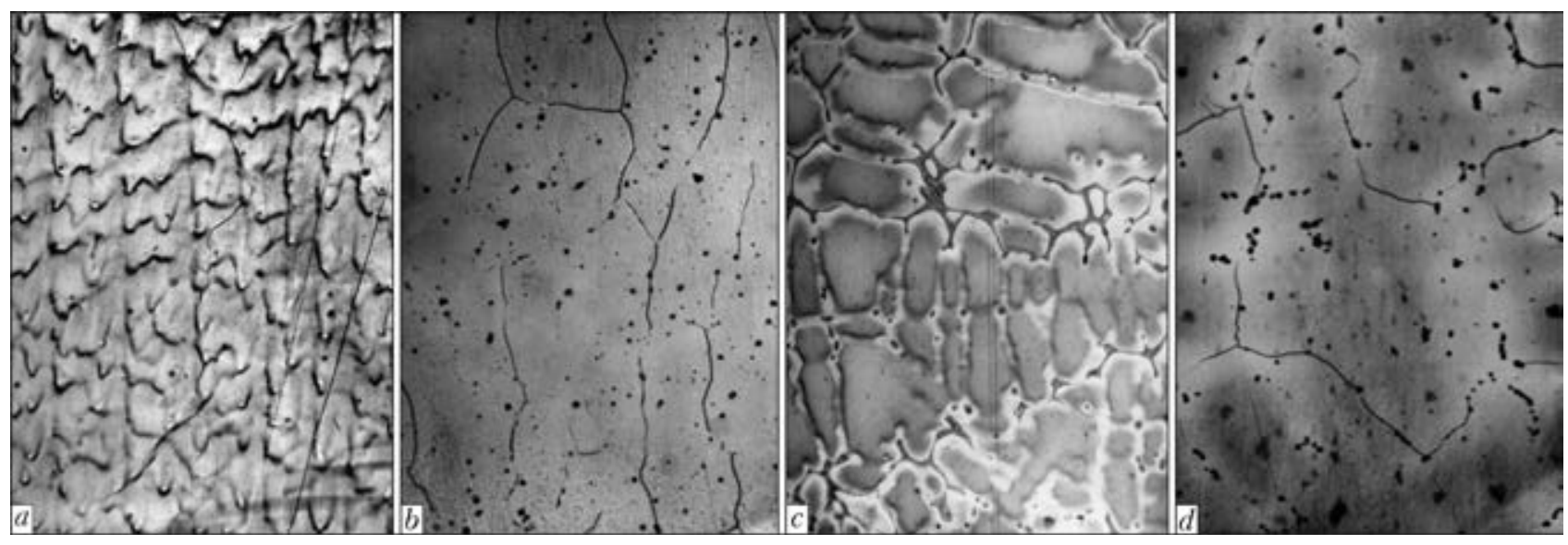

Figure 2. Microstructure $(\times 200)$ of ingots of $\mathrm{Cu}-\mathrm{Mn}-\mathrm{Ni}$ system alloys with $20 \mathrm{wt} . \% \mathrm{Mn}(a, b)$ and 25 wt.\% Mn $(c, d)$ in as-cast condition $(a, c)$ and after annealing at $950{ }^{\circ} \mathrm{C}(b, d)$ 


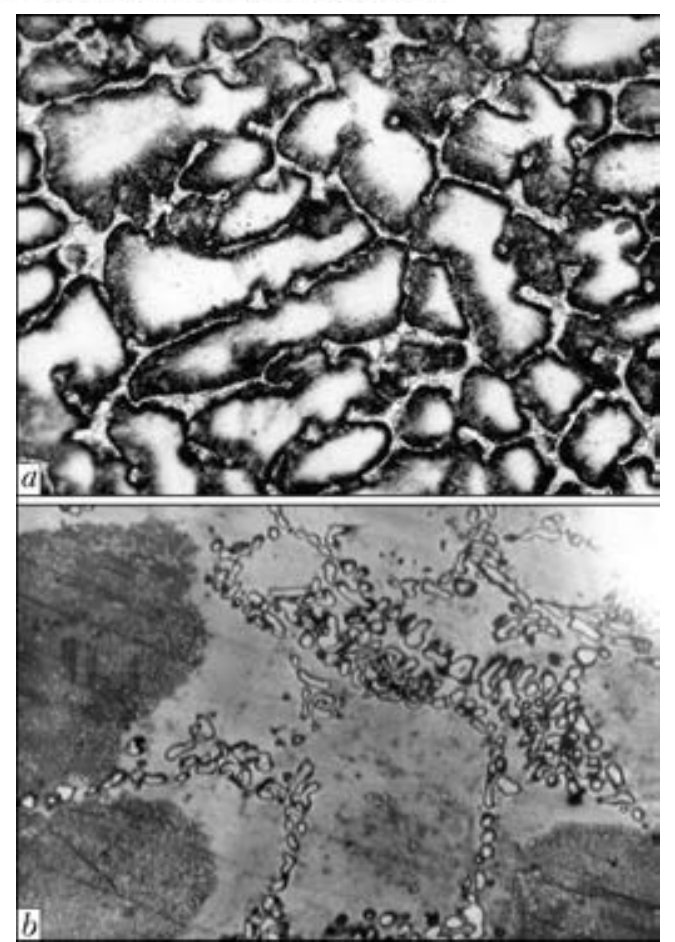

Figure 3. Microstructure $(\times 200)$ of ingots of $\mathrm{Cu}-\mathrm{Mn}-\mathrm{Ni}$ system alloys with $35 \mathrm{wt} . \% \mathrm{Mn}$ in as-cast condition $(a)$ and after annealing at $950{ }^{\circ} \mathrm{C}(b)$

At further increase of manganese content (30 wt.\% in ingot 10), the quantity of second phase is increased, and at $35 \mathrm{wt} \% \mathrm{Mn}$ (ingot 11), it fills the entire space between the dendrites (Figure 3,a). Analysis of ternary $\mathrm{Ni}-\mathrm{Mn}-\mathrm{Cu}$ diagram [2] shows that at such a component ratio matrix embrittlement and strengthening results from ordering (or precipitation of NiMn type phase).

In the studied alloys the composition of intermetallic phase, precipitating along the crystallite boundaries, differs from precipitates inside the matrix mainly by increased silicon content, which is one of the elements stabilizing the ordered matrix phase. Therefore, silicon presence should facilitate alloy solidification in interdendritic areas of the ingot in the form of intermetallic phase. In this case, annealed alloys are also two-phase (Figure 3,b), have an increased hardness and brittleness, and fail along crystallite boundaries at treatment.
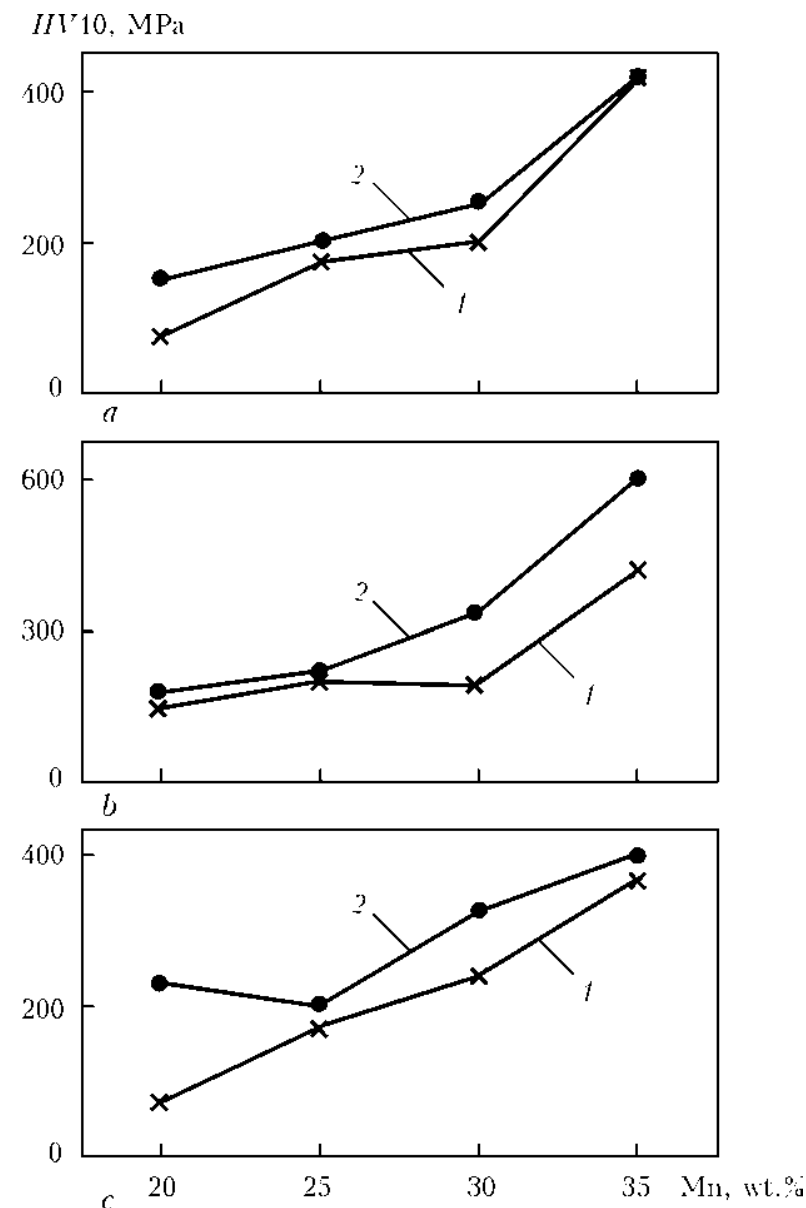

Figure 4. Dependence of microhardness of dendritic (1) and interdendritic (2) areas for ingots 8-11 on manganese content: $a$ - ingot edges; $b$ - intermediate part; $c$ - ingot central part

Curves reflecting the dependence of microhardness of dendritic and interdendritic areas of cast metal on manganese content, show that at addition of 35 wt.\% Mn to the alloy (ingot 11) hardnesses of the matrix and intermetallic interlayers are close or coincide that allows once more assuming the ordered matrix condition (Figure 4). The curves have a characteristic plateau of dendrite hardness in the range of $25-30 \% \mathrm{Mn}$ (except for the curve describing the ingot central parts).

Filler with a high content of manganese and appearance of strengthening phases should increase the angle of inclination of the curve that is observed on some graphs (see Figure 4). An

Table 2. Composition and pouring temperature of the alloys

\begin{tabular}{|c|c|c|c|c|c|c|c|c|c|}
\hline \multirow{2}{*}{ Ingot number } & \multicolumn{7}{|c|}{ Charge composition, wt.\% } & \multirow{2}{*}{$\begin{array}{l}\text { Ingot mass, } \\
\text { kg }\end{array}$} & \multirow{2}{*}{$\begin{array}{c}\text { Pouring } \\
\text { temperature, } \\
{ }^{\circ} \mathrm{C}\end{array}$} \\
\hline & $\mathrm{Ni}$ & $\mathrm{Mn}$ & $\mathrm{Cu}$ & $\mathrm{Si}$ & $\mathrm{Cr}$ & Mo & $\mathrm{Ce}$ & & \\
\hline 12 & 55 & 25 & 19 & 0.8 & - & - & - & 5 & 1300 \\
\hline 13 & 52 & 25 & 19 & 0.8 & 2 & 0.75 & 0.3 & 22 & 1200 \\
\hline 14 & 52 & 25 & 19 & 0.8 & 2 & 0.75 & 0.3 & 22 & 1250 \\
\hline 15 & 52 & 25 & 19 & 0.8 & 2 & 0.75 & 0.3 & 22 & 1300 \\
\hline
\end{tabular}



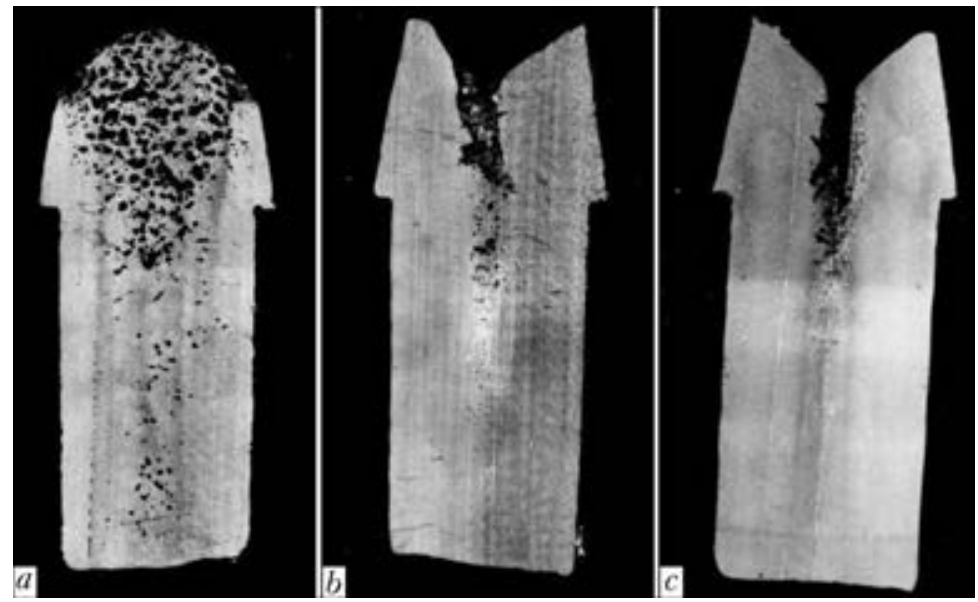

Figure 5. Longitudinal cut of ingots of $\mathrm{Ni}-\mathrm{Mn}-\mathrm{Cu}-\mathrm{Si}-\mathrm{Cr}-\mathrm{Mo}-\mathrm{Ce}$ system alloy with different pouring temperature: $a-$ $1200 ; b-1250, d-1300{ }^{\circ} \mathrm{C}$

abrupt change of the trend of the curve at manganese content of $30 \mathrm{wt} . \%$ and higher, certainly is indicative of intensive development of the process of strengthening due to ordering.

Mechanical characteristics of the alloys are also in accordance with hardness values. Ingots with low manganese content are readily formable and ductile, whereas with manganese increase in the alloys their ductility decreases and treatment becomes more complicated. Alloys with 35 wt.\% Mn fail at machining and electrical-discharge treatment.

A considerable problem in melting high-manganese alloys is porosity development in the in-
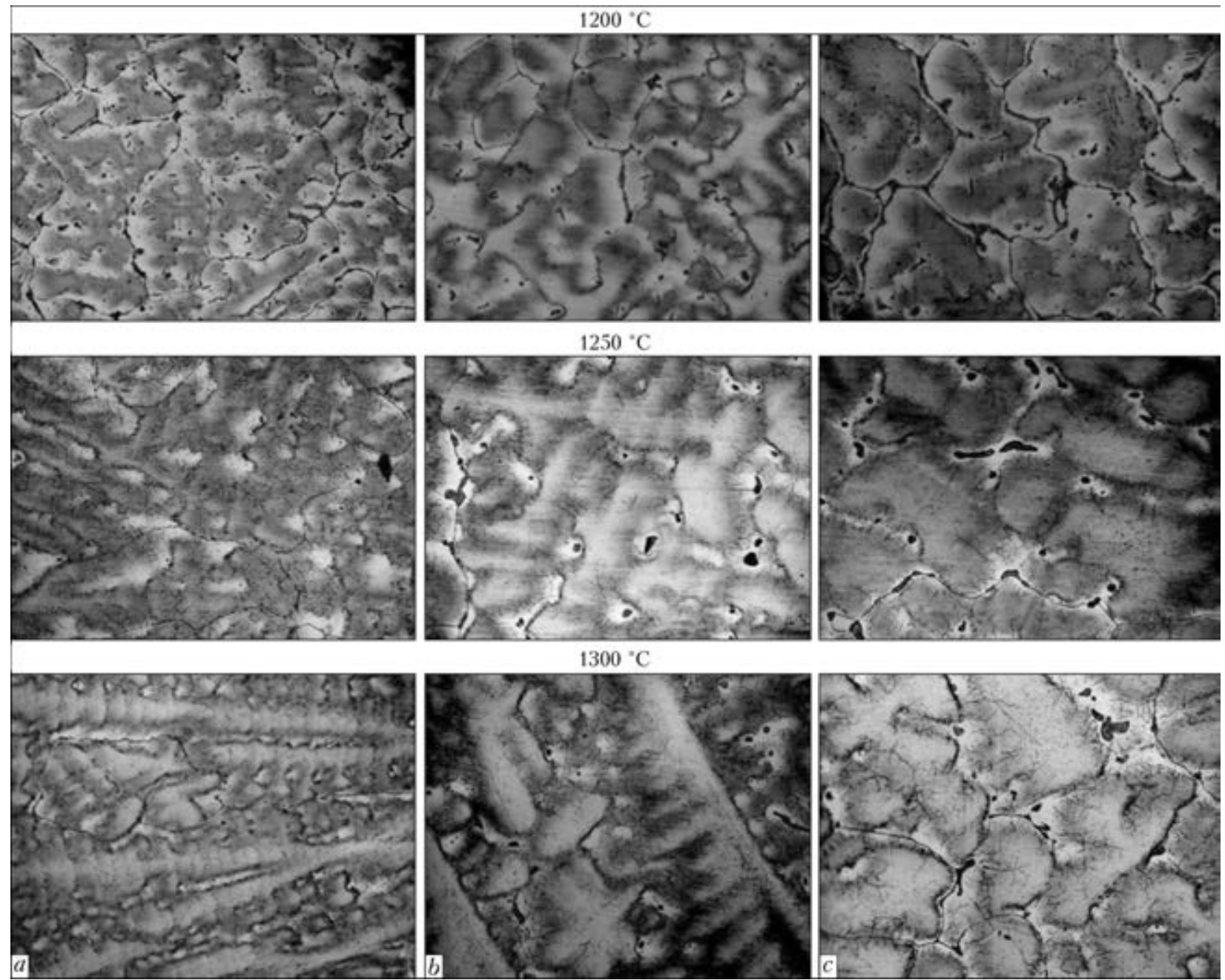

Figure 6. Microstructure $(\times 200)$ of $\mathrm{Ni}-\mathrm{Mn}-\mathrm{Cu}-\mathrm{Si}-\mathrm{Cr}-\mathrm{Mo}$ system alloys poured at different temperature: $a-$ ingot edge; $b$ - intermediate part; $c$ - ingot central part 
SCIENTIFIC AND TECHNICAL

Table 3. Composition and mechanical characteristics of test studied alloys

\begin{tabular}{|c|c|c|c|c|c|c|c|c|c|c|c|c|c|}
\hline \multirow{2}{*}{$\begin{array}{l}\text { Ingot } \\
\text { number }\end{array}$} & \multicolumn{8}{|c|}{ Composition, wt. $\%$} & \multicolumn{4}{|c|}{ Mechanical characteristics } & \multirow{2}{*}{ Shielding atmosphere } \\
\hline & $\mathrm{Ni}$ & Mn & $\mathrm{Cu}$ & $\mathrm{Si}$ & $\mathrm{Cr}$ & Mo & $\mathrm{Ce}$ & $\mathrm{Al}$ & $\begin{array}{c}\sigma_{\mathrm{y}} \\
\mathrm{MPa}\end{array}$ & $\begin{array}{c}\sigma_{\mathrm{t}} \\
\mathrm{MPa}\end{array}$ & $\delta, \%$ & $\psi, \%$ & \\
\hline \multirow[t]{2}{*}{5} & \multirow[t]{2}{*}{54} & 25 & 20 & 1 & \multirow[t]{2}{*}{-} & \multirow[t]{2}{*}{-} & \multirow[t]{2}{*}{-} & 0.8 & \multirow[t]{2}{*}{615} & \multirow[t]{2}{*}{970} & \multirow[t]{2}{*}{39} & \multirow[t]{2}{*}{54} & \multirow[t]{6}{*}{ «Cryolite» flux } \\
\hline & & 23.9 & 20 & 0.9 & & & & 0.22 & & & & & \\
\hline \multirow[t]{2}{*}{6} & \multirow[t]{2}{*}{50} & 30 & 19 & \multirow[t]{2}{*}{-} & \multirow[t]{2}{*}{-} & \multirow[t]{2}{*}{-} & \multirow[t]{2}{*}{0.1} & 0.8 & \multirow[t]{2}{*}{453} & \multirow[t]{2}{*}{760} & \multirow[t]{2}{*}{40} & \multirow[t]{2}{*}{53} & \\
\hline & & 23.7 & 20.7 & & & & & 0.36 & & & & & \\
\hline \multirow[t]{2}{*}{7} & \multirow[t]{2}{*}{53} & 25 & 19 & 1 & 2 & 0.75 & \multirow[t]{2}{*}{0.3} & - & \multirow[t]{2}{*}{580} & \multirow[t]{2}{*}{900} & \multirow[t]{2}{*}{41} & \multirow[t]{2}{*}{50} & \\
\hline & & 22.6 & 19.8 & 0.94 & 2.8 & ND & & & & & & & \\
\hline \multirow[t]{2}{*}{2} & 54.8 & 23.8 & 20.5 & 0.87 & \multirow[t]{2}{*}{-} & \multirow[t]{2}{*}{-} & \multirow[t]{2}{*}{-} & - & \multirow[t]{2}{*}{-} & - & - & - & Argon \\
\hline & 52.5 & 22.8 & 19.9 & 0.96 & & & & & & & & & (after degassing) \\
\hline 3 & 54.8 & 23.8 & 20.5 & 0.87 & - & 1.5 & - & - & 568 & 950 & 36 & 48 & \\
\hline & 52.5 & & 21.6 & 0.71 & & 1.44 & & & & & & & \\
\hline
\end{tabular}

gots, which is manifested both in submerged-arc and in argon-arc melting. The regularity of its appearance has not been established, as it is very expensive to melt out a large number of alloys for statistical assessment. Therefore, special experiments were performed to determine the influence of alloy melting temperature on porosity formation (Table 2). Melting was conducted with ANM-10 flux, the application of which is simpler than that of cryolite.

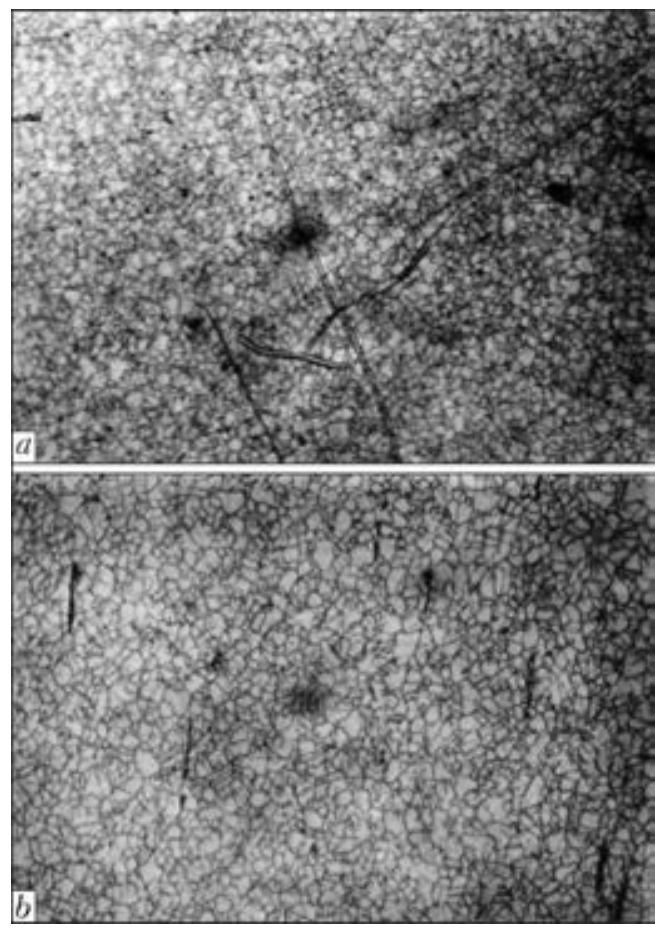

Figure 7. Microstructure $(\times 400)$ of $\mathrm{Ni}-24.3 \mathrm{Mn}-22.5 \mathrm{Cu}-$ $0.64 \mathrm{Si}$ alloy rolled into a rod with $14 \mathrm{~mm}$ side: $a-$ in-plane structure normal to the rolling direction; $b-$ rod structure along the rolling direction
Liquid metal was poured into cast iron moulds. Produced ingots were cut along and ground over the cut surface. It is readily seen (Figure 5) that ingot porosity is reduced with increase of pouring temperature; however, the size of shrinkage cavity is increased. The same regularity was established also at microstructural investigations in different parts of the ingots. Naturally, this is particularly clearly seen, if we compare the structures in the ingot central part (Figure 6), as this is related to the conditions of heat removal from the liquid metal and direction of crystallite growth, respectively.

Obtained results were the basis for conducting further experiments. A number of alloys of the above-considered quaternary system (and also with some additional alloying) with less than 25 wt.\% Mn content were melted by submergedarc and argon-arc process. Obtained ingots were rolled into a square with 25 or $14 \mathrm{~mm}$ side, from which specimens were cut out for metallographic studies and samples were taken for chemical analysis. Experimental results are given in $\mathrm{Ta}-$ ble 3 .

From the tabulated data it follows that losses of manganese - an element with a high vapour pressure - are not higher than 1 wt.\% in argonarc melting with preliminary degassing, whereas in submerged-arc melting a large scatter is observed, which is higher than 5 wt.\% in some cases.

Filler of small amounts of aluminium, chromium and molybdenum does not essentially affect the mechanical properties of melted metal, namely ductile high-strength alloys were produced. For most of the melts, rupture strength of the alloys was above $90 \mathrm{MPa}$, while relative 
elongation was about $40 \%$. Alloy structure is fine-grained solid solution, rolling texture is not clearly manifested. However, grains across the rolling direction are noticeably smaller than those along the rolling direction.

The considered alloys have an acceptable melting range, and they can become widely accepted in industry for brazing steels of various classes, hard alloys and other materials.

\section{Conclusions}

1. Melting in argon atmosphere (with preliminary degassing) of $\mathrm{Ni}-\mathrm{Mn}-\mathrm{Cu}$ system alloys with high manganese content allows producing ingots of a more stable composition. However, the difference in quality is not so radical as to override the high cost of this process, compared to submerged-arc melting.

2. Nickel alloys with high manganese content are prone to porosity. One of the methods to solve this problem is to increase pouring temperature.

3. At up to 25 wt.\% Mn ductile, high-strength alloys are produced, which are readily formable. At higher manganese content the alloys become harder and more brittle, and do not lend themselves to forming.
4. Braze alloys based on the considered alloys will become widely accepted for brazing steels of different classes, hard alloy and other materials, also in dissimilar combinations.

1. Salli, A. (1959) Manganese. Moscow: Metallurgizdat.

2. Bochvar, N.R., Guzej, L.S., Lysova, E.V. et al. (1979) Binary and multicomponent systems on copper base. Moscow: Nauka.

3. Chjan-Bao-Chan (1958) Examination of ternary alloys $\mathrm{Cu}-\mathrm{Mn}-\mathrm{Ni}$. Izvestiya Vuzov. Tsvet. Metallurgiya, 5, 107-115.

4. Bazhenov, V.E. (2013) Study of crystallization processes of ternary alloys for the purpose of evaluation of their susceptibility to nonequilibrium crystallization: Syn. of Thesis for Cand. of Techn. Sci. Degree.

5. (2003) Reference book on soldering. Ed. by I.E. Petrunin. 3rd ed. Moscow: Mashinostroenie.

6. Lashko, S.V., Lashko, N.F. (1988) Brazing of metals. Moscow: Mashinostroenie.

7. Khorunov, V.F. (2008) Principles of brazing thinwalled high-alloy steel structures. Kiev: Naukova Dumka.

8. Khorunov, V.F., Doroshenko, L.K., Vasiliev, V.G. (1988) Diagram of meltability and structure of alloys of nickel-manganese-copper-silicon system. Avtomatich. Svarka, 9, 32-36.

Received 14.01.2014 


\title{
INVESTIGATION OF THERMAL RESISTANCE OF DEPOSITED METAL DESIGNED FOR RESTORATION OF MILL ROLLS
}

\author{
A.A. BABINETS, I.A. RYABTSEV, I.A. KONDRATIEV, I.I. RYABTSEV and G.N. GORDAN \\ E.O. Paton Electric Welding Institute, NASU
}

11 Bozhenko Str., 03680, Kiev, Ukraine. E-mail: office@paton.kiev.ua

\begin{abstract}
The method of experimental evaluation of thermal resistance of deposited specimens was updated. The new method allows evaluating the nature of propagation of thermal fatigue cracks across the thickness of deposited layer, as well as the effect of deposition of intermediate layers of different composition on thermal resistance of specimens. Using the updated procedure, the investigations of effect of deposition of a plastic sublayer by wire Sv-08A on thermal resistance of specimens, deposited by flux-cored wires PP-Np35V9Kh3GSF and PP-Np-25Kh5FMS, which are most widely used for restoration and strengthening of hot mill steel rolls, were carried out. Hardfacing of the plastic sublayer allowed increasing the general thermal resistance of deposited specimens by 1.2-1.5 times. In addition, it was found that the plastic sublayer arrests the propagation of thermal fatigue cracks into the base metal, thus preventing, to a certain degree, the fracture of the deposited part. 6 Ref., 1 Table, 5 Figures.
\end{abstract}

Keywords: arc hardfacing, hardfacing of mill rolls, multilayer hardfacing, plastic sublayer, thermal resistance, procedure of tests

Thermal resistance or resistance against formation of fire cracks is one of the most important characteristics defining the service life of mill rolls. Thermal fatigue cracks are appeared on the surface of rolls after relatively small numbers of heat changes as a result of effect of cyclic thermal stresses occurring due to non-free changes in sizes of separate regions of the part at cyclic changes of temperature [1-3].

At the present time the steel mill rolls at the majority of metallurgical plants are restored by the methods of hardfacing using materials, which produce the deposited metal of type of heat-resistant and semiheat-resistant tool steels [1]. In this case a plastic sublayer is deposited by wires of $\mathrm{Sv}$-08A type, as a rule, before the working layer deposition.

The preliminary evaluation of thermal resistance of hardfacing materials is carried out by using different laboratory procedures, based mainly on multiple repetition of cycles of heating and cooling of specimens of definite sizes, which is leading, as a result, to cracking of their surface. As a rule, using the existing methods the thermal resistance is evaluated by number of heat-cooling cycles up to appearance of a net of fire cracks $[4,5]$.

Carried out earlier investigations of thermal resistance of deposited metal of 35V9Kh3GSF and 25Kh5FMS type [1], mostly often used for restoration of steel rolls of hot rolling showed that it amounts to 70-200 heat-cooling cycles before the appearance of developed net of thermal cracks. The depth of propagation of these cracks into the deposited layer is usually $0.5-2.5 \mathrm{~mm}$. The further increase in heat-cooling cycles leads only to the fuller opening of cracks, and the crack depth is not almost increased. Thus, at tests using this procedure it is impossible to evaluate the development of thermal fatigue cracks into the depth of deposited layer and effect of sublayer on the nature of development of thermal fatigue cracks. When investigating the thermal resistance of deposited metal it is necessary to account also for structural changes, which can occur in it as a result of cyclic high-temperature effects. Irreversible changes of structure and properties of the deposited metal during service predetermine mainly the serviceability and reliability of the deposited mill rolls.

The aim of this work was to update the methods of investigation of thermal resistance and to study the nature of development of thermal fatigue cracks in multilayer deposited metal. It was also necessary to investigate the structural transformations in deposited metal of selected types as a result of tests of its thermal resistance.

To study the nature of development of thermal fatigue cracks into depth of the deposited layer, the following procedure was developed. From the results of preliminary experiments on thermal resistance a fixed number of heat-cooling cycles, 
Chemical composition and hardness of deposited metal

\begin{tabular}{|c|c|c|c|c|c|c|c|c|}
\hline \multirow{2}{*}{ Type of deposited metal } & \multicolumn{7}{|c|}{ Content of alloying elements, wt.\% } & \multirow{2}{*}{ Hardness $H R C$} \\
\hline & $\mathrm{C}$ & $\mathrm{Si}$ & $\mathrm{Mn}$ & $\mathrm{Cr}$ & $\mathrm{W}$ & $\mathrm{V}$ & Mo & \\
\hline PP-Np-35V9Kh3GSF (without sublayer) & 0.34 & 0.74 & 0.60 & 3 & 9.30 & 0.43 & - & $51-53$ \\
\hline PP-Np-35V9Kh3GSF + Sv-08A sublayer & 0.32 & 0.70 & 0.56 & 2.84 & 9.06 & 0.40 & - & $49-51$ \\
\hline PP-Np-25Kh5FMS (without sublayer) & 0.26 & 0.79 & 0.64 & 5.50 & - & 0.40 & 1.01 & $49-51$ \\
\hline PP-Np-25Kh5FMS + Sv-08A sublayer & 0.26 & 0.76 & 0.64 & 5.40 & - & 0.40 & 0.99 & $48-50$ \\
\hline
\end{tabular}

equal to 200, was selected. This guaranteed the appearance of a developed net of fire cracks on the surface of test specimens, and then the deposited surface of the specimen was grinded until their full removal. Here, the thickness of grinded layer of deposited metal was recorded, and then the specimen was subjected to repeated thermal cycling at the same number of cycles. Operations of thermal cycling and grinding are repeated up to reaching the minimum possible thickness of a wear-resistant layer, equal to $1.5-2.0 \mathrm{~mm}$. Further, the specimen was cut in spot of heating, and the depth and nature of propagation of thermal fatigue crack were investigated on a macrosection.

This procedure was used in investigation of thermal fatigue crack development in metal deposited by flux-cored wires PP-Np-35V9Kh3GSF and PP-Np-25Kh5FMS without and with sublayer, deposited by solid wire Sv-08A. Steel $40 \mathrm{Kh}$ was used as a base metal. Semi-products for next manufacture of specimens for thermal resistance testing were deposited by two schemes:

- deposition by wire 35V9Kh3GSF or 25Kh5FMS in four layers without sublayer;

- deposition of sublayer by wire Sv-08A in two layers and next two-layer deposition by the wire $35 \mathrm{~V} 9 \mathrm{Kh} 3 \mathrm{GSF}$ or $25 \mathrm{Kh} 5 \mathrm{FMS}$.

After deposition the semi-products were subjected to delayed cooling under the flux layer. Total thickness of deposited layer in all the cases was about the same and amounted approximately to $10 \mathrm{~mm}$. Chemical composition of metal, deposited by wires 35V9Kh3GSF and 25Kh5FMS, is given in the Table. Specimens of $40 \times 40 \times$ $\times 40 \mathrm{~mm}$ size were cut out from semi-products for investigation of thermal resistance of deposited metal. Deposited surface of specimens was subjected to grinding.

Using the updated procedure, the investigation of thermal resistance of specimens was carried out in unitized-modular installation for testing different properties of the deposited metal [5]. The deposited surface of specimens was heated periodically by a gas cutter up to $800{ }^{\circ} \mathrm{C}$ for $11 \mathrm{~s}$ (diameter of heat spot was about $15 \mathrm{~mm}$ ), and then it was cooled by running water down to $70-80{ }^{\circ} \mathrm{C}$ for $8 \mathrm{~s}$.

For specimen, deposited by wire 35V9Kh3GSF without sublayer, a strongly developed net of fire was typical (Figure 1, $a$ ). After 200 heat-cooling cycles the regrinding was made until full removal of the crack net. In total, 800 cycles and three regrindings of specimens were made, the removal of metal during each of them was $1.3-1.8 \mathrm{~mm}$. When the thickness of metal reached about $2 \mathrm{~mm}$, the tests were interrupted, the specimen was cut out and macrosection was manufactured. Figure 2, $a$ shows how the largest crack is transferred from the deposited metal into base one.

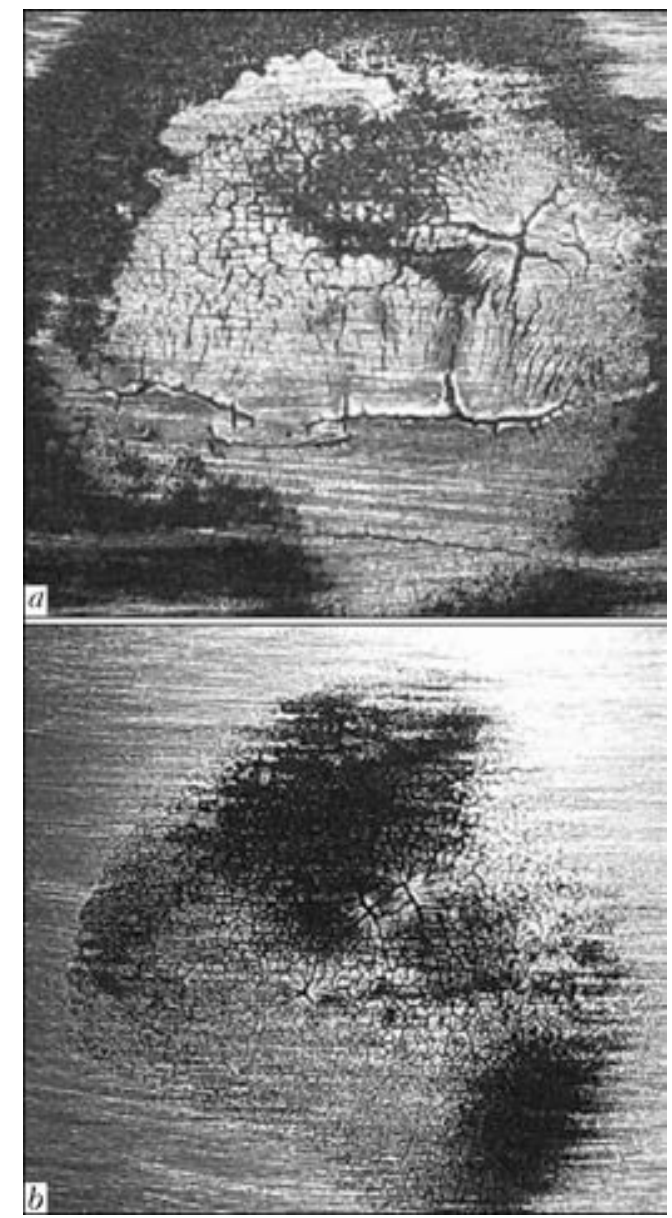

Figure 1. Appearance of surface of specimens deposited by flux-cored wire PP-Np-35V9Kh3GSF without $(a)$ and with Sv-08A sublayer (b) after thermal tests 


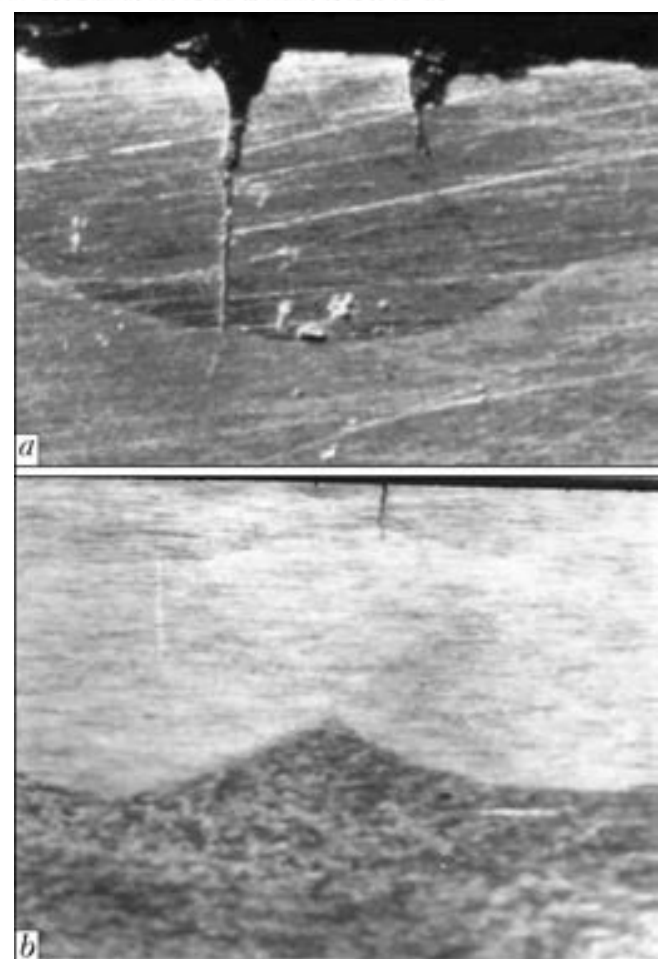

Figure 2. Cross macrosections section of specimens deposited by flux-cored wire PP-Np-35V9Kh3GSF without $(a)$ and with Sv-08A sublayer (b) after thermal tests

In specimen, deposited by wire 35V9Kh3GSF along Sv-08A sublayer, the much less expressed net of cracks was observed (Figure 1, b), their depth was smaller. This influenced on value of metal removal for each regrinding, it was $0.4-$ $1.1 \mathrm{~mm}$. Probably, the deposition of plastic sublayer has led to reduction of residual hardfacing stresses in a working layer, and its thermal resistance increased [6]. Taking into account the smaller single removal of damaged metal, the

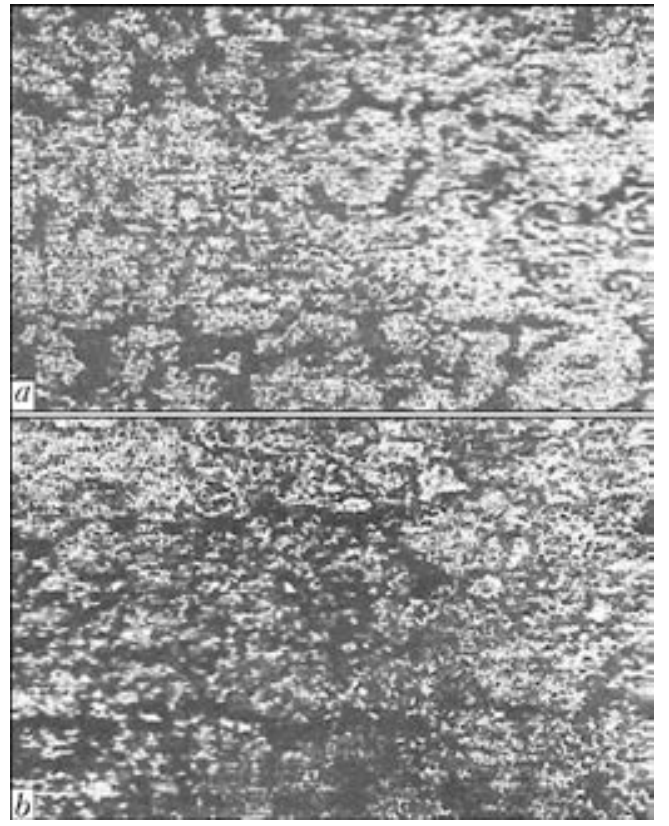

Figure 3. Microstructure $(\times 400)$ of 35V9Kh3GSF deposited metal before $(a)$ and after $(b)$ thermal tests total number of heat-cooling cycles was increased to 1200 , i.e. by 1.5 times, as compared with that in specimen without sublayer. After reaching the minimum possible thickness of wear-resistant layer the specimen was cut out, and macrosection was manufactured (Figure 2, b). It is seen clearly that the crack is passed through the wear-resistant layer and arrested in a low-carbon sublayer.

Similar results were obtained in testing specimens, deposited by flux-cored wire 25Kh5FMS without and with a sublayer, deposited by wire $\mathrm{Sv}$-08A. The only difference, i.e. the higher thermal resistance of deposited metal 25Kh5FMS [1], has led to the fact that removal of metal after each 200 heat-cooling cycles was relatively small, thus resulting in significant increase of total cycles of tests. Also, in this case the deposition of sublayer has led to the increase of thermal resistance of the deposited working layer. In hardfacing without sublayer the total number of heat-cooling cycles was 2000, and metal removal after each 200 cycles was $0.4-0.6 \mathrm{~mm}$. In hardfacing with Sv-08A sublayer the thickness of asgrinded layer after each 200 cycles of tests was about $0.2-0.3 \mathrm{~mm}$. Taking into account the small removal of material after each cycle of testing, it was managed to perform 2400 cycles of tests on this specimen, i.e. by 1.2 times more than on specimen without sublayer.

Thus, it can be considered that the hardfacing of $\mathrm{Sv}-08 \mathrm{~A}$ sublayer allows increasing the general thermal resistance of specimens, deposited by wires 35V9Kh3GSF and 25Kh5FMS, by 1.2-1.5 times.

The nature of crack propagation in 25Kh5FMS deposited metal was similar to the nature of propagation of cracks in 35V9Kh3GSF deposited metal. In hardfacing without sublayer the thermal fatigue cracks transferred into the base metal, and in hardfacing with a plastic sublayer the cracks were arrested in this layer. Microstructure of deposited metal of type 35V9Kh3GSF and 25Kh5FMS was examined before and after thermal tests. Microstructure of metal after hardfacing was examined in a last deposited layer, while after thermal resistance tests it was examined in the zone of thermal cycling (location of thermal cracks) at the distance of about 10-20 $\mu \mathrm{m}$ from the deposited layer surface.

Microstructure of 35V9Kh3GSF deposited layer before and after tests is shown in Figure 3. Metal 35V9Kh3GSF has a martensitic structure with microhardness $H V 5140 \mathrm{MPa}$ directly after deposition, and precipitations of residual austenite and negligible amount of eutectics were revealed along the boundaries of polygonization 
(Figure 3, $a$ ). After thermal tests the decay of martensitic component $(H V 3090 \mathrm{MPa})$ was noted, here the small regions of residual austenite were retained (Figure $3, b$ ).

Microstructure of 25Kh5FMS deposited metal was also examined before and after thermal tests (Figure 4). It was found that the structure of deposited metal directly after hardfacing represents a fine-acicular martensite-bainite mixture ( $H V$ 3860-4120 MPa), the polygonization boundaries are not clearly formed. In sites of their formation the precipitations of carbide eutectics are observed (Figure 4, $a$ ).

After tests on thermal resistance the structural changes were occurred in deposited metal of type 25Kh5FMS, proving about coagulation and spheroidization of carbides (Figure $4, b$ ). Decay of martensite and also partial decay of eutectics along the boundaries of polygonization took place, thus leading to the decrease in microhardness of matrix of deposited metal to $H V 2210 \mathrm{MPa}$.

Examination of microstructure showed that as result of multiple thermal cycling the structural changes occur in surface layer of deposited metal of both types, leading to its softening. This was also confirmed by X-ray diffraction analysis. For example, after thermal cycling the content of $\alpha$-phase was increased from 84 up to $87 \%$ in metal of type $35 \mathrm{~V} 9 \mathrm{Kh} 3 \mathrm{GSF}$ due to appearance of ferrite component. In this case the compression stresses of the II kind increased from 0.27 up to $0.44 \mathrm{GPa}$.

The X-ray spectrum microanalysis was made in Camebax SX50 analyzer for study of distribution of main alloying elements in structure of deposited specimens before and after thermal tests at the depth up to $20 \mu \mathrm{m}$ from the surface, parallel to deposit, in automatic mode at interval of $2-99 \mu \mathrm{m}$ along the front of fire crack net. Figure 5 gives results of examinations of deposited metal of type 35V9Kh3GSF. Distribution of main alloying elements in the deposited metal was almost uniform (Figure 5, $a$ ) and remained almost the same after thermal tests, except one moment, namely fatigue crack zone the abrupt decrease in content of alloying elements ( $\mathrm{Fi}^{-}$ gure $5, b$ ) was observed, probably due to their oxidation.

Thus, as a result of multiple heating and cooling the diffusion of main alloying elements was not revealed in surface layer of deposited metal of die steel type, but changes in structure were observed, leading to softening of the deposited metal.

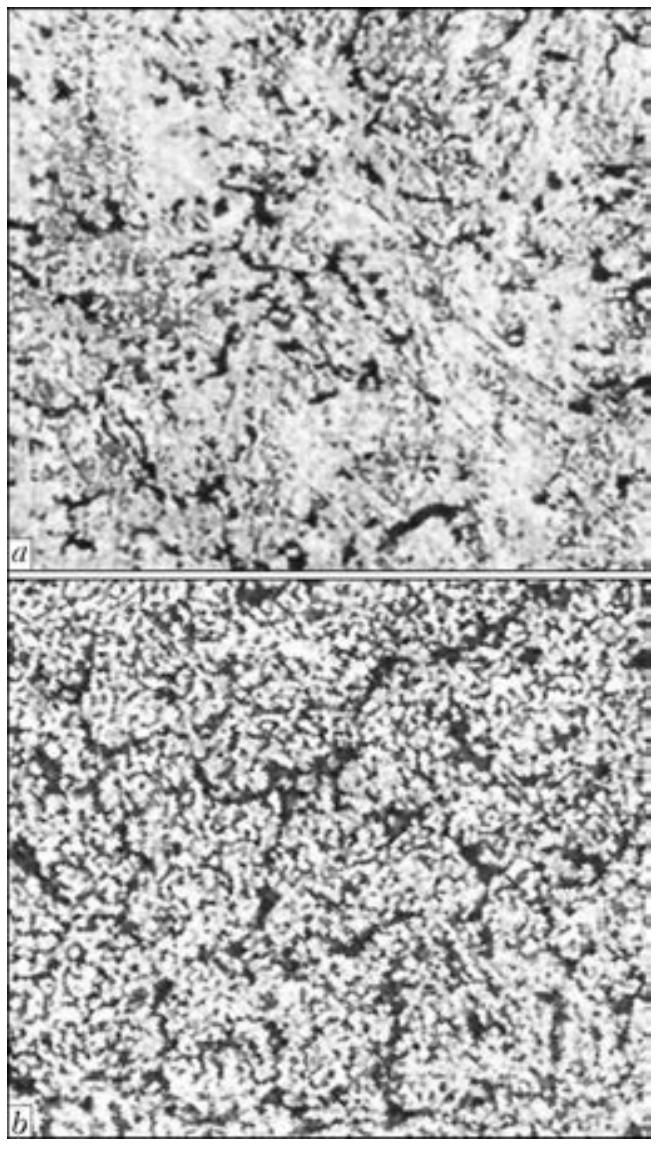

Figure 4. Microstructure $(\times 400)$ of 25Kh5FMS deposited metal before $(a)$ and after $(b)$ thermal tests

The carried out investigations showed the positive effect of a plastic sublayer on thermal resistance of deposited metal of type $35 \mathrm{~V} 9 \mathrm{Kh} 3 \mathrm{GSF}$ and $25 \mathrm{Kh} 5 \mathrm{FMS}$. Owing to more favorable distribution of residual stresses, the thermal resistance of deposited working layer not only increased in hardfacing, but a plastic sublayer arrests also the propagation of cracks $\mathrm{W}, \% \mathrm{Cr}, \% \mathrm{~V}, \%$
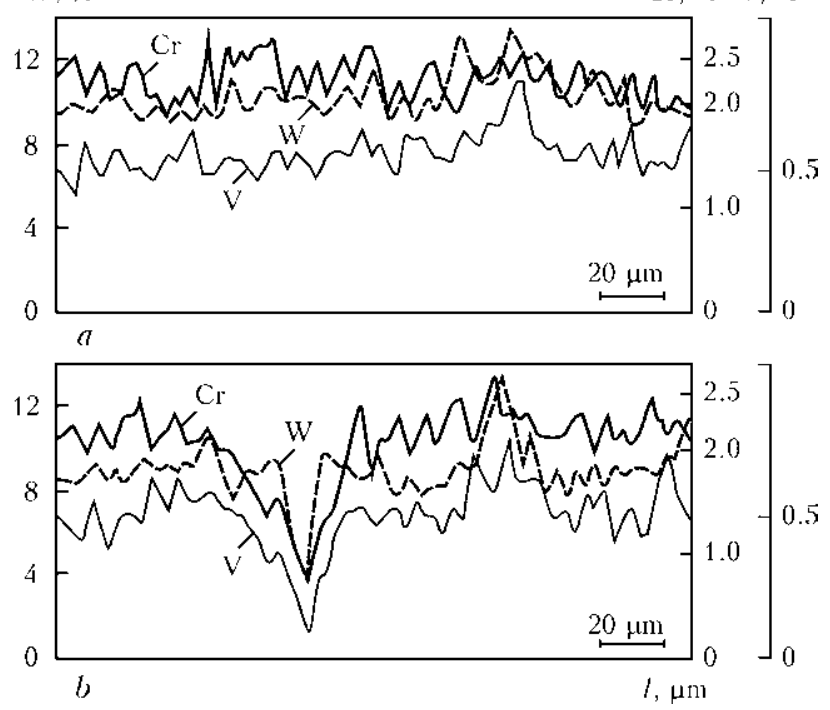

Figure 5. Distribution of main alloying elements in 35V9Kh3GSF deposited metal before $(a)$ and after $(b)$ thermal tests 
into the base metal preventing, to a certain degree, the fracture of the deposited part.

\section{Conclusions}

1. The method of experimental evaluation of thermal resistance of deposited specimens was updated. The new method allows evaluating the nature of propagation of thermal fatigue cracks across the thickness of deposited layer, as well as the effect of deposition of intermediate layers of different composition of thermal resistance of specimens.

2. Using the updated procedure the investigations of effect of deposition of a plastic sublayer by wire Sv-08A on thermal resistance of specimens, deposited by flux-cored wires PP-Np35V9Kh3GSF and PP-Np-25Kh5FMS, which are used for restoration and strengthening of hot mill steel rolls, were carried out. Deposition of the plastic sublayer allowed increasing the general thermal resistance of deposited specimens by $1.2-$
1.5 times. In addition, it was found that the plastic sublayer arrests the propagation of thermal fatigue cracks into the base metal, thus preventing, to a certain degree, the fracture of the deposited part.

1. Ryabtsev, I.A., Kondratiev, I.A. (1999) Mechanized hardfacing of metallurgical equipment. Kiev: Ekotekhnologiya.

2. Dulnev, P.A., Kotov, P.I. (1980) Thermal fatigue of metals. Moscow: Mashinostroenie.

3. Balandin, Yu.F. (1967) Thermal fatigue of metals in ship power machine building. Leningrad: Sudostroenie.

4. Tylkin, M.A. (1971) Increase in service life of metallurgical equipment parts. Moscow: Metallurgiya.

5. Ryabtsev, I.I., Chernyak, P.F., Osin, V.V. (2004) Block-module unit for deposited metal tests. Svarshchik, 1, 18-20.

6. Senchenkov, I.K., Chervinko, O.P., Ryabtsev, I.A. (2013) Numerical modeling of stress-strain and microstructural state of hot roll during multilayer hardfacing and service. In: Mathematical problems of technical mechanics: Transact., Issue 2(22), 139-144.

Received 05.02.2014 


\title{
INCREASE OF FATIGUE RESISTANCE OF SHEET WELDED JOINTS OF ALUMINUM ALLOYS USING HIGH-FREQUENCY PEENING
}

\author{
V.V. KNYSH, I.N. KLOCHKOV, M.P. PASHULYA and S.I. MOTRUNICH \\ E.O. Paton Electric Welding Institute, NASU \\ 11 Bozhenko Str., 03680, Kiev, Ukraine. E-mail: office@paton.kiev.ua
}

\begin{abstract}
A work is dedicated to experimental investigation of dependencies of fatigue resistance of sheet $(\delta=2-3 \mathrm{~mm})$ welded joints of average and high strength aluminum alloys, which were produced using consumable-electrode pulsed-arc welding in inert gases (PMIG) as well as determination of efficiency of rise of their fatigue life through application of high-frequency mechanical peening (HFMP) by set parameters of strengthening. Efficient parameters of HFMP strengthening of sheet welded joints with the help of portable manual equipment USP-300 were determined based on measurement of microhardness, local geometry parameters of weld and angular residual lipping distortion. Influence of HFMP of zone of weld to base metal transition on measurement of stress concentration factor, welding residual stresses and structure of surface layer of butt joints of small thickness aluminum alloys was investigated. It is shown that increase of radius of weld to base metal transition and elimination of angular residual lipping distortion after HFMP treatment provides for 1.35-1.49 reduction of stress concentration factor in the joints. It is determined that life on the basis of testing $2 \cdot 10^{6}$ cycles of stress alternation for strengthened butt joints from D16T alloy shows 5 times rise, that for AMg6 alloy makes 4 times and 7 times for 6061-T6 alloy in comparison with initial as-welded condition. The recommendations are given on efficient HFMP strengthening of sheet welded joints for increase of their fatigue life and elimination of residual welding deformations. 15 Ref., 2 Tables, 11 Figures.
\end{abstract}

$\boldsymbol{K} \boldsymbol{e} \boldsymbol{y} \boldsymbol{w} \boldsymbol{o r d} \boldsymbol{s}:$ welded joint, high-cycle fatigue, alumi num alloys, fatigue life, high-frequency mechanical peening, consumable-electrode pulsed-arc welding, increase of fatigue resistance

Application of aluminum alloys as structural materials for manufacture of lightweight structures of different designation were determined by their physical, strength, technological and service properties [1-4]. Sheet welded structures from aluminum alloys with high strength and life indices are widely used in airspace industry, building, transport machine building etc. Significant experience was accumulated on application of aluminum alloys in the sheet welded structures of different designation. It showed that problem of providing of necessary life in operation under alternating load conditions is still relevant [4, 5]. Continuous work on improvement of consumables, implementation of new welding methods, application of different design solutions for structure assemblies and postweld heat treatment [57] is performed for solving this problem.

One of the perspective technologies allowing solving the questions of rise of welding efficiency of aluminum alloys with simultaneous reduction of their softening and improvement of welded joint quality is a high-production consumable- electrode pulsed arc-welding in inert gases (PMIG) $[6,8]$.

However, according to GOST, developed in the beginning of the 1970s and acting to present time, the process of consumable electrode welding of aluminum alloys can be applied only to the elements not less than $3 \mathrm{~mm}$ in butt joints and not less that $4 \mathrm{~mm}$ in lap joints. Current pulse power sources with synergic control of the process of consumable electrode welding allow expanding the thickness ranges of materials to be welded towards their lower values at well optimized modes of PMIG process.

However, in practice, development of quality small thickness joints using PMIG technology can be insufficient for providing of necessary fatigue life of the welded joint of structure elements from aluminum alloys of average and high strength without application of postweld strengthening treatment. One of the current high-productive technologies of strengthening of the welded metal structures is high-frequency mechanical peening (HFMP), which is based on application of ultrasonic energy for plastic surface deforming (PSD) of material [9]. It should be noted that data on application of HFMP for sheet $(\delta \leq 3 \mathrm{~mm})$ butt welded joints of aluminum alloys are absent in the world and domestic literature. 
Aim of the present work is experimental determination of effective parameters for technology of HFMP of sheet butt welded joints from aluminum AMg6, D16T and 6061-T6 alloys, produced using PMIG, and seting of the dependencies of rise of fatigue resistance and fatigue life of the strengthened joints.

Studied alloys of $2 \mathrm{~mm}$ thickness and welding wire Sv-AMg6 (GOST 7871-75) of $1.2 \mathrm{~mm} \mathrm{di-}$ ameter were used for optimizing of butt welding modes. First-grade argon was applied as a shielding gas. Automatic PMIG welding was carried out using welding machines Fronius TPS-2700 and Fronius TPS-450. Surface of the metal before welding was dressed by scraper to $0.03-0.08 \mathrm{~mm}$ depth. Tilt angle of welding head made $10-15^{\circ}$, distance from torch nozzle to metal being welded was $8-12 \mathrm{~mm}$, arc length (distance between metal and wire end) made 3-5 $\mathrm{mm}$, argon consumption was $20 \mathrm{l} / \mathrm{min}$. Welding of the butt joints was carried out on removable backings from stainless steel with grooves for formation of weld root reinforcement of $2 \mathrm{~mm}$ width and $0.8 \mathrm{~mm}$ depth, that provided good reverse formation of the weld.

Geometry parameters of the welds (width $b$ and height $h$ of weld reinforcement on welded joint surface) were determined using macrosections. Geometry parameters of the weld root reinforcement virtually corresponded with the dimensions of forming grooves of the backings. Values of rate of energy input were calculated on formula $q_{\mathrm{i}}=K_{\mathrm{ef}} I_{\mathrm{w}} U_{\mathrm{a}} / v_{\mathrm{w}}, \mathrm{kJ} / \mathrm{cm}$, where $K_{\mathrm{ef}}$ is the efficient performance of the arc ( 0.72 for argon).

The calculations showed that, if the same depth of penetration of $2 \mathrm{~mm}$ thick metal is maintained, than 3 times increase of welding speed (for example, from 20 to $60 \mathrm{~m} / \mathrm{h}$ ) requires 1.5 times rise of current intensity and 1.15 times increase of arc voltage, but finally, results in 1.6 times reduction of rate of energy input of the welding process [10]. Such energy decrease reduces softening of welded joints from average

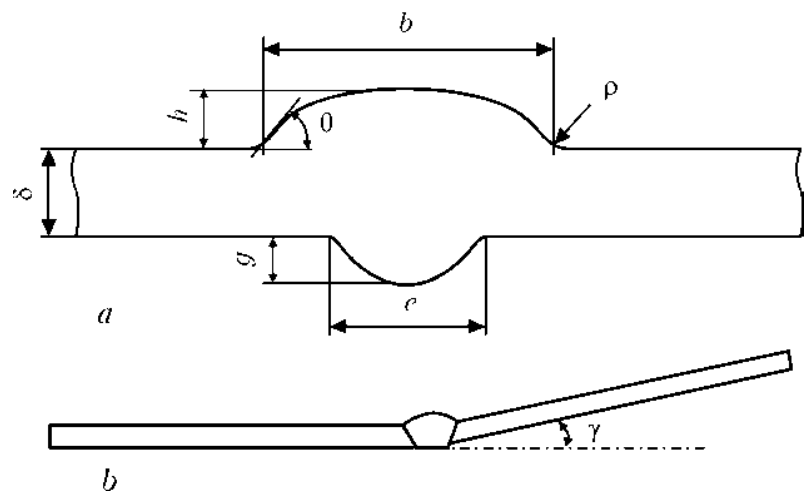

Figure 1. Parameters, determining SCF values of butt welded joints: $a-$ geometry parameters of joint; $b-$ angular distortion of butt joint and high strength aluminum alloys that promotes rise of their fatigue resistance.

It is well known that the main factors, determining fatigue resistance of structural material welded joints, are stresses concentration, caused by weld shape, and residual welding stresses (RWS), promoted by thermo-plastic strains, appearing during cooling $[5,9,11]$. In this connection, the values of stress concentration factor (SCF) were determined, the levels were measured and dependencies of RWS distribution in the butt welded joints of studied aluminum alloys were set.

Quantity determination of SCF requires data on real geometry of the welded joint. The maximum stresses in the butt joints act in zones of transition of weld surface to base metal at transverse loading in relation to weld and they depend mainly on such parameters as radius $\rho$ and angle $\theta$ of fillet surface (Figure 1, $a$ ). Among main geometry parameters of the butt welds, determining stress concentration, are also width $b$ and $e$, and height $h$ and $g$ of reinforcement from face and root of the weld. SCF depends also on value of angular distortion (Figure 1, b) in sheet aluminum alloy welded joints, for which angular distortion of welded sheets $\gamma$ is typical (angular displacement in welded joint zone, caused by bending of one welded plate relatively to another).

SCF values of the butt joints were determined by Stakanov-Korostylev-Rybin formula [12]

$$
\alpha_{\sigma}^{\prime}=1+\left[\frac{\rho}{\sin \theta}\left(\frac{2}{\delta}+\frac{4}{b}+\frac{0.8}{h}\right)\right]^{-0.5} .
$$

Area of expression (1) application covers the ranges of weld reinforcement size [13]: $\rho / \delta=$ $=0.01-0.10 ; h / \delta=0.1-0.2 ; \theta=15-30^{\circ} ; b / \delta=$ $=0.15-2.80$. SCF due to angular distortion were determined on formula of Colchen [14]

$$
K_{\gamma}=1+3.1 \frac{\sin \gamma}{\delta}
$$

where $\delta$ is the thickness of plates being welded.

Total SCF in the butt joint considering angular distortion was determined on formula

$$
\alpha_{\sigma}=\alpha_{\sigma}^{\prime} K_{\gamma} \text {. }
$$

It is found that angle $\gamma$ varies in the range of $2-5^{\circ}$ for all studied materials at $2 \mathrm{~mm}$ thickness of plates being welded, and corresponding SCF values due to angular distortion $K_{\gamma}$ made 1.04-1.14.

Profilometer-based method was selected for measurement of weld geometry parameters. Portable profilimeter, developed at the E.O. Paton Electric Welding Institute, and engineer microscope BMI-1, equipped with head having mechanical indicator and cone tip, were used in realizing of this method. The profiles of joint surfaces were designed based on measurement results 
Table 1. Geometry parameters of profiles of welds of butt PMIG-welded joints $(\delta=2 \mathrm{~mm})$

\begin{tabular}{||c|c|c|c|c|c|c|c|}
\hline \multirow{2}{*}{ Alloy } & $\begin{array}{c}\text { Side of joint } \\
\text { treatment }\end{array}$ & $\rho, \mathrm{mm}$ & $\theta, \mathrm{deg}$ & $b, \mathrm{~mm}$ & $h, \mathrm{~mm}$ & $\gamma_{\mathrm{av}}, \mathrm{deg}$ & 3 \\
\hline \multirow{2}{*}{ D16T } & Face & $0.39 / 0.11$ & $24 / 4$ & $5.33 / 0.15$ & $1.19 / 0.12$ & $1.66 / 0.21$ \\
\cline { 2 - 7 } & Root & $0.33 / 0.08$ & $29 / 2$ & $3.46 / 0.15$ & $1 / 0.15$ & $1.82 / 0.26$ \\
\hline \multirow{2}{*}{ AMg6 } & Face & $0.55 / 0.21$ & $35 / 9$ & $6.59 / 0.19$ & $1.34 / 0.16$ \\
\cline { 2 - 7 } & Root & $0.31 / 0.16$ & $34 / 13$ & $3.72 / 0.47$ & $1.10 / 0.18$ & $1.68 / 0.14$ \\
\hline \multirow{2}{*}{$6061-T 6$} & Face & $1.01 / 0.32$ & $28 / 3$ & $7.20 / 0.46$ & $1.78 / 0.48$ \\
\cline { 2 - 7 } & Root & $0.37 / 0.21$ & $51 / 10$ & $4.70 / 0.65$ & $1.37 / 0.21$ \\
\hline
\end{tabular}

Note. Here and in Table 2 numerator - average value; denominator - their root-mean-square deviation.

using computer processing. Table 1 shows the results of measurement of geometry parameters for typical profiles of studied aluminum alloy welded joints. Determined values of theoretical SCF lie in 1.61-1.68 range for face and 1.78-1.88 for weld root.

Measurements of RWS in studied alloy welded joints with the weld in midsection of the plate were carried out by non-destructive acoustic method [15]. Figure 2 shows dependence of maximum level of residual stresses on width of welded plates from 6061-T6 and AMg6 alloys, and Figure 3 represents distribution of the residual stresses in welded plate from AMg6 alloy of $600 \times$ $\times 600 \times 2 \mathrm{~mm}$ size, measured along butt weld at $2 \mathrm{~mm}$ distance from fusion zone. It can be seen that the maximum levels of values of the residual stresses longitudinal to weld achieve (0.4$0.5) \sigma_{0.2}$, and transverse residual stresses, acting, as a rule, along the direction of application of external loading are 2 times lower $((0.20-$ $0.25) \sigma_{0.2}$ ) in PMIG welding of sheet aluminum alloys $(\delta=2 \mathrm{~mm})$. Increase of width of plates being welded, virtually, provides for stabilizing of the maximum level of transverse residual stresses at width more than $200 \mathrm{~mm}$.

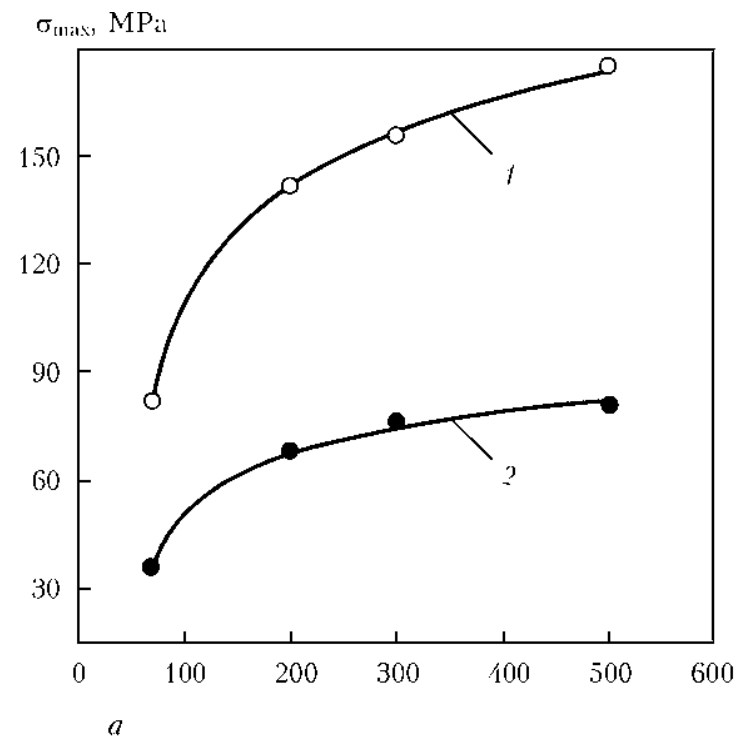

Effective parameters for treatment of butt welded joints using HFMP technology without breaking their geometry stability were determined at one-side peening of solid D16T alloy plate of $300 \times 100 \times 2 \mathrm{~mm}$ size. Standard peens of 2, 3 and $5 \mathrm{~mm}$ diameter were used for treatment of metal surface along the plate centerline, and angle $\gamma$ of plate plane deviation relatively to initial condition was measured at that. The experimental dependencies of change of deviation angle on linear speed of movement of operating tool along the treated surface were derived based on measurement results (Figure 4).

Treatment rate $4-10 \mathrm{~mm} / \mathrm{s}$ resulted in formation of maximum angle of plate lipping distortion equal $1-5^{\circ}$. The value of maximum deviation angle $\left(\gamma=5^{\circ}\right)$ due to one-side treatment of solid plate corresponds to the value of possible angle of residual strain of sheet PMIG-welded joints from studied aluminum alloys (see Figure 1,b). Therefore, recommended rate of joint treatment lied in $4-10 \mathrm{~mm} / \mathrm{s}$ range. Treatment of the joints with linear speed of operating tool movement $7-9 \mathrm{~mm} / \mathrm{s}$ is recommended in order to rise efficiency and achieve maximum reduction of SCF

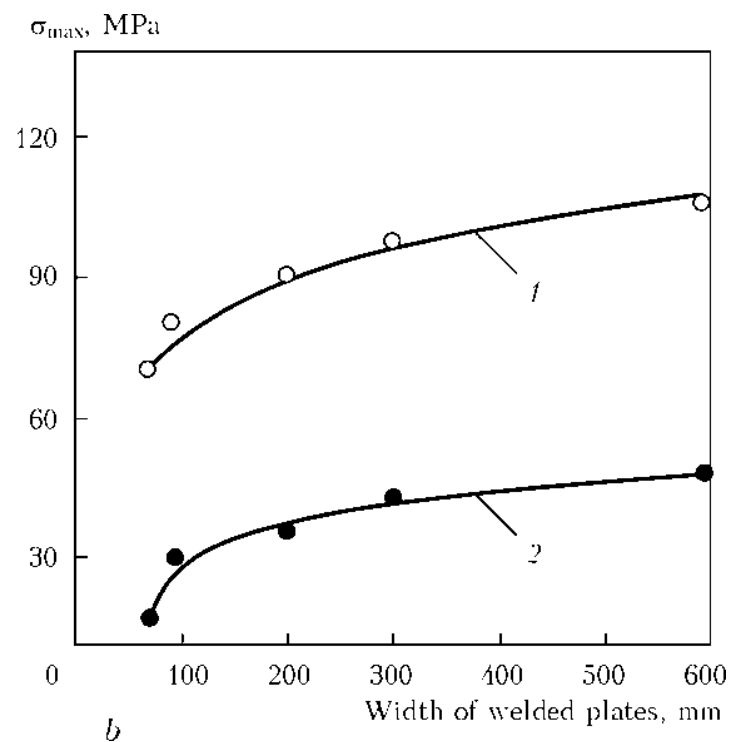

Figure 2. Dependence of maximum level of residual stresses on width of welded plates 2 mm thick: $a-$ alloy 6061 -T6 $\left(\sigma_{0.2}=262 \mathrm{MPa}\right) ; b-\operatorname{AMg} 6\left(\sigma_{0.2}=200 \mathrm{MPa}\right) ; 1-$ longitudinal $\sigma_{x} ; 2-$ transverse $\sigma_{y}$ stresses 


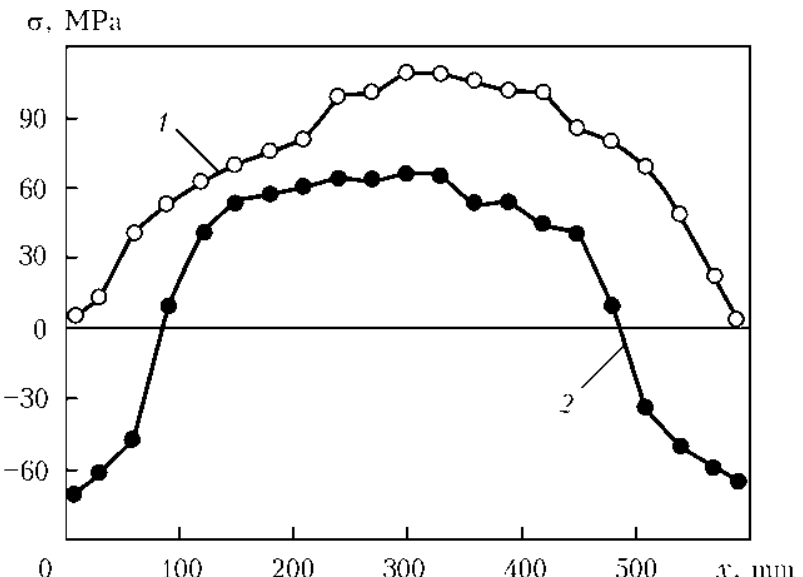

Figure 3. Distribution of residual stresses in welded plate of AMg6 alloy $600 \times 600 \times 2 \mathrm{~mm}$ in size, measured along weld at $2 \mathrm{~mm}$ distance from fusion zone: 1 - longitudinal $\sigma_{x} ; 2-$ transverse $\sigma_{y}$ stresses

in HFMP strengthening of sheet welded joints of aluminum alloys. Considering that transition radius of weld to base metal is lower from the root side than from the face one (see Table 1) $3 \mathrm{~mm}$ diameter peens were taken for strengthening of fusion zone from face side of the weld and that for root side had $2 \mathrm{~mm}$. In further investigations, all the specimens of butt joints were strengthened using HFMP with indicated effective parameters of treatment.

Calculations of theoretical SCF values in the welded joints after treatment were carried out,

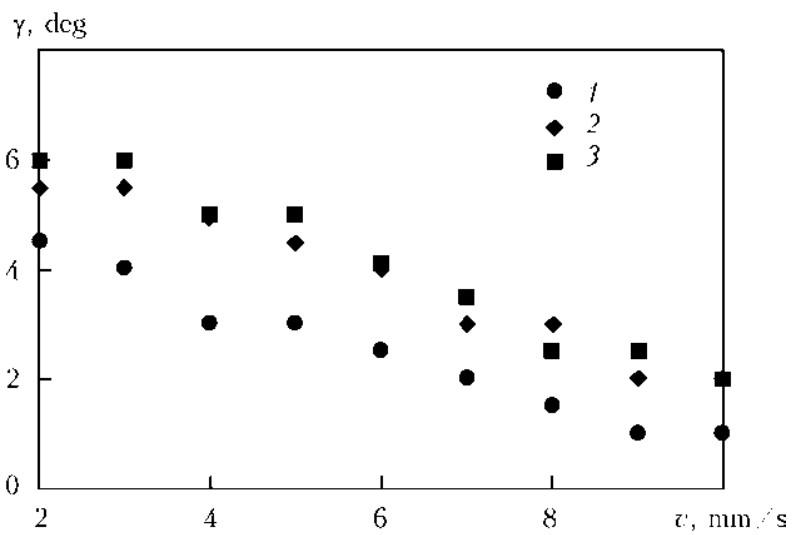

Figure 4. Dependence of angular distortion of $300 \times 100 \times$ $\times 2 \mathrm{~mm}$ size plate from alloy D16T at one-side peening of metal along plate centerline on linear speed of operating tool travel at HFMP: $1-d=2 ; 2-3 ; 3-5 \mathrm{~mm}$

and their comparison with corresponding SCF values of as-welded joints was performed. Peening of zones of weld to base metal transition is carried out in joint strengthening using HFMP that results in formation of cylindrical surfaces in form of grooves in this zone. Profile of the formed groove has radius which, as a rule, corresponds to radius of spherical surface of applied percussion peens. Geometry parameters of the weld profiles, necessary for SCF determination, were received using profilograms of fusion zone of the strengthened welded joints. Table 2 shows the SCF values of welded joints from studied
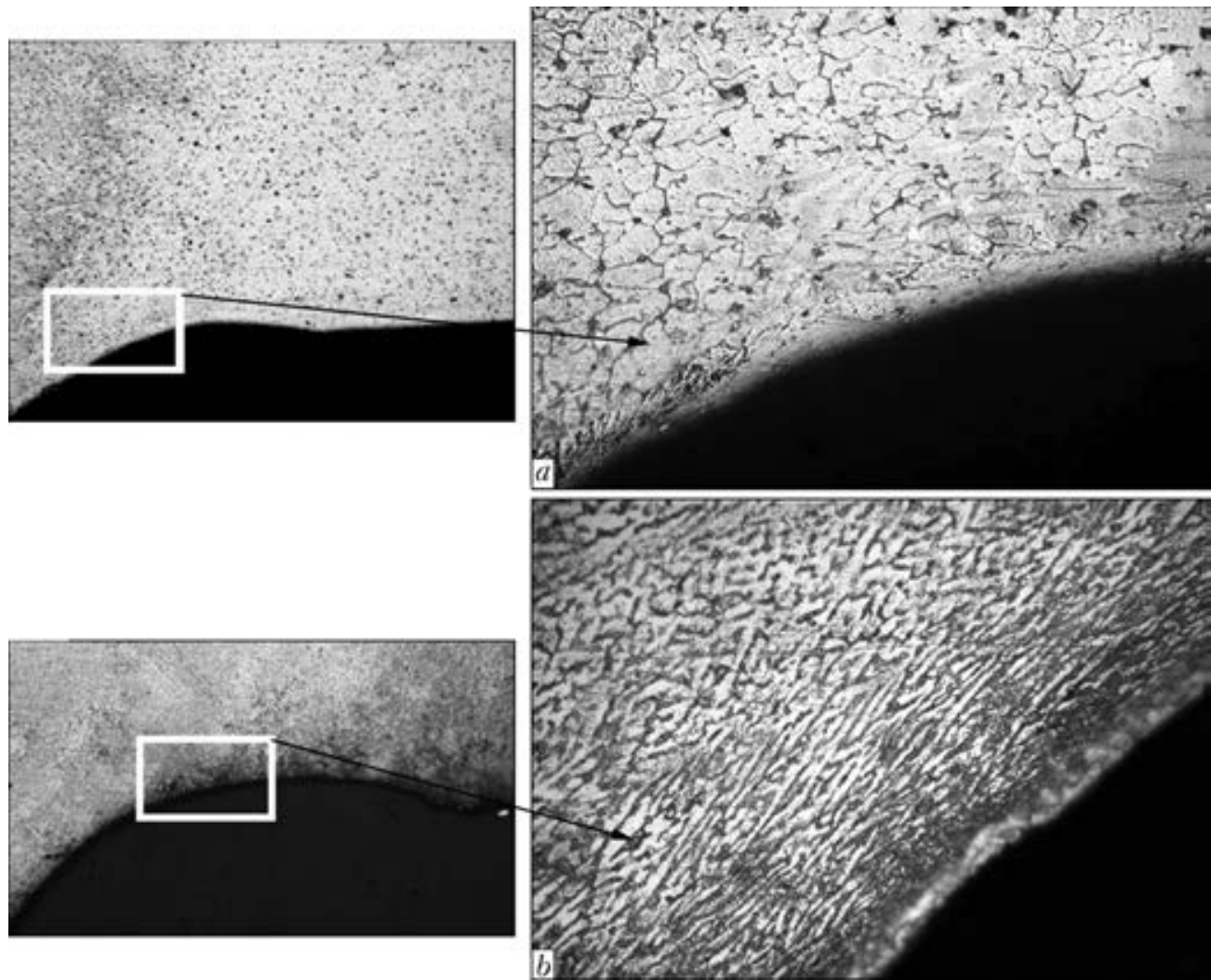

Figure 5. Microstructure of subsurface layer of weld to base metal transition zone from root side of D16T $(a-\times 500)$ and AMg6 alloy $(b-\times 400)$ after HFMP (etched) 
Table 2. Values of SCF of butt PMIG-welded joints before strengthening $\alpha_{\sigma}$ and after HFMP $\alpha_{\sigma}^{\text {str }}$

\begin{tabular}{|c|c|c|c|c||}
\hline \multirow{2}{*}{ Alloy } & $\begin{array}{c}\text { Side of joint } \\
\text { treatment }\end{array}$ & $\alpha_{\sigma}$ & $\alpha_{\sigma}^{\text {str }}$ & $\alpha_{\sigma} / \alpha_{\sigma}^{\text {str }}$ \\
\hline \multirow{2}{*}{ AMg6 } & Face & $1.68 / 0.14$ & $1.13 / 0.07$ & 1.49 \\
\cline { 2 - 5 } & Root & $1.78 / 0.48$ & $1.21 / 0.06$ & 1.47 \\
\hline \multirow{2}{*}{$6061-\mathrm{T} 6$} & Face & $1.61 / 0.21$ & $1.19 / 0.12$ & 1.35 \\
\cline { 2 - 5 } & Root & $1.88 / 0.27$ & $1.27 / 0.11$ & 1.48 \\
\hline \multirow{2}{*}{ D16T } & Face & $1.66 / 0.21$ & $1.16 / 0.10$ & 1.43 \\
\cline { 2 - 5 } & Root & $1.82 / 0.26$ & $1.13 / 0.11$ & 1.39 \\
\hline
\end{tabular}

alloys after HFMP in accordance with determined parameters of treatment. It can be seen from the Table that reduction of average values of SCF in strengthened joints can make 1.5 times at effective parameters of strenghtening. Such reduction of SCF (to $50 \%$ ) in the strengthened joints is the important factor, promoting increase of their fatigue resistance.

The metallographic investigations of treated surface were carried out at up to $\times 500$ magnification in zone of weld to base metal transition for the welded joints from studied D16T and AMg6 alloys. The results of structure examination of strengthened surface layer showed absence of cracks, cleavages and delamination in this layer (Figure 5).

Change of grain structure at up to $250 \mu \mathrm{m}$ depth is observed in subsurface layer of the joint after HFMP of the fusion zone. At that, deformed grains are elongated in the planes parallel to treated surface tangent line. Measurement of microhardness of weld, HAZ and base metal of AMg6 welded joint in as-welded condition and after HFMP of these zones showed that PSD resulted in $65-75 \%$ rise of hardness of weld metal at 50-60 $\mu \mathrm{m}$ depth, that for HAZ made 16-25\% and $22 \%$ for base metal (Figure 6 ).

The change of metal structure and rise of hardness in the subsurface layers after HFMP show that present structural factor and strain hardening, in addition to reduction of SCF value, can have positive effect on increase of joint fatigue resistance.

Strain-gauging was used for measurements of the residual stresses in AMg5 alloy welded plates of $300 \times 300 \times 2 \mathrm{~mm}$ size in as-welded condition and after HFMP of the fusion zone.

Figure 7 represents received measurement data of RWS along the butt weld at $3 \mathrm{~mm}$ distance from the fusion zone for as-welded joints and joints after strengthening. As can be seen from presented diagrams, the transverse residual stresses, acting of which corresponds with direction of applied external loads, causing stress concentration in the fusion zone, are insignificant. Their maximum values in middle part of the weld makes only $40 \mathrm{MPa}$ and after strengthening these stresses reduce by 23-

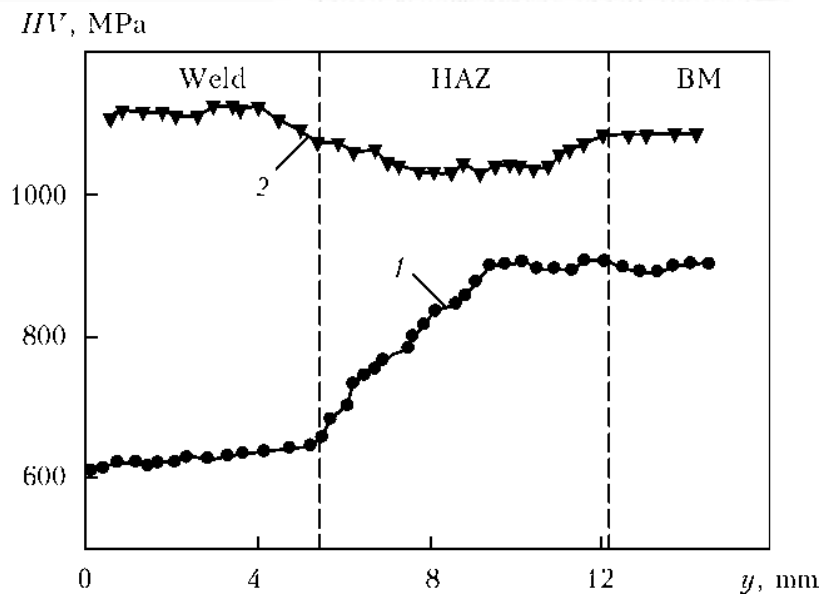

Figure 6. Distribution of microhardness in AMg6 alloy welded joint in direction normal to weld at 50-60 $\mu \mathrm{m}$ depth (beginning of coordinates - in weld center): 1 - microhardness before; 2 - after HFMP

$30 \%$ more. Such stress levels have no significant effect on joint fatigue resistance.

Current servohydraulic machine MTS 318.25 with maximum loading $250 \mathrm{kN}$ was used for fatigue testing of the specimens from base metal and welded joints. Corset type specimens ( $\mathrm{Fi}-$ gure 8) were tested at set constant values of stress
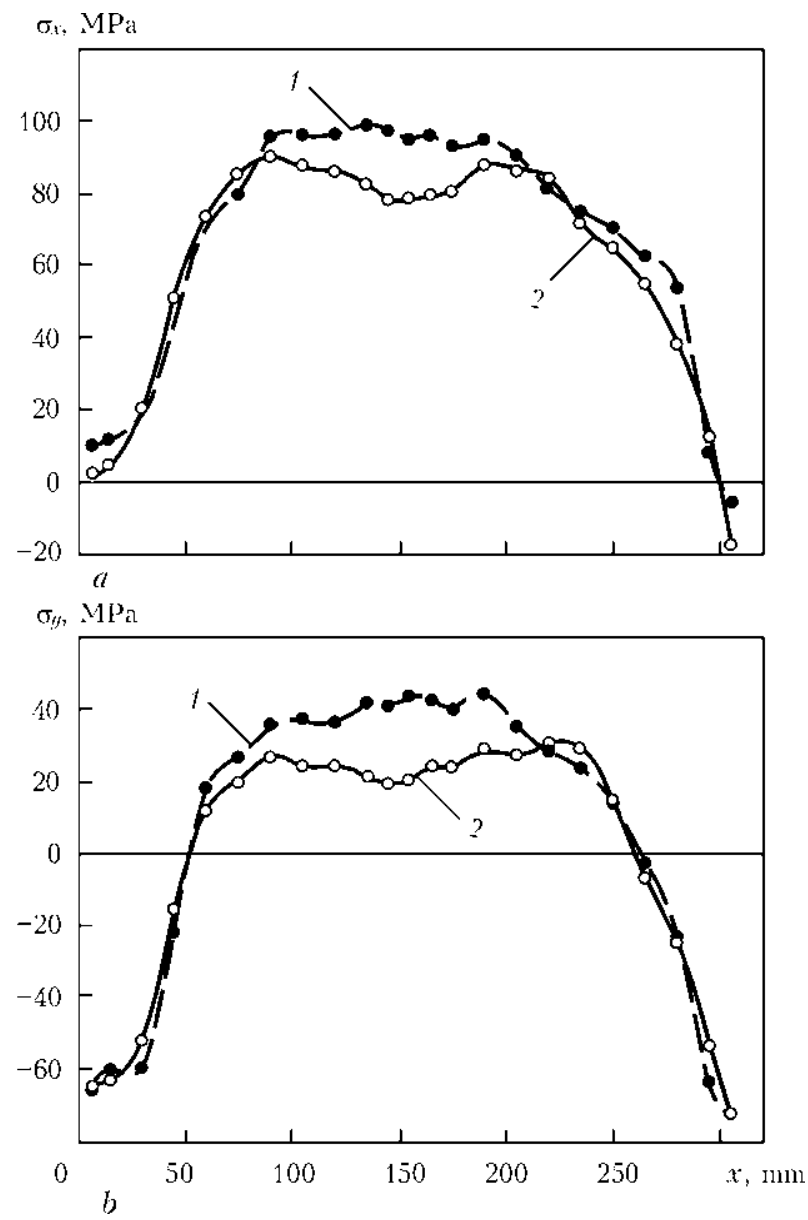

Figure 7. Distribution of residual stresses in AMg6 alloy welded plates of $300 \times 300 \times 2 \mathrm{~mm}$ size before (1) and after (2) HFMP, measured in sections parallel to weld at $3 \mathrm{~mm}$ distance from weld: $a-$ longitudinal $\sigma_{x} ; b-$ transverse $\sigma_{y}$ stresses 


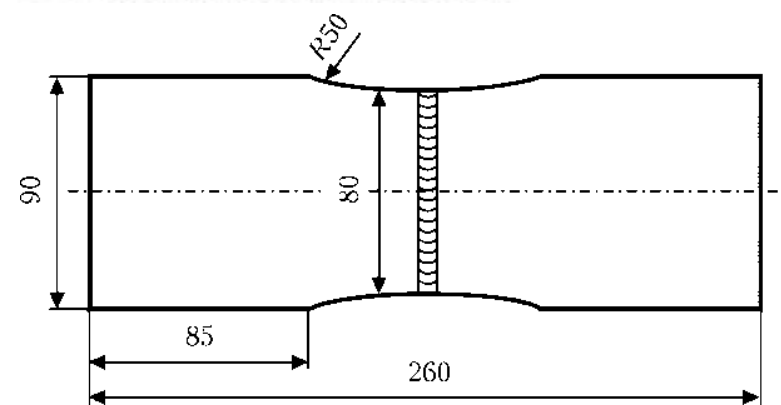

Figure 8. Shape and geometry dimensions of welded specimens for fatigue tests

range, corresponding to range of fatigue life of $5 \cdot 10^{4}-2 \cdot 10^{6}$ cycles of stress alternation at constant asymmetry of cycle to complete fracture. Respective fatigue curve (line of regression of experimental data) was plotted in $2 \sigma_{a}-\lg N$ coordinates based on the results of carried fatigue tests for each series of the specimens using set experimental data of restricted fatigue limits.

Figure 9 represents experimental data, received on results of fatigue tests of four series of specimens of AMg6 alloy welded joints. For asymmetry of stress cycle $R_{\sigma}=0$, the restricted fatigue limit of HFMP-strengthened fusion zones of the butt joints on the basis of $2 \cdot 10^{6}$ cycles rised by $27 \%$ in comparison with the fatigue limit of as-welded joints. At that, fatigue life of the joints increases 4 times. Peening efficiency somewhat
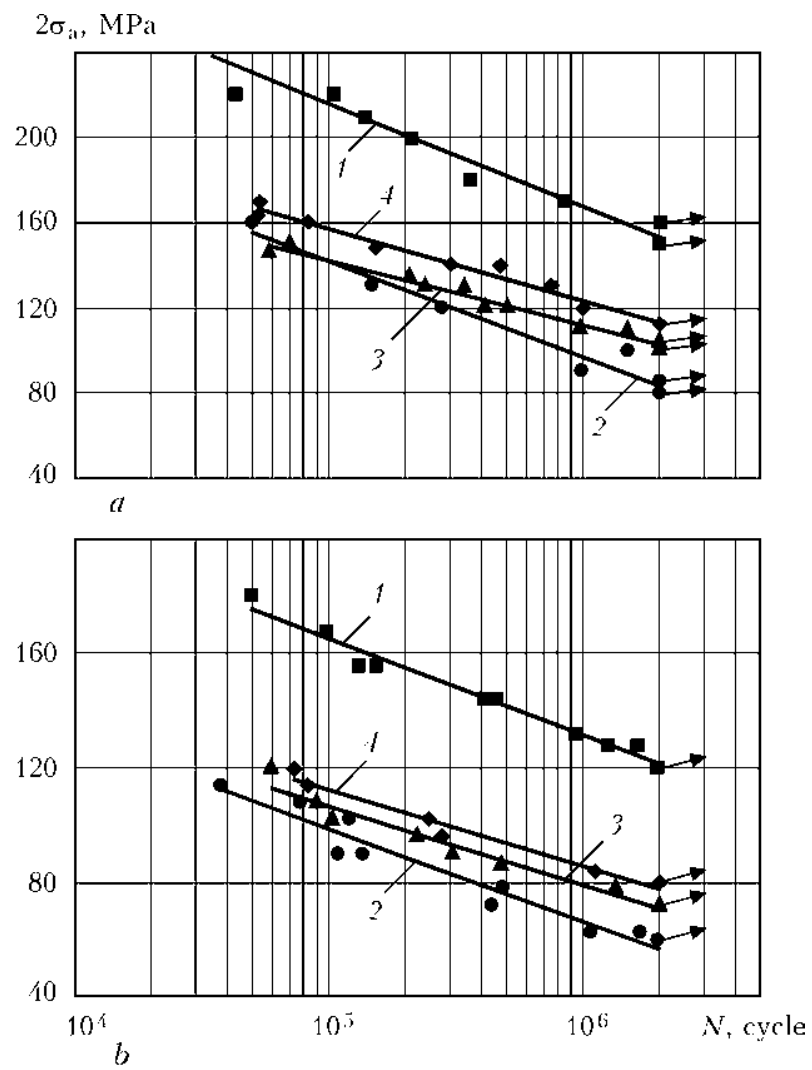

Figure 9. Fatigue curves for AMg6 alloy welded joints $2 \mathrm{~mm}$ thick corresponding to asymmetry of stress cycle $R_{\sigma}=0$ ( $a$ ) and $0.4(b)$ : 1 - base metal; 2 - as-welded; 3 - HFMPstrengthened joints; 4 - joints with mechanical dressing of weld reinforcement

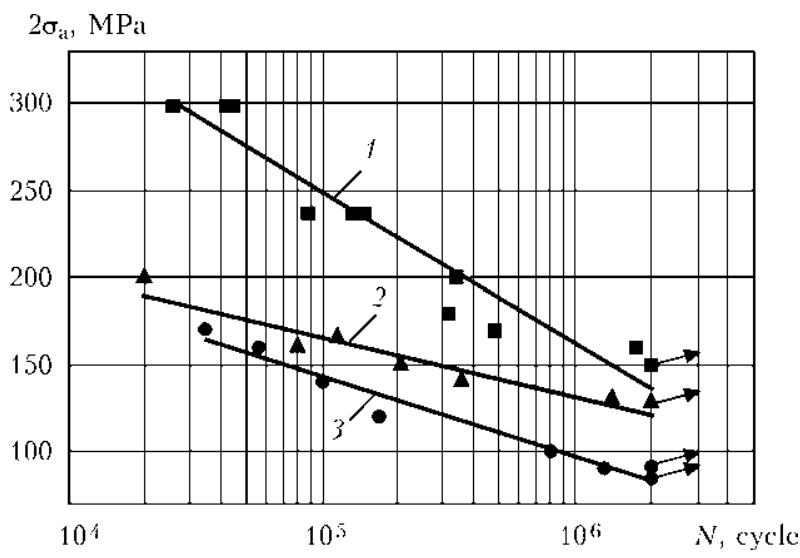

Figure 10. Fatigue curves for 6061-T6 alloy welded joints $2 \mathrm{~mm}$ thick corresponding to asymmetry of stress cycle $R_{\sigma}=$ $=0.1: 1-$ base metal; $2-$ as-welded; $3-$ HFMPstrengthened joints

reduces at increase of stress cycle asymmetry. Thus, the restricted fatigue limit on the basis of $2 \cdot 10^{6}$ cycles of stress alternation rised by $21 \%$ at $R_{\sigma}=0.4$. Strengthening efficiency reduces at rise of amplitude of applied stresses and HFMP treatment has, virtually, no effect for zero-to-compression $\left(R_{\sigma}=0\right)$ as well as repeated $\left(R_{\sigma}=0.4\right)$ alternate loading already in the area of life below $10^{5}$ cycles. Received experimental data on fatigue resistance of HFMP-strengthened welded joints rise in high-cycle area to values close to that in the joints with removed weld reinforcement. This
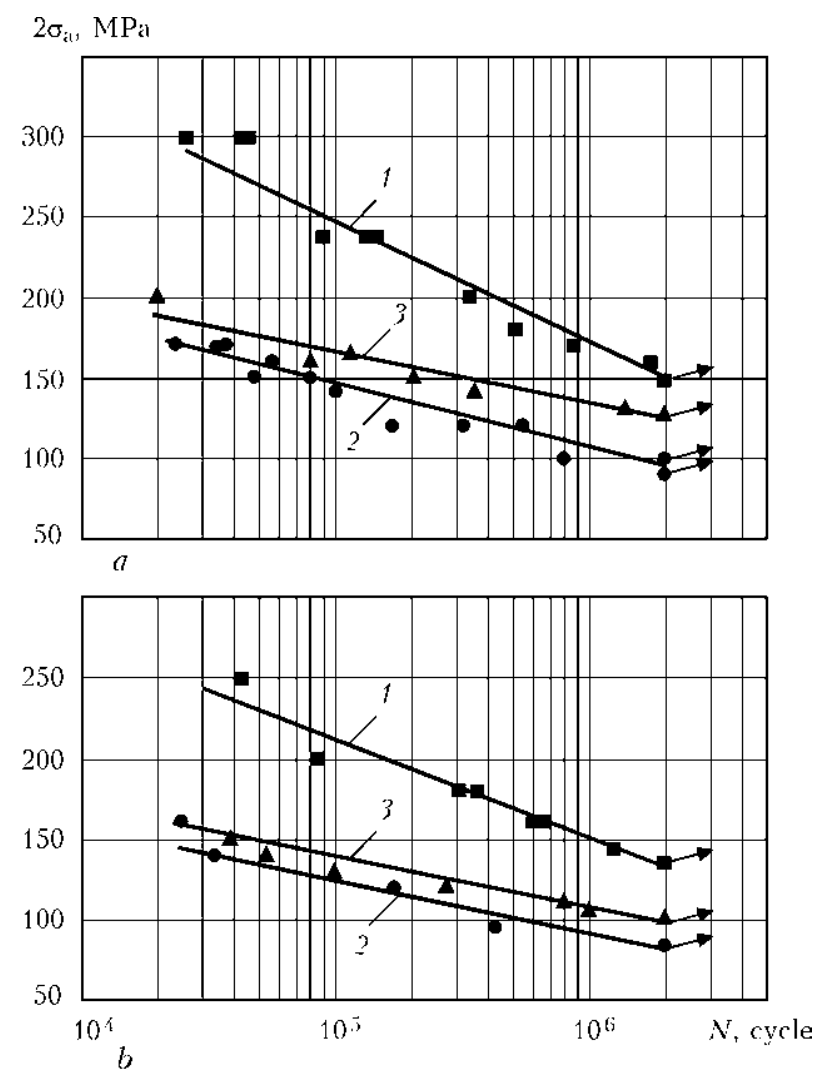

Figure 11. Fatigue curves for D16T alloy butt welded joints $2 \mathrm{~mm}$ thick corresponding to asymmetry of stress cycle $R_{\sigma}=$ $=0.1(a)$ and 0.4 (b): 1 - base metal; 2 - as-welded; 3 - HFMP-strengthened joints 
indicates the prospects of application of low-cost HFMP instead of laborious generally accepted mechanical treatment.

Increase of fatigue resistance of HFMPstrengthened fusion zones of butt joints from 6061-T6 heat-hardenable alloy is observed in all range of life of $5 \cdot 10^{5}-2 \cdot 10^{6}$ cycles of stress alternation (Figure 10). At that, their fatigue life rises up to 7 times in comparison with initial as-welded condition, and the restricted fatigue limit on the basis of $2 \cdot 10^{6}$ cycles has increased by $40 \%$.

The restricted fatigue limit of butt welded joint from high-strength aluminum alloy D16T on the basis of $2 \cdot 10^{6}$ cycles of stress alternation with $R_{\sigma}=0.1$ asymmetry rised after HFMP of zone of weld to base metal transition by $30 \%$ in comparison with as-welded joints, and the fatigue life of the joints increased 5 times (Figure 11, a). Similar to AMg6 alloy, rise of stress cycle asymmetry decreases efficiency of HFMP strengthening. Thus, the restricted fatigue limit on the basis of $2 \cdot 10^{6}$ cycles increases only by $13 \%$ at $R_{\sigma}=0.4$ and the fatigue life at that rises 3 times (Figure 11, b).

Received results shows that HFMP strengthening of the fusion zones of sheet butt welded joints of aluminum alloys AMg6, D16T and 6061T6 can significantly rise their fatigue life.

\section{Conclusions}

1. Weld parameters for butt welded joints from D16T, AMg6 and 6061-T6 alloys of $2 \mathrm{~mm}$ thickness were determined and evaluated in as -welded and after HFMP strengthening condition. These joints were made for the first time using optimized PMIG welding technology.

2. Nature of distribution of the residual stresses was investigated for PMIG welding of sheet $(\delta=$ $=2 \mathrm{~mm}$ ) aluminum alloys of average and high strength. It is shown that the maximum values of residual tensile stresses longitudinal to weld make $(0.4-0.5) \sigma_{0.2}$, and transverse residual stresses, acting, as a rule, along the direction of external loading, are 2 times lower $\left((0.20-0.25) \sigma_{0.2}\right)$.

3. Effective parameters of HFMP strengthening of sheet welded joints from aluminum alloys of average and high strength were determined. Range of linear speed of operating tool movement during HFMP makes 7-9 mm/s, peen diameter is 3 and $2 \mathrm{~mm}$ for face and root sides of the weld, respectively. Using of such parameters provides for PSD of metal in treated zone of the joints without deviation of their geometry at $0.23-$ $0.28 \mathrm{~mm}$ depth. Application of HFMP of fusion zone of the butt welded joints results in $20-50 \%$ reduction of the transverse residual tensile stresses near weld. At that, SCF values in zones of stress concentrators of the butt joints reduce
1.35-1.49 times and its absolute values lie in 1.13-1.27 range for studied alloys.

4. Efficiency of HFMP strengthening of the fusion zones for rising of fatigue life in sheet butt joints from aluminum alloys was experimentally verified. It is determined that life of strengthened D16T alloy joints in high-cycle area of $5 \cdot 10^{5}$ $2 \cdot 10^{6}$ cycles of stress alternation shows 5 times rise and that for AMg6 alloy is 4 times and in the case of 6061-T6 alloy it makes 7 times in comparison with as-welded condition.

5. It is experimentally determined that the fatigue limit on the basis of $2 \cdot 10^{6}$ cycles of stress alternation of the sheet butt joints from aluminum alloy AMg6, strengthened using HFMP, achieves the level of fatigue limit of the joints with removed weld reinforcements that $20 \%$ higher of fatigue limit of the untreated joints. Therefore, HFMP with set parameters can be recommended for strengthening of such joints instead of more expensive and technologically complex mechanical dressing of the weld.

1. Elagin, V.I. (2009) Structural nanoalloys alloys on aluminium base. Tsvet. Metally, 6, 103-111.

2. Filatov, Yu.A. (1996) Wrought alloys based on Al$\mathrm{Mg}-\mathrm{Sc}$ system. Metallovedenie $i$ Term. Obrab. Metallov, 6, 33-36.

3. Fridlyander, I.N., Beletsky, V.M., Krivov, G.A. (2000) Aluminium alloys in aircraft structures. Tekhnologich. Sistemy, 1(3), 5-17.

4. Ishchenko, A.Ya., Labur, T.M., Bernadsky, V.N. et al. (2006) Aluminium and its alloys in current welded structures. Kiev: Ekotekhnologiva.

5. Ishchenko, A.Ya., Labur, T.M. (2013) Welding of current structures from aluminium alloys. Kiev: Naukova Dumka.

6. Mashin, V.S., Pavshuk, V.M., Dovbishchenko, I.V. et al. (1991) 'Influence of pulsed-arc welding conditions of aluminium ADO on shape and porosity of welds. Avtomatich. Svarka, 4, 57-60.

7. Shonin, V.A., Mashin, V.S., Vojtenko, O.V. et al. (2003) Improvement of fatigue resistance of tee welded joints in sheet aluminium alloy AMg6. The Paton Welding J., 7, 7-10.

8. Ostrovsky, O.S., Gudko, A.V., Kudryashyov, O.N. et al. (1992) Consumable-electrode pulsed-arc welding of large-sized structures of aluminium alloys. Svaroshn. Proizvodstvo, 10, 7-9.

9. Lobanov, L.M., Kirian, V.I., Knysh, V.V. et al. (2006) Improvement of fatigue resistance of welded joints in metal structures by high-frequency mechanical peening (Review). The Paton Welding J., 9, 2-8.

10. Mashin, V.S., Pashulya, M.P., Shonin, V.A. et al. (2010) Consumable electrode pulsed argon-arc welding of sheet aluminium alloys. Ibid., 5, 38-41.

11. Trufyakov, V.I. (1990) Strength of welded joints under alternative loads. Kiev: Naukova Dumka.

12. Stakanov, V.I., Kostylyov, V.I., Rybin, Yu.K. (1987) Stress concentration in butt welded joints. Avtomatich. Svarka, 11, 19-23.

13. Karkhin, V.A., Kopelman, L.A. (1976) Stress concentration in butt joints. Svarochn. Proizvodstvo, 2, 6-7.

14. Colchen, D. (2000) Application des calculs aux elements finis pour definer et valider des modeles analytiques de calcul de contrainte sur un assemblage bout a bout en alliage d'aluminium. Soudage et Techniques Connexes, $54(\mathbf{3} / \mathbf{4}), 3-16$.

15. Gushcha, O.I., Smilenko, V.N., Kot, V.G. et al. (2009) Testing of stresses based on application of subsurface acoustic waves. Tekhn. Diagnostika $i$ Nerazrush. Kontrol, 1, 11-13. 


\title{
PECULIARITIES OF ALLOYING OF WELD METAL OF HIGH-STRENGTH ALUMINIUM ALLOY WELDED JOINTS WITH SCANDIUM
}

\author{
V.E. FEDORCHUK, O.S. KUSHNARYOVA, T.A. ALEKSEENKO and Yu.V. FALCHENKO \\ E.O. Paton Electric Welding Institute, NASU \\ 11 Bozhenko Str., 03680, Kiev, Ukraine. E-mail: office@paton.kiev.ua
}

\begin{abstract}
The problem of effect of solidification rate on structure of weld metal of scandium-containing aluminium alloys is considered. Peculiarities of scandium precipitation from melt in solidification of aluminium alloys under non-equilibrium conditions, simulating fusion welding, are investigated. Procedure of investigations has been developed and confirmed experimentally. Advantage of offered procedure over the existing ones consists in the fact that it allows simulate almost all the methods of fusion, from argon arc non-consumable electrode welding to electron beam welding. It is shown that the procedure satisfies the put aims completely. Microstructural investigations of ingots in height showed that within the interval of solidification rates from $10^{3.3}$ to $10^{2.5}{ }^{\circ} \mathrm{C} / \mathrm{s}$ the change of form of solidification occurs from dendritic to subdendritic ones. It was found that at rates of solidification, commensurable with solidification of weld metal, up to $0.41 \% \mathrm{Sc}$ can be contained in solid solution of alloys. When applying the highly concentrated power sources, such as electron beam, it is possible to reach the similar value also in welds. In arc methods of welding approximately $0.3 \%$ Sc can be assimilated in solid solution of weld metal. It was found that it is necessary to provide its content in weld metal at the level of $0.35-0.40 \mathrm{wt} \%$ to maximization of effect from alloying of welds with scandium. In this case the increase in mechanical properties of weld metal is provided both by refining of its crystalline structure, and also by hardening the solid solution by scandium. 7 Ref., 3 Tables, 4 Figures.
\end{abstract}

Keywords: high-strength aluminium alloys, scandium, alloying, weld metal, modifying of cast structure

During development of new alloys the investigations have been always carried out directed to optimization of amount of modifying additions to the alloy. These investigations are especially urgent in use of scandium, as its adding into aluminium alloys increases their cost by $5-10$ times [1-3]. However, these investigations are carried out for conditions of industrial production of aluminium alloys, where the rate of solidification $\left(v_{\text {sol }}\right)$ of ingots are low, and further they are subjected to pressure treatment (pressing, extrusion, rolling). In case of weld metal the situation is somewhat different. The weld has a cast structure, which is not further subjected to pressure treatment, and the rate of solidification is by 1-2 orders higher than that in industrial production of alloys [4].

The aim of this work is the development of method of producing ingots at the solidification rate corresponding to the solidification of weld metal in fusion welding and defining the peculiarities of weld metal alloying with scandium in welding of high-strength aluminium alloys.

The investigations were carried out on ingots of model alloys of the following composition, \%:
99.95Al, $\mathrm{Al}-0.8 \mathrm{Sc}, \mathrm{Al}-0.6 \mathrm{Sc}, \mathrm{Al}-6.3 \mathrm{Cu}-0.8 \mathrm{Sc}$, $\mathrm{Al}-8.5 \mathrm{Zn}-2.3 \mathrm{Mg}-1.9 \mathrm{Cu}-0.2 \mathrm{Zr}-0.45 \mathrm{Sc}$. To produce the homogeneous chemical composition in all the points being investigated, the alloys were preliminary melted in resistance furnaces with next solidification at $v_{\text {sol }}=10-30{ }^{\circ} \mathrm{C} / \mathrm{s}$. After this, they were crushed and a charge was prepared for further experiments. Metal was poured into a specially designed wedge-type water-cooled mould, which allows providing the different rates of melt solidification in ingot height. In narrow part the ingot had $0.5 \mathrm{~mm}$ thickness, $15 \mathrm{~mm}$ width and $95 \mathrm{~mm}$ height. Cooling rate in different regions of the wedge-type ingot was calculated by a dendritic parameter of crystallites on the basis of procedure, suggested by Dobatkin [5].

Experiment procedure. Before casting the melt was overheated to $1000{ }^{\circ} \mathrm{C}$ up to complete dissolving of all the intermetallics, then it was cooled in crucible at continuous stirring up to casting temperature and solidified into the mould. Rate of solidification of metal was determined by structure of ingot of pure aluminium $(99.95 \%)$.

Analysis of the ingot microstructure showed that it is dendritic across the entire section. Size of dendrites is varied from 700 up to $3000 \mu \mathrm{m}$ in 


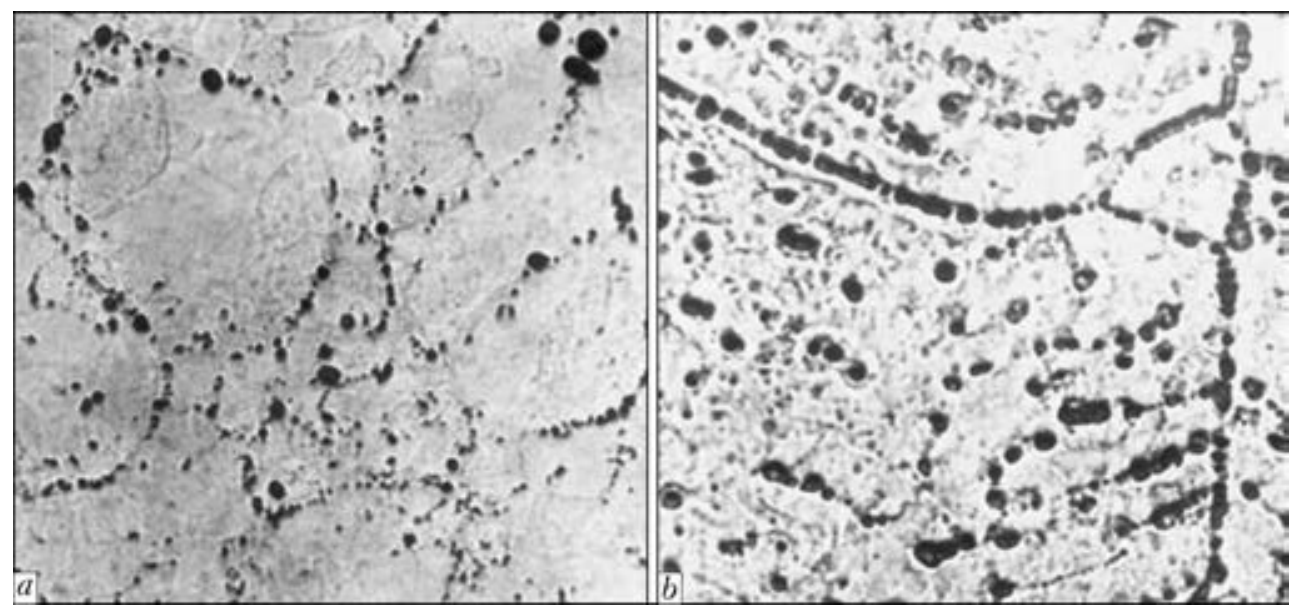

Figure 1. Microstructure $(\times 500)$ of cast metal of alloy Al-08\% Sc produced by the method of rapid solidification of melt from $800{ }^{\circ} \mathrm{C}$ at $v_{\text {sol }}=10^{2}(a)$ and $10^{5}(b){ }^{\circ} \mathrm{C} / \mathrm{s}$

the zone of maximum and minimum rates of solidification, respectively. Measurement of dendritic parameter showed that in narrow part of the ingot it is $2.7-3.0 \mu \mathrm{m}$, that corresponds to $v_{\text {sol }} \sim 10^{4.5}-10^{5}{ }^{\circ} \mathrm{C} / \mathrm{s}[5]$. At transition from the ingot narrow part to the wide one the size of dendrites and dendritic parameter are gradually increased. In the ingot middle part the structure corresponds to that for welds in $\mathrm{EBW}\left(v_{\text {sol }}=\right.$ $\left.=10^{3}{ }^{\circ} \mathrm{C} / \mathrm{s}\right)$. In the ingot wide part the dendritic parameter is $25-27 \mu \mathrm{m}$, that corresponds to $v_{\text {sol }}=$ $=10^{2} \mathrm{C} / \mathrm{s}$, typical of TIG welding of aluminium alloys.

Adding of scandium into aluminium changes the nature of solidification of ingots. Thus, for alloy with $0.8 \%$ Sc the dendritic structure is formed in the narrow part, where the maximum rate of solidification is observed (Figure 1). The subdendritic structure is formed in the wide part of the ingot at $v_{\mathrm{sol}}=10^{2}{ }^{\circ} \mathrm{C} / \mathrm{s}$.

$\mathrm{X}$-ray and X-ray spectral microanalysis of alloy $\mathrm{Al}-0.8 \mathrm{Sc}$ showed that in the ingot narrow part $\left(v_{\text {sol }}=10^{5}{ }^{\circ} \mathrm{C} / \mathrm{s}\right)$ all the scandium is located in aluminium solid solution (Tables 1 and 2). This fact can be confirmed by investigation of microhardness of solid solution of ingots. Thus, for alloy $\mathrm{Al}-0.8 \mathrm{Sc}$ the mean microhardness of ingot directly after casting is $483 \mathrm{MPa}$, and after artificial ageing at $330{ }^{\circ} \mathrm{C}$ during $1000 \mathrm{~s}$ it is $1281 \mathrm{MPa}$. This increase in hardness in $\mathrm{Al}-\mathrm{Sc}$

Table 1. Scandium content in different zones of ingots of alloy $\mathrm{Al}-0.8 \% \mathrm{Sc}$

\begin{tabular}{|c|l|c|}
\hline$v_{\text {sol }},{ }^{\circ} \mathrm{C} / \mathrm{s}$ & \multicolumn{1}{|c|}{ Structural constituent } & Sc, wt.\% \\
\hline \multirow{2}{*}{$10^{2}$} & Base (solid solution) & 0.427 \\
\cline { 2 - 4 } & Intermetallic & 18.551 \\
\hline \multirow{2}{*}{$10^{5}$} & Base (solid solution) & 0.812 \\
\cline { 2 - 3 } & Intermetallic & - \\
\hline
\end{tabular}

system can be obtained only at scandium precipitation from solid solution and formation of dispersed intermetallic particles (Figure 2). Precisely the same nature of change in microhardness is observed also in ingots of alloy $\mathrm{Al}-0.6 \mathrm{Sc}$, however, the decrease in scandium content leads to decrease in microhardness of ingots before and after artificial ageing.

Analysis of microstructure in height of ingots showed that within the interval of solidification rates from $10^{3.3}$ up to $10^{2.5}{ }^{\circ} \mathrm{C} / \mathrm{s}$, the structure of ingots is mixed (dendritic-subdendritic), i.e. at these rates the change of form of solidification from dendritic to subdendritic is occurred. $\mathrm{Mi}$ crohardness of ingots is decreased due to precipitation of a part of scandium into primary intermetallics and, respectively, depletion of solid solution of scandium in aluminium.

Table 2. Results of X-ray phase analysis of alloys investigated

\begin{tabular}{|c|c|c|c|}
\hline Alloy & $T_{\text {cast }},{ }^{\circ} \mathrm{C}$ & $v_{\text {sol }},{ }^{\circ} \mathrm{C} / \mathrm{s}$ & $\begin{array}{c}\text { Presence of } \\
\text { intermetallics } \\
\mathrm{Al}_{3} \mathrm{Sc}\end{array}$ \\
\hline \multirow[t]{8}{*}{$\mathrm{Al}-0.8 \% \mathrm{Sc}$} & \multirow[t]{2}{*}{670} & $10^{2}$ & + \\
\hline & & $10^{5}$ & + \\
\hline & \multirow[t]{2}{*}{720} & $10^{2}$ & + \\
\hline & & $10^{5}$ & - \\
\hline & \multirow[t]{2}{*}{800} & $10^{2}$ & + \\
\hline & & $10^{5}$ & - \\
\hline & \multirow[t]{2}{*}{900} & $10^{2}$ & + \\
\hline & & $10^{5}$ & - \\
\hline \multirow[t]{6}{*}{$\mathrm{Al}-6 \% \mathrm{Cu}-0.8 \% \mathrm{Sc}$} & \multirow[t]{2}{*}{720} & $10^{2}$ & + \\
\hline & & $10^{5}$ & - \\
\hline & \multirow[t]{2}{*}{800} & $10^{2}$ & + \\
\hline & & $10^{5}$ & - \\
\hline & \multirow[t]{2}{*}{900} & $10^{2}$ & + \\
\hline & & $10^{5}$ & - \\
\hline
\end{tabular}




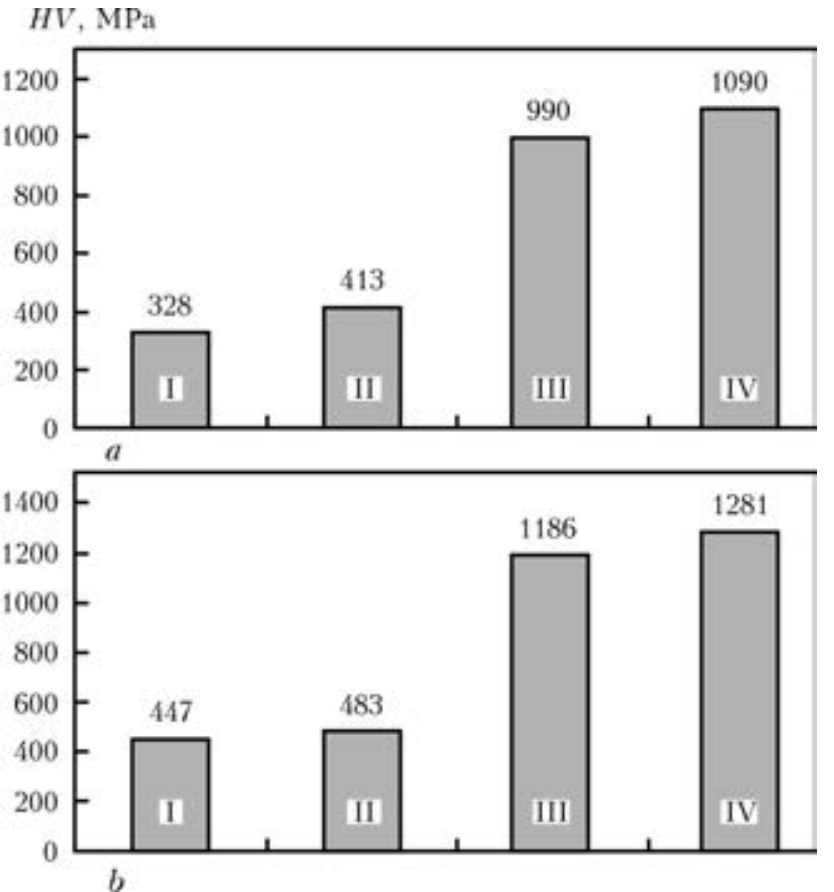

Figure 2. Microhardness of cast metal of alloys $\mathrm{Al}-0.6 \%$ $\mathrm{Sc}$ and $\mathrm{Al}-0.8 \% \mathrm{Sc}$ at different solidification rate: $a-$ $10^{2} ; b-10^{5}{ }^{\circ} \mathrm{C} / \mathrm{s} ; \mathrm{I}$, III $(0.6 \% \mathrm{Sc})$ - directly after casting; II, IV ( $0.8 \%$ Sc $)$ - after additional artificial ageing

At $v_{\text {sol }}=10^{2}{ }^{\circ} \mathrm{C} / \mathrm{s}$, the structure of ingot $\mathrm{Al}-$ $0.8 \mathrm{Sc}$ is subdendritic. Maximum size of subdendrites is $75 \mu \mathrm{m}$, minimum $-20 \mu \mathrm{m}$. Scandium content in solid solution is decreased to $0.41 \%$ (see Table 1). Mean size of primary scandium intermetallics is $10-12 \mu \mathrm{m}$. Scandium content in them is changed from 14.3 to $20.6 \%$. A part of scandium is included into composition of eutectic precipitations along the boundaries of subdendrites. The length of these colonies can reach $45 \mu \mathrm{m}$.

It can be concluded from the given data that during melt heating above $800{ }^{\circ} \mathrm{C}$ the complete dissolution of scandium intermetallics, inherited from charge materials, is occurred. At $v_{\text {sol }}=$ $=10^{5}{ }^{\circ} \mathrm{C} / \mathrm{s}$, the state of melt at the moment of alloy casting can be judged by solid solution of ingots. At $v_{\text {sol }}=10^{2}{ }^{\circ} \mathrm{C} / \mathrm{s}$, the structure of metal of welds of real welded joints can be predicted by the structure of ingots.

Investigation of peculiarities of solidification of model alloys. For all the alloys, which were overheated above $720{ }^{\circ} \mathrm{C}$ before the solidification and solidified with rate of $10^{5}{ }^{\circ} \mathrm{C} / \mathrm{s}$, it was not managed to identify the particles of intermetallics $\mathrm{Al}_{3} \mathrm{Sc}$ by the methods of optic and scanning electron microscopy. X-ray phase analysis showed that at $v_{\text {sol }}=10^{5}{ }^{\circ} \mathrm{C} / \mathrm{s}$, these particles are observed only in the sample, solidified from $670{ }^{\circ} \mathrm{C}$ (see Table 2). It was found by the method of differential thermal analysis that intermetal-
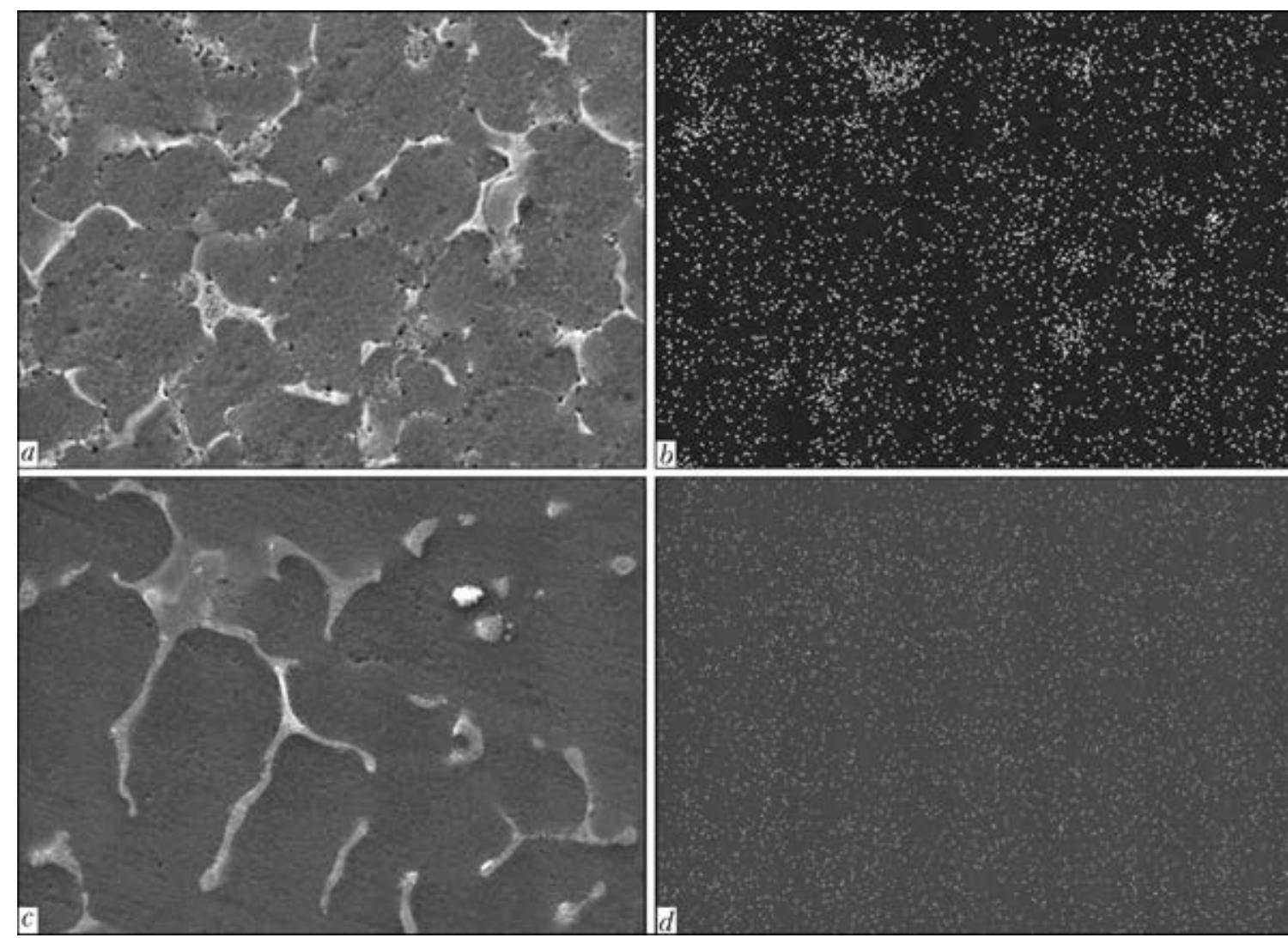

Figure 3. Distribution $(\times 2020)$ of scandium across the section of ingot of alloy $\mathrm{Al}-6.4 \% \mathrm{Cu}-0.8 \%$ Sc solidified from $670(a, b)$ and $900{ }^{\circ} \mathrm{C}(c, d)$ at $v_{\text {sol }}=10^{2}{ }^{\circ} \mathrm{C} / \mathrm{s}$ 
Table 3. Chemical composition (wt.\%) of structural constituents of ingots of alloy $\mathrm{Al}-8.5 \% \mathrm{Zn}-2.3 \% \mathrm{Mg}-1.9 \% \mathrm{Cu}-0.2 \% \mathrm{Zr}-$ $0.45 \% \mathrm{Sc}$

\begin{tabular}{|c|c|c|c|c|c|c|c|}
\hline$T_{\text {cast }},{ }^{\circ} \mathrm{C}$ & $v_{\mathrm{sol}},{ }^{\circ} \mathrm{C} / \mathrm{s}$ & Phase & $\mathrm{Sc}$ & $\mathrm{Zn}$ & $\mathrm{Mg}$ & $\mathrm{Cu}$ & $\mathrm{Zr}$ \\
\hline \multirow[t]{6}{*}{670} & \multirow[t]{3}{*}{$10^{2}$} & Solid solution & 0.18 & 4.88 & 1.06 & 0.56 & 0.08 \\
\hline & & Eutectics & 1 & 17.19 & 5.26 & 7.43 & 0.55 \\
\hline & & Intermetallic & 16.94 & 3.41 & 0.22 & 0.22 & 29 \\
\hline & \multirow[t]{3}{*}{$10^{5}$} & Solid solution & 0.24 & 5.58 & 1.30 & 0.84 & 0.20 \\
\hline & & Eutectics & 0.29 & 10.21 & 2.99 & 3.14 & - \\
\hline & & Intermetallic & 16.13 & 3.01 & - & 0.46 & 16.76 \\
\hline \multirow[t]{6}{*}{800} & \multirow[t]{3}{*}{$10^{2}$} & Solid solution & 0.21 & 5.70 & 1.24 & 0.71 & - \\
\hline & & Eutectics & 0.96 & 12.20 & 3.63 & 4.68 & 1.70 \\
\hline & & Intermetallic & 11.11 & 7.90 & 1.80 & 2.64 & 16 \\
\hline & \multirow[t]{3}{*}{$10^{5}$} & Solid solution & 0.46 & 6.08 & 1.49 & 1.03 & - \\
\hline & & Eutectics & 0.30 & 16.83 & 5.20 & 7.44 & - \\
\hline & & Intermetallic & 6.83 & 10.36 & 2.50 & 4.61 & 6.88 \\
\hline
\end{tabular}

lics $\mathrm{Al}_{3} \mathrm{Sc}$ in alloy $\mathrm{Al}-0.8 \mathrm{Sc}$ are beginning to precipitate at $730{ }^{\circ} \mathrm{C}$. In alloy $\mathrm{Al}-6 \mathrm{Cu}-0.8 \mathrm{Sc}$ the temperature of precipitation of intermetallics is decreased by $15{ }^{\circ} \mathrm{C}$ and it is $715{ }^{\circ} \mathrm{C}$.

Figure 3 gives the distribution of scandium across the section of ingots at $v_{\text {sol }}=10^{2}{ }^{\circ} \mathrm{C} / \mathrm{s}$. It is seen that at $670{ }^{\circ} \mathrm{C}$ temperature of casting the regions with increased content of scandium are observed. With increase in casting temperature up to $900{ }^{\circ} \mathrm{C}$ the distribution of scandium is leveled across the section of ingots. It can be stated that non-uniform distribution of scandium, observed in real welds of joints, is predetermined by the metallurgical heredity of metal being welded and non-equilibrium conditions, at which the weld is formed $[4,6]$.

Ingots of alloy $\mathrm{Al}-8.5 \mathrm{Zn}-2.3 \mathrm{Mg}-1.9 \mathrm{Cu}-$ $0.2 \mathrm{Zr}-0.45 \mathrm{Sc}$ were solidified from three temperatures: 800,730 and $670{ }^{\circ} \mathrm{C}$ without preliminary overheating, i.e. the ingots were heated to casting temperature and solidified at once into copper wedge-type mould. According to data of equilibrium diagram for $\mathrm{Al}-\mathrm{Sc}$ system at $800{ }^{\circ} \mathrm{C}$, scandium was completely dissolved in melt, $730{ }^{\circ} \mathrm{C}$ is the temperature of beginning of formation of intermetallic particles $\mathrm{Al}_{3} \mathrm{Sc}$ in melt, and $670{ }^{\circ} \mathrm{C}$ is the approximate temperature of casting of alloys under industrial conditions. Microstructure of produced ingots is given in Figure 4.

At high solidification rate $\left(>10^{3}{ }^{\circ} \mathrm{C} / \mathrm{s}\right)$ of alloy $\mathrm{Al}-8.5 \mathrm{Zn}-2.3 \mathrm{Mg}-1.9 \mathrm{Cu}-0.2 \mathrm{Zr}-0.45 \mathrm{Sc}$ a mixed dendritic-subdendritic structure is formed. In this case the subdendritic structure is observed in the form of small regions in the central part of ingots. The mean size of dendrites is 90,70 and $60 \mu \mathrm{m}$ at solidification temperature of 670 , 730 and $800{ }^{\circ} \mathrm{C}$, respectively, and size of subdendrites is $5-18 \mu \mathrm{m}$. Along the boundaries of dendrites and subdendrites the eutectic precipitations, containing zinc, magnesium, copper and zirconium, are observed, while in the centre of solidification the precipitations of fine scandium intermetallics are present. X-ray spectral microanalysis showed that except scandium they also contain main alloying elements: zinc, magnesium, copper (Table 3). During overheating of melt up to $900{ }^{\circ} \mathrm{C}$ and higher, and also next cooling to casting temperature, these intermetalliucs are not observed. During solidification from $670{ }^{\circ} \mathrm{C}$ at $v_{\text {sol }}=10^{5}{ }^{\circ} \mathrm{C} / \mathrm{s}$, the solid solution of alloy $\mathrm{Al}-8.5 \mathrm{Zn}-2.3 \mathrm{Mg}-1.9 \mathrm{Cu}-0.2 \mathrm{Zr}-0.45 \mathrm{Sc}$ contains $0.21-0.28 \% \mathrm{Sc}$, while during solidification from $800{ }^{\circ} \mathrm{C}$ at the same rate it contains $0.45 \%$ Sc. Mean size of intermetallics $\mathrm{Al}_{3}(\mathrm{Sc}$, $\mathrm{Zr})$ at casting temperatures of 730 and $800{ }^{\circ} \mathrm{C}$ is $1-3 \mu \mathrm{m}$, maximum size is $10-12 \mu \mathrm{m}$, at $670{ }^{\circ} \mathrm{C}$ the maximum size of intermetallics is $30 \mu \mathrm{m}$.

With decrease in rate of solidification the gradual change in solidification is occurred from mixed subdendritic-dendritic to subdendritic ones. Thus, in casting from $800{ }^{\circ} \mathrm{C}$ this process takes place within the interval of rates $10^{4}$ $10^{3.5}{ }^{\circ} \mathrm{C} / \mathrm{s}$, at casting from $800{ }^{\circ} \mathrm{C}$ into mould, heated up to $300{ }^{\circ} \mathrm{C}$, and casting from $730{ }^{\circ} \mathrm{C}$ into cold mould it takes place within the interval of $10^{3.5}-10^{2.5}{ }^{\circ} \mathrm{C} / \mathrm{s}$, i.e. with decrease of degree of melt overcooling the change in solidification form is occurred at its lower rates. Mean size of subdendrites at minimum rate is $18 \mu \mathrm{m}$ and that of intermetallics $\mathrm{Al}_{3}(\mathrm{Sc}, \mathrm{Zr})$ is $3-6 \mu \mathrm{m}$. At $670{ }^{\circ} \mathrm{C}$ 


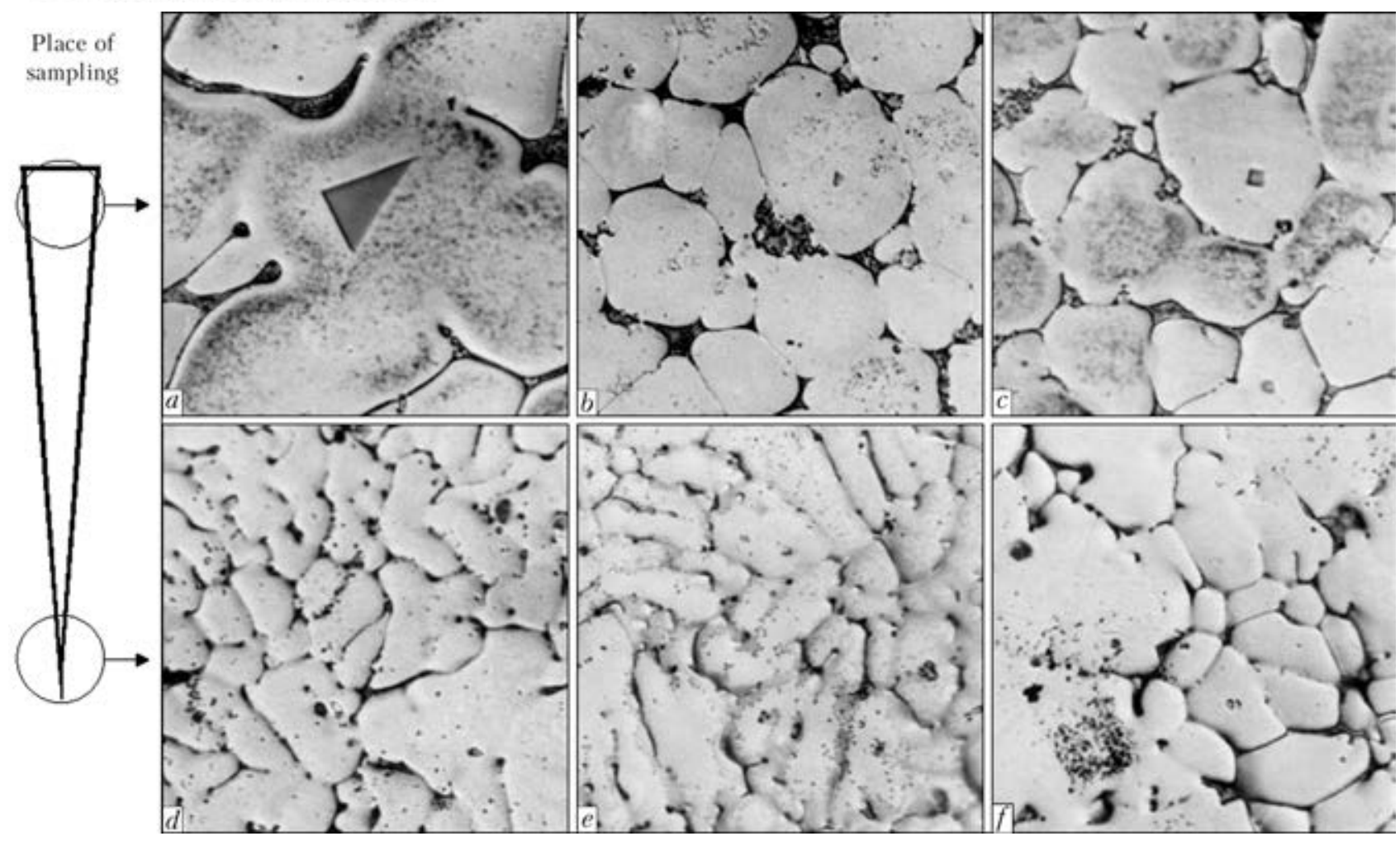

Figure 4. Microstructure $(\times 800)$ of cast metal of alloy $\mathrm{Al}-8.5 \% \mathrm{Zn}-2.3 \% \mathrm{Mg}-1.9 \% \mathrm{Cu}-0.2 \% \mathrm{Zr}-0.45 \% \mathrm{Sc}$ at $v_{\mathrm{sol}}=$ $=10^{2}(a-c)$ and $10^{5}(d-f){ }^{\circ} \mathrm{C} / \mathrm{s}: a, d-T_{\text {cast }}=670 ; b-e-730 ; c, f-800{ }^{\circ} \mathrm{C}$

the form of solidification across the section of ingots remains unchanged, i.e. subdendritic-dendritic, however, here the sizes of dendrites are increased from 90 up to $180 \mu \mathrm{m}$, those of subdendrites - from 5 up to $18 \mu \mathrm{m}$. Maximum size of primary intermetallics, which are precipitated within the whole volume of ingot, is $30 \mu \mathrm{m}$. Content of scandium in solid solution is $0.18-0.22 \%$.

Thus, at rates of solidification, commensurable with solidification of weld metal, the solid solution of alloys can contain up to $0.41 \% \mathrm{Sc}$. When applying highly concentrated power sources, such as electron beam, it is possible to obtain this value also in real welds. In case of application of arc methods of welding $0.3 \% \mathrm{Sc}$ can be assimilated in solid solution of weld metal. Coming from the above-mentioned, the conclusion can be made that the weld metal should contain scandium at the level of $0.35-0.40 \%$. Basing on the earlier investigations of real welds, carried out at the E.O. Paton Electric Welding Institute [7], it is necessary to add $0.3 \% \mathrm{Sc}$ into metal being welded and $0.5 \%$ Sc into filler wires to provide this concentration. In this case the increase of mechanical properties of metal of welds will be provided by refining of grain and solid-solution hardening of cast metal.

1. Davydov, V.G., Rostova, T.D., Zakharov, V.V. et al. (2000) Scientific principles of making an alloying addition of scandium to aluminium alloys. Mat. Sci. and Eng. A, 280, 30-36.

2. Rybin, V.V., Andreev, G.N., Barakhtina, N.N. et al. (2006) Some aspects in development of modern marine high-strength aluminium alloys with scandium. Voprosy Materialovedeniya, 1, 92-101.

3. Fridlyander, I.N., Danilov, S.F., Malysheva, E.N. (1992) Structure and properties of Al-Li alloys, alloyed with scandium. Proc. of $6^{\text {th }}$ Int. Aluminium-Lithium Conf., 1, 381-386.

4. Rabkin, D.M., Lozovskaya, A.V., Sklabinskaya, I.E. (1992) Metals science of aluminium and its alloys. Kiev: Naukova Dumka.

5. (2001) Selected transactions of V.I. Dobatkin. Moscow: All-Russian Institute of Light Alloys.

6. Markashova, L.I., Grigorenko, G.M., Lozovskaya, A.V. et al. (2006) Effect of scandium additions on structure-phase state of weld metal in aluminium alloy joints after heat treatment. The Paton Welding J., 6, 7-11.

7. Ishchenko, A.Ya., Lozovskaya, A.V., Poklyatsky, A.G. et al. (1999) Structure and properties of joints made in welding of alloy AMg6 using filler wires with scandium. Avtomatich. Svarka, 4, 19-25.

Received 27.02.2014 


\title{
TECHNOLOGICAL PECULIARITIES OF LASER, MICROPLASMA AND HYBRID LASER-MICROPLASMA WELDING OF ALUMINIUM ALLOYS
}

\author{
V.D. SHELYAGIN ${ }^{1}$, A.M. ORISHICH ${ }^{2}$, V.Yu. KHASKIN ${ }^{1}$, A.G. MALIKOV ${ }^{2}$ and A.A. CHAJKA ${ }^{1}$ \\ ${ }^{1}$ E.O. Paton Electric Welding Institute, NASU \\ 11 Bozhenko Str., 03680, Kiev, Ukraine. E-mail: office@paton.kiev.ua \\ ${ }^{2}$ S.A. Khristianovich Institute of Theoretical and Applied Mechanics, Siberian Branch of RAS \\ 4 /1 Institutskaya Str., 630090, Novosibirsk, Russia. E-mail:admin@itam.nse.ru
}

\begin{abstract}
Actuality of application of laser, microplasma and hybrid laser-microplasma (HLMP) methods of aluminium alloys welding is shown. Technological schemes of laser and laser-microplasma welding are selected. Appropriate experiments have been carried out for study of technological peculiarities of three selected methods for producing butt and edge sheet joints. It was found that there are the following main drawbacks in microplasma welding: in case of complete penetration a weld sagging is observed, at welding currents of more than 30 A the tendency to undercut formation takes plase, with increase in speed for more than $40 \mathrm{~m} / \mathrm{h}$ the stability of process is decreased. It is characteristic of HLMP welding: stability of the process at high (above $60 \mathrm{~m} / \mathrm{h}$ ) speeds of welding, decrease (by 1.5-2 times as compared with microplasma welding) in width of welds, significant decrease (up to full removal) in residual deformations, absence of spattering. It was found that typical defects of laser and laser-microplasma welding of are the sagging of welds, made without backing, formation of undercuts and inner pores of $0.1-0.2 \mathrm{~mm}$ diameter. The following main ways of elimination of these defects can be taken into consideration: feeding of filler materials (for example, in the form of wire); use of steel backings (including those with grooves for lower bead formation); welding along raised edge (with edge welds); application of welding modes with modulation of sources power; overlap welding (requires careful preparation of surfaces). Optimum values of energy input in $\mathrm{CO}_{2}$-laser welding are 36-70 $\mathrm{J} / \mathrm{mm}$ by the criteria of quality of joints formation, absence of pores and cracks. Reduction of energy input leads to disappearance of key hole and lack of penetration of metal, while increase in energy input - to hot crack formation. Typical macro- and microstructure of metal of welds and HAZ made by microplasma, hybrid and laser welding are given. 7 Ref., 11 Figures.
\end{abstract}

$\boldsymbol{K} \boldsymbol{e} \boldsymbol{y} \boldsymbol{w} \boldsymbol{o r d s}:$ welding, aluminium alloys, laser emis sion, microplasma, hybrid laser-microplasma welding, types of joints, experiments, modes, structures

Aluminium alloys are widely used in nowadays industry for manufacture of light structures. The main peculiarity of their welding is the need in removal of oxide film $\mathrm{Al}_{2} \mathrm{O}_{3}$, formed on the surface during interaction with air oxygen. Commonly, the surfaces of these alloys for their welding are prepared by a mechanical method. Microplasma welding with variable-polarity pulses gives an opportunity of a cathode cleaning of surfaces being welded [1]. Combination of processes of laser and microplasma welding allows not only providing the cleaning of surfaces, but also contributing to the formation of a hybrid laser-plasma discharge, which gives a possibility to significantly increase the welding efficiency, and also quality of welded joints [2]. However, it does not mean that it diminishes the actuality of the laser welding. According to data of some researchers [3], a proper selection of laser welding modes allows producing quality joints at minimum overheating of the base metal.

In literature [3, 4], the results of testing different technological schemes of laser and lasermicroplasma welding are described. Usually, the laser welding of aluminium alloys is performed using the quality gas shielding of upper and lower sides of the weld (Figure 1). Scheme, shown in Figure 2, can be considered as one of the most promising ones for joining the sheet aluminium alloys [4]. In investigations, carried out using this scheme, the peculiarities of formation of joints in the range of $40-200 \mathrm{~J} / \mathrm{mm}$ energy inputs were studied. However, the welding of thinwalled products in the range of $10-30 \mathrm{~J} / \mathrm{mm}$ also represents an interest. One of the aspects of the present work is devoted to the investigations for producing quality joints in this range.

The second important moment is the defining the optimum energy inputs of laser welding of similar products. In this case, as a criterion of optimization it is rational to study the quality of 


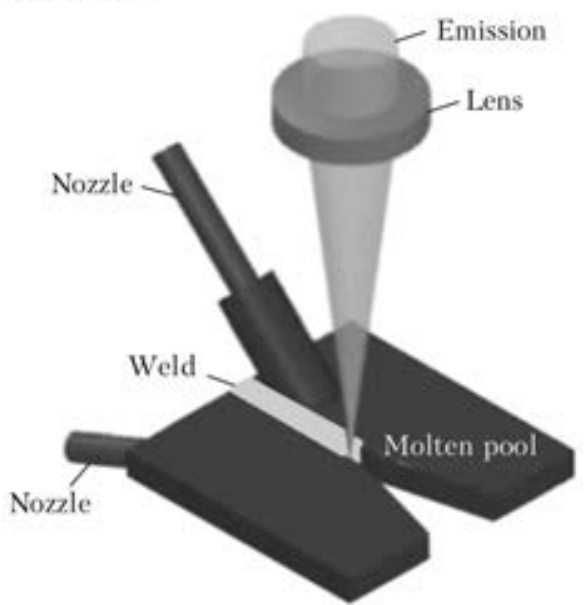

Figure 1. Technological scheme of laser welding of aluminium alloys

formation of joints, absence of defects in the form of pores and cracks, as well as minimization of HAZ.

Therefore, the aim of work was to study the technological peculiarities of laser, microplasma and hybrid laser-microplasma (HLMP) welding of thin-walled products of aluminium alloys for producing quality permanent structures used in aircraft and rocket construction. Such formation of welds was selected as the criteria of quality of welded joints, at which undercuts, lack of penetration, inner pores, blowholes were absent and also the finest-dispersed structures of metal of welds and HAZ were formed.

Investigation of welding of sheet aluminium alloys by $\mathrm{CO}_{2}$-laser at wave length $\lambda=10.6 \mu \mathrm{m}$ was carried out at the S.A. Khristianovich Institute of Theoretical and Applied Mechanics ( $\mathrm{Si}-$ berian Branch of RAS). To produce welded joints, the automated laser technological complex (ALTC) «Sibir 1», designed at S.A. Khristianovich ITAM, was used, which included the continuous $\mathrm{CO}_{2}$-laser of up to $8 \mathrm{~kW}$ at beam quality parameter 0.7 [5], technological table of gantry type and computer system of ALTC control (Figure 3). Laser emission was focused to

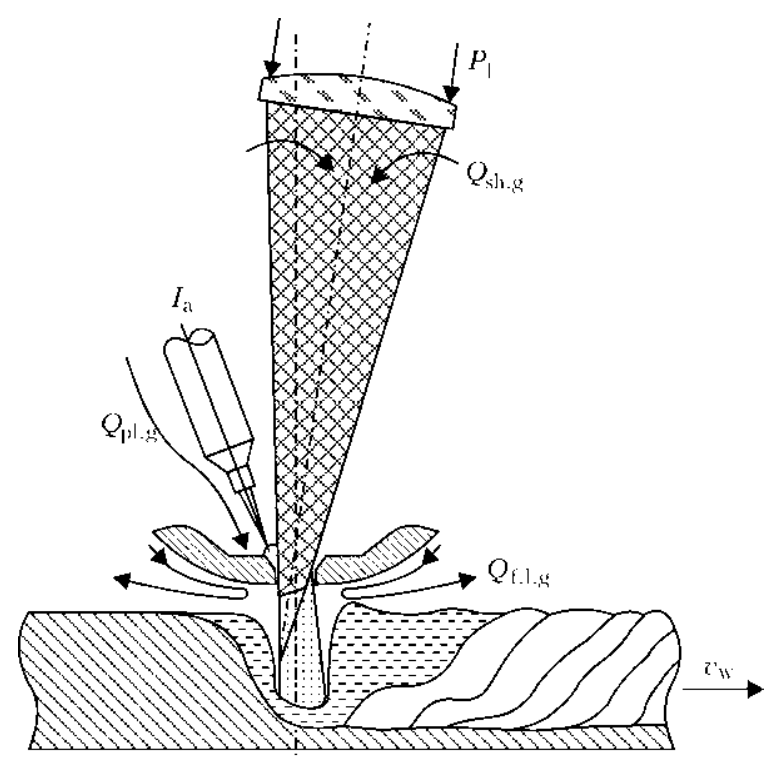

Figure 2. Scheme of hybrid welding process realized by using integrated direct-action plasmatron: $P_{1}-$ laser power, $\mathrm{kW} ; I_{\mathrm{a}}-$ welding current, A; $Q_{\mathrm{f} . l . g}-$ consumption of gas shielding the focusing lens, $1 / \mathrm{min}$; $Q_{\mathrm{pl} . \mathrm{g}}-$ consumption of plasma gas, $1 / \min ; Q_{\text {sh.g }}-$ consumption of shielding gas, $\mathrm{l} / \mathrm{min} ; v_{\mathrm{w}}-$ welding speed, $\mathrm{m} / \mathrm{h}$

metal surface by means of ZnSe-lens at $254 \mathrm{~mm}$ focal distance.

According to scheme of Figure 1, $a$, jet of helium gas was supplied co-axially with a laser beam. To shield the weld being formed, a shielding nozzle was used, from which the same gas was supplied. Weld root was shielded by argon. During experiments a welding head was arranged above a fixed workpiece. Optimum power parameters of laser welding of alloy AMg5 were determined during investigations.

At the E.O. Paton Electric Welding Institute a complex of laser-microplasma welding with a hybrid plasmatron, shown in Figure 4, was manufactured, which allows realizing a selected scheme of welding (see Figure 2). The peculiar features of this plasmatron refer to the arrangement of axes of tungsten electrode and focused emission at minimum angles to vertical. To focus
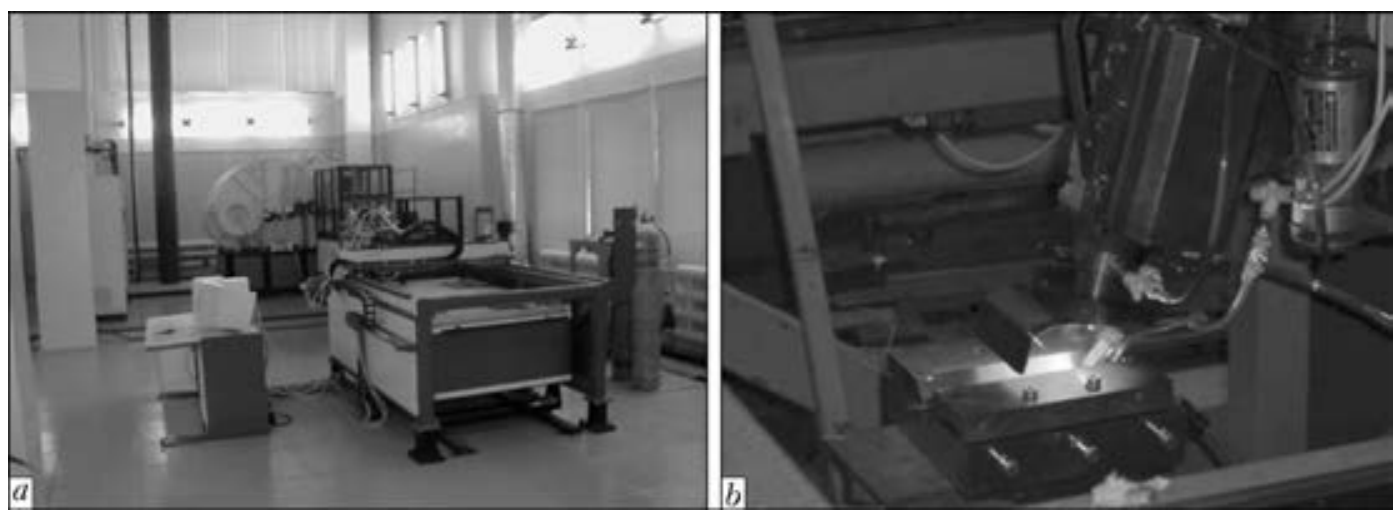

Figure 3. Appearance of ALTC «Sibir 1» $(a)$ and laboratory stand $(b)$ for laser welding 


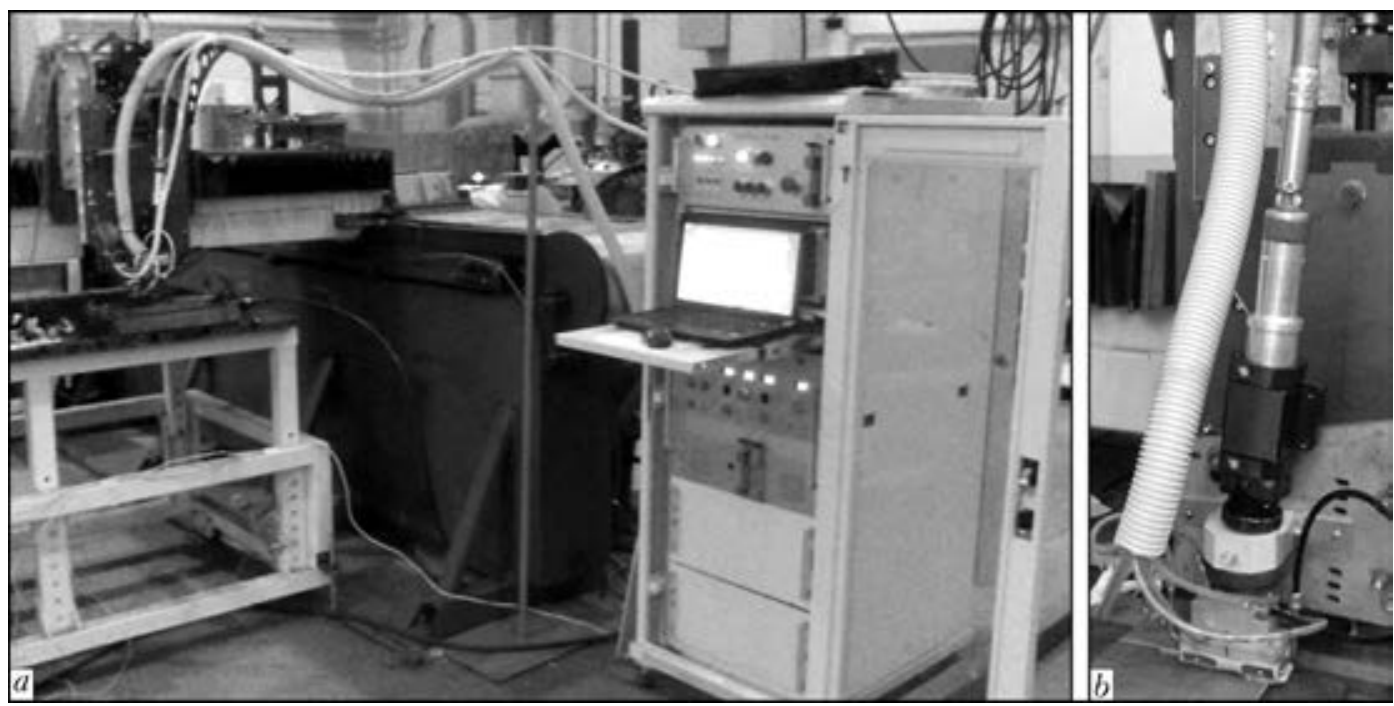

Figure 4. Appearance of complex of laser-microplasma welding ( $a$ ) and hybrid plasmatron $(b)$

the emission of fiber laser of YLR-400-AC model (IPG, Germany) $(\lambda=1.07 \mu \mathrm{m}$, power of up to $400 \mathrm{~W}$ ), the lens with $200 \mathrm{~mm}$ focal distance, shielded from entry of welding aerosols by a gas (argon) and protective glass, was used. Consumption of argon, shielding the lens, was $Q_{\text {f.l.g }}=$ $=3-6 \mathrm{l} / \mathrm{min}$. Arc plasma was generated using a tungsten electrode of $1.6 \mathrm{~mm}$ diameter, copper plasma-forming nozzle with $1.5 \mathrm{~mm}$ diameter hole. Argon was used as plasma and shielding gas with consumptions $Q_{\text {pl.g }}=0.1-0.31 / \mathrm{min}$, $Q_{\text {sh.g }}=6-9 \mathrm{l} / \mathrm{min}$. Welding current of straight polarity, used in experiments, did not exceed $40 \mathrm{~A}$ at arc voltage of up to $22 \mathrm{~V}$.

Hybrid plasmatron was supplied from power source of MPU-50 type, designed for continuous and pulsed welding currents of up to $50 \mathrm{~A}$. Laser emission was supplied to plasmatron by means of a collimator. Plasmatron was fastened to the three-coordinate manipulator carrier, on the working table of which a welding clamping frame was arranged for fixation of specimens.

Alloys $\operatorname{AMg} 2(\delta=1$ and $2.5 \mathrm{~mm}), \operatorname{AMg} 4(\delta=$ $=1 \mathrm{~mm}), \operatorname{AMg} 5(\delta=1.5 \mathrm{~mm})$ and $\operatorname{AMg} 6(\delta=$ $=1.4 \mathrm{~mm}$ ) were used as a material for specimens to be welded. Size of specimens was $(100-300) \times$ $\times(10-50) \times \delta \mathrm{mm}$. Welding was performed without backing. Laser welding of butt welds was performed both by $\mathrm{CO}_{2}$-laser and also by fiber laser. In case of $\mathrm{CO}_{2}$-laser the emission power was enough to provide a stable penetration. In welding with the fiber laser the power of continuous emission of $400 \mathrm{~W}$ was not enough for producing the penetration of depth of more than $0.1-0.3 \mathrm{~mm}$ because of a high reflection.

In experiments on microplasma and hybrid welding of butt and edge joints the current of straight polarity $I_{\text {str }}$ was set within $10-40 \mathrm{~A}$, while that of reverse polarity $I_{\text {rev }}$ was $6-15 \mathrm{~A}$, duration of pulses of straight polarity $\tau_{\text {str }}=20$ and $30 \mathrm{~ms}$, while that of reverse polarity $\tau_{\text {rev }}=$ $=10 \mathrm{~ms}$.

Experiments on microplasma welding with variable-polarity pulses allowed revealing the following main drawbacks (Figure 5): in case of complete penetration the weld sagging takes place; at higher currents of straight polarity (above $30 \mathrm{~A}$ ) the tendency to undercut formation is observed; at increase of speed $\left(v_{\mathrm{w}} \geq 40 \mathrm{~m} / \mathrm{h}\right)$ the process stability is deteriorated.

Experiments on HLMP welding showed the main advantages, namely stability of the process at higher (above $60 \mathrm{~m} / \mathrm{h}$ ) speeds of welding was increased; width of welds was 1.5-2.0 times decreased; residual deformations were significantly decreased; spattering was absent. Such peculiarity of hybrid welding was found as tendency to formation of undercuts in butt joints at currents of straight polarity of above 30 A (Figure 6).

Investigation of ways of elimination of typical defects of laser-microplasma welding of aluminium alloys showed that the following ones can be considered as main: feeding of filler ma-

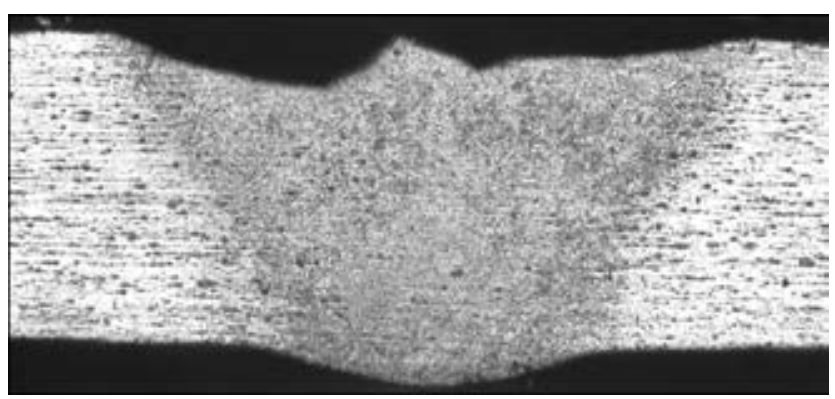

Figure 5. Macrostructure $(\times 25)$ of cross section of butt plasma-welded joint of alloy $\operatorname{AMg} 6(\delta=1.4 \mathrm{~mm})$ at $v_{\mathrm{w}}=$ $=30 \mathrm{~m} / \mathrm{h}$ 


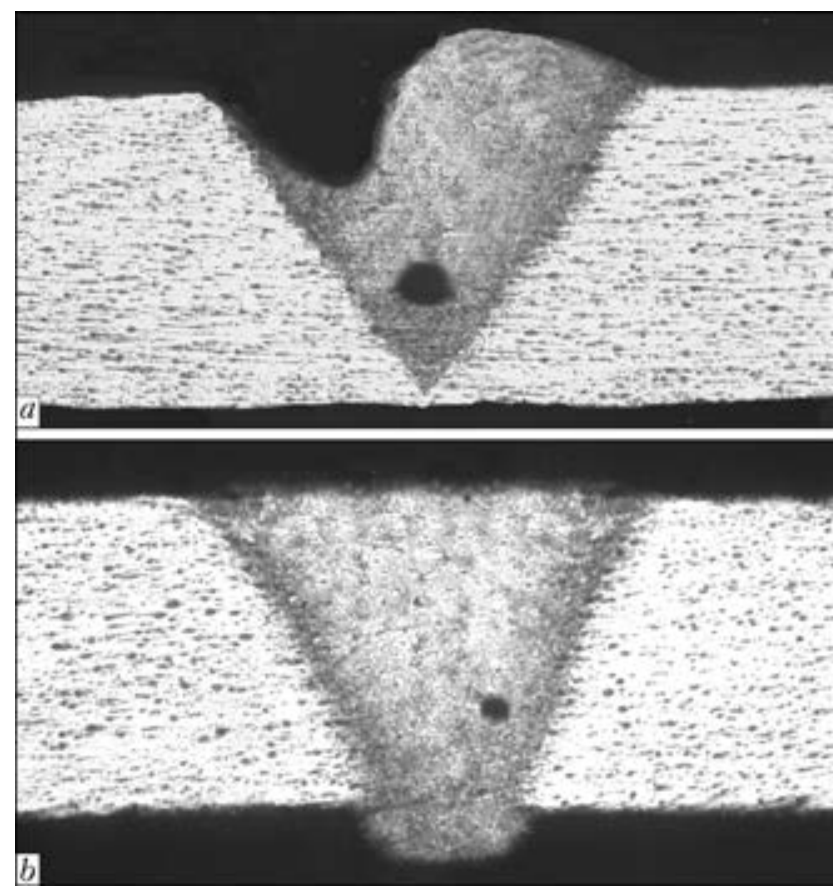

Figure 6. Macrostructure $(\times 25)$ of cross section of penetration $(a)$ and butt joint $(b)$ made by hybrid method on alloy $\operatorname{AMg} 6(\delta=1.4 \mathrm{~mm})$ at $v_{\mathrm{W}}=150 \mathrm{~m} / \mathrm{h}$

terial; welding along raised edges or by edge welds (Figure 7); overlap welding.

To carry out the metallographic examinations, the templates were cut out from welded specimens in weld cross section, which then were clamped into aluminium clamping frames, grinded and polished (electric polishing was used). The microstructure was revealed by etching in solution of $10 \mathrm{~cm}^{3}$ of hydrofluoric acid, $15 \mathrm{~cm}^{3}$ of hydrochloric acid and $30 \mathrm{~cm}^{3}$ of water. The obtained samples were studied in optic microscope «Neophot-30» at magnifications from 25 up to 500 .

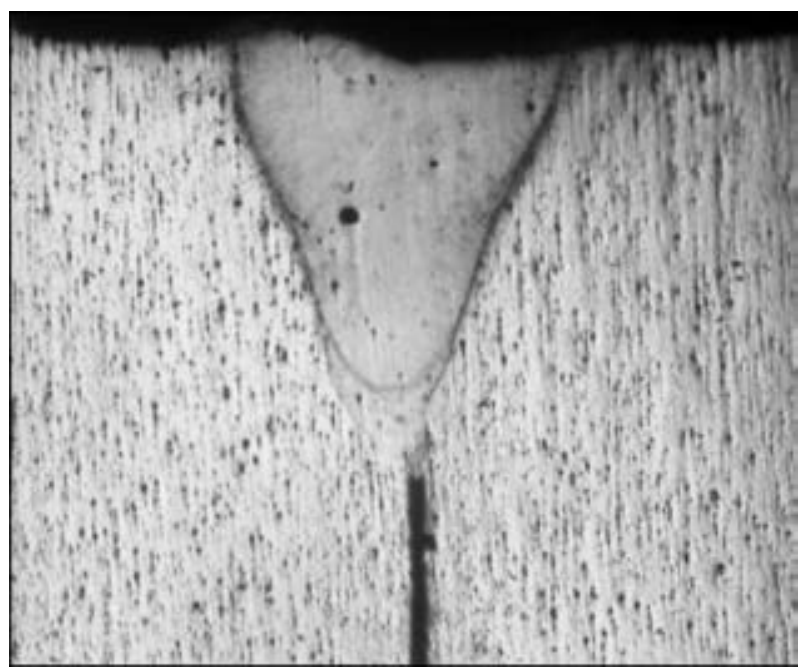

Figure 7. Macrostructure $(\times 25)$ of cross section of quality edge joint of alloy $\mathrm{AMg} 6(\delta=1.4 \mathrm{~mm})$ made by hybrid method at $v_{\mathrm{w}}=168 \mathrm{~m} / \mathrm{h}$
Firstly, the panoramic types of AMg6 alloy welds $(\delta=1.4 \mathrm{~mm})$ were studied (Figures $5-7)$. Figure 5 shows macrostructure of cross section of plasma-welded joint at the mode: $I_{\text {str }}=30 \mathrm{~A}$, $I_{\text {rev }}=10 \mathrm{~A}, \tau_{\text {str }}=20 \mathrm{~ms}, \tau_{\text {rev }}=10 \mathrm{~ms}, U_{\mathrm{a}}=19 \mathrm{~V}$, $v_{\mathrm{w}}=30 \mathrm{~m} / \mathrm{h}$. In spite of small sagging of weld as a whole, it has structure typical of microplasma welding. Its macrostructure is fine-crystalline, dense, without visible defects. Weld width in the upper part is approximately $2.7 \mathrm{~mm}$, and in the lower part it is $0.7 \mathrm{~mm}$. HAZ size is small enough and it is about $0.27 \mathrm{~mm}$.

Further, penetration (Figure 6, $a$ ) and butt weld (Figure $6, b$ ), made by hybrid method, were studied. In both cases the welding mode was similar: $I_{\text {str }}=30 \mathrm{~A}, I_{\text {rev }}=10 \mathrm{~A}, \tau_{\text {str }}=20 \mathrm{~ms}, \tau_{\mathrm{rev}}=$ $=10 \mathrm{~ms}, U_{\mathrm{a}}=21.5 \mathrm{~V}, v_{\mathrm{w}}=150 \mathrm{~m} / \mathrm{h}, P_{1}=$ $=400 \mathrm{~W}$, focus was on the specimen surface. Difference of penetration depth of sheet of alloy AMg6 from welding of butt joint is due to the gap presence between the edges being welded. Typical defects were undercut on one of weld sides and formation of inner pore of $0.1-0.2 \mathrm{~mm}$ diameter. Elimination of these defects is connected with decrease in arc pressure and plasma gas.

Edge joints of alloy AMg6 $(\delta=1.4 \mathrm{~mm})$ were made by hybrid (Figure 7 ) and laser (Figure 8) methods. The mode of hybrid welding was: $I_{\text {str }}=$ $=12 \mathrm{~A}, I_{\text {rev }}=7 \mathrm{~A}, \tau_{\text {str }}=30 \mathrm{~ms}, \tau_{\text {rev }}=10 \mathrm{~ms}$, $U_{\mathrm{a}}=16 \mathrm{~V}, v_{\mathrm{w}}=168 \mathrm{~m} / \mathrm{h}, Q_{\mathrm{pl.g}}=0.1 \mathrm{l} / \mathrm{min}$, $Q_{\text {sh.g }}=9 \mathrm{l} / \mathrm{min}, Q_{\text {f.l.g }}=3-6 \mathrm{l} / \mathrm{min}, P_{1}=400 \mathrm{~W}$, focus was on the specimen surface. In case of laser welding the weld of about $0.35 \mathrm{~mm}$ depth was formed at speed of $110 \mathrm{~m} / \mathrm{h}$ and maximum power $(400 \mathrm{~W})$.

Size of width of weld and HAZ in hybrid welding at increase of speed decreased and was as follows. For butt joint (Figure 6,b) the width of weld upper part was $1.9 \mathrm{~mm}$, lower part $0.46 \mathrm{~mm}, \mathrm{HAZ}-0.08 \mathrm{~mm}$; for edge joint ( $\mathrm{Fi}^{-}$ gure $7, b$ ) the width of weld upper part was $1.14 \mathrm{~mm}$, lower part - $0.39 \mathrm{~mm}, \mathrm{HAZ}-$ $0.05 \mathrm{~mm}$.

Figure 8 shows the microstructure of metal of welds, produced in cases of microplasma, hybrid and laser welding more in detail. Microstructure of butt and edge joints in hybrid welding was studied separately. Investigation of microstructure in all the produced joints indicates the presence of dendritic structure of cast metal in welds, which becomes somewhat coarser to the periphery. Weld metal has a rather fine-grain structure (grain value is about $50 \mu \mathrm{m}$ ). When evaluating the dispersity of structure of weld metal of test joints, the dendritic parameter is the basic characteristic of structure dispersity alongside with 


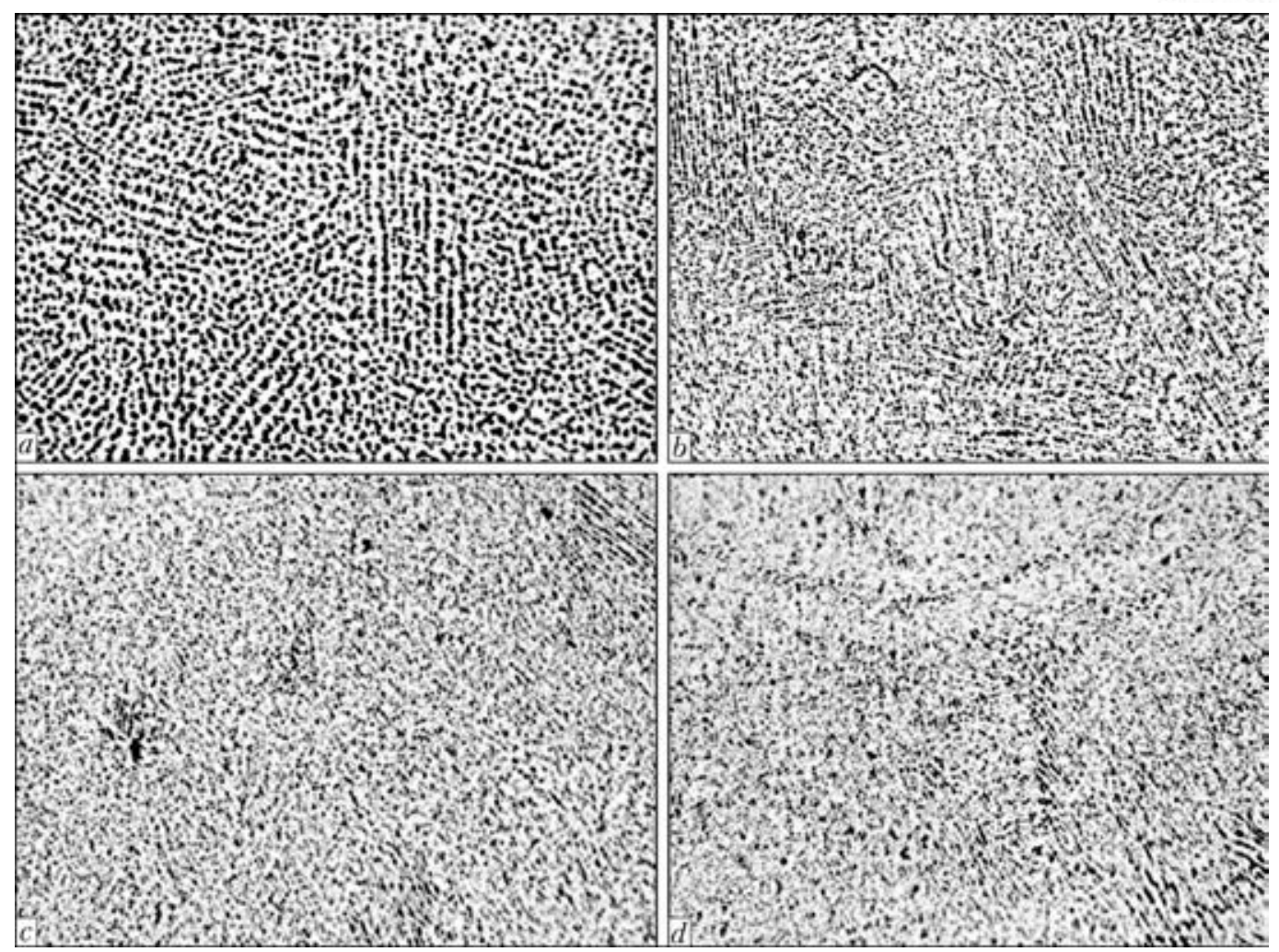

Figure 8. Microstructure $(\times 500)$ of metal of welds obtained by plasma $(a)$, hybrid method in butt $(b)$ and edge $(c)$ joints and by laser $(d)$

a volumetric fraction of structure constituents, thickness of excessive inclusions and their specific surface. It is seen from the comparison of microstructures that the most coarse-dispersed structure is observed in plasma welding, and the most fine-dispersed structure is observed in case of laser welding. Dendritic parameter is about $4 \mu \mathrm{m}$ for plasma welding and almost 3 times decreased for laser welding. In hybrid welding the finerdispersed structure is observed in edge joint. In our opinion, this is due to the increase in welding speed, which became possible by improvement of absorption of laser emission in raised edge.

Investigation of effect of technological parameters of $\mathrm{CO}_{2}$-laser welding on the peculiarities of formation of butt joints of aluminium alloy $\operatorname{AMg} 5(\delta=1.5 \mathrm{~mm})$ was carried out according to scheme in Figure 1. For this, the oxide film from the surface of specimens was removed before welding by using the solution MR-35, developed in NIIKhimProm (Russia). For comparison of obtained results the butt welding and laser beam passing over the metal were used.

In welding of aluminium alloys the pores formation is possible, the source of which is hydrogen, well dissolving in aluminium at melting temperature. Alloys of $\mathrm{Al}-\mathrm{Mg}$ system are characterized by increased susceptibility to porosity in welding, as magnesium increases the hydrogen solubility in aluminium [6]. In accordance with statistics, one of the main defects (about $48 \%$ of rejection) of welded structures of aluminium and magnesium alloys is the gas porosity. Therefore, during this work the porosity of welds was evaluated. As a result of visual-optic investigation the following was found.

In laser welding the «ripple» was observed at all the modes (Figure 9, $a$ ). This is due to the non-stationary processes in weld pool and interruptions in its solidification. Pores, craters in weld and drops of metal, forming during welding, are the defects of welded joints. At the initial moment of welding the numerous pores are observed, caused by metal overheating at increase of speed by technological table. With increase in speed of the process the lack of penetration is observed caused by decrease in power supplied per unit of volume of metal being melted.

To investigate the structure of welds, two macrosections from each specimen were manufactured. For etching the Keller agent was used [7]. In all the cases the scattered pores of small diameters (to $0.2 \mathrm{~mm}$ ) were observed (Figures 10 and 11). For specimens, butt welded by $\mathrm{CO}_{2}$-laser at $420 \mathrm{~m} / \mathrm{h}$ speed, the weld sagging is typical, exceeding $10 \%$ of metal thickness (Figure 10, $a)$. Moreover, undercuts are observed on penetrated sound specimens (Figure 10, $b$ ). At optimum parameters of the process a small porosity is observed (pores of $0.1-0.2 \mathrm{~mm}$ diameter), 

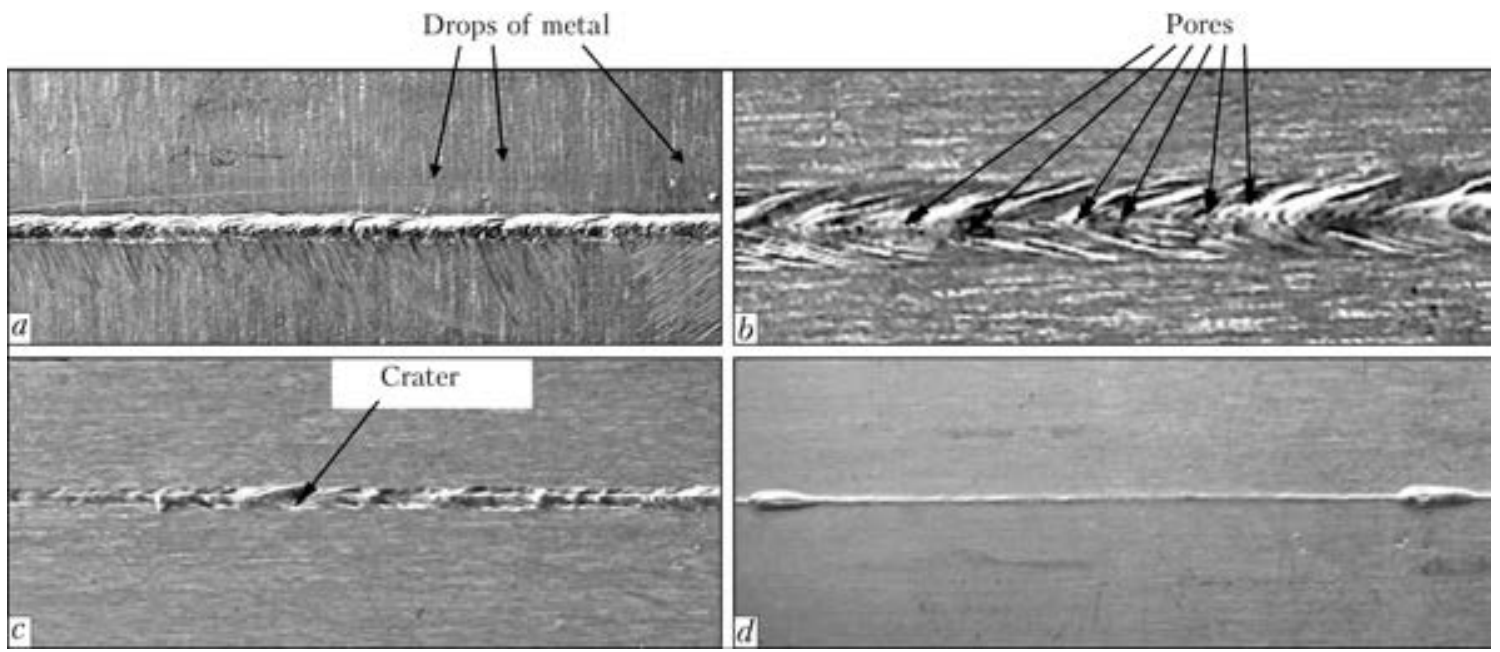

Figure 9. Appearance and typical defects of welded joints $(\times 3): a-c-$ face side; $d-$ reverse side
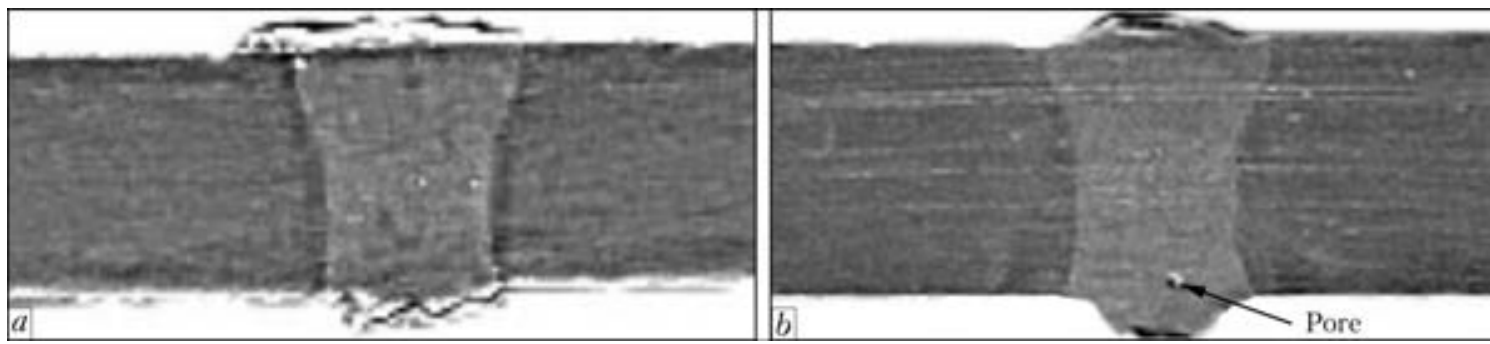

Figure 10. Macrostructure $(\times 20)$ of welded joints of alloy $\operatorname{AMg} 5(\delta=1.5 \mathrm{~mm})$ at $v_{\mathrm{W}}=360 \mathrm{~m} / \mathrm{h}$

which can be considered admissible. It should be noted that a small porosity is also observed in base metal.

It should be noted in conclusion that to produce the quality butt joints of sheet aluminium alloys both in case of laser and also in case of HLMP welding, it is necessary to apply the energy input of about $20 \mathrm{~J} / \mathrm{mm}$ per one millimeter of penetration depth in the range of $100-300 \mathrm{~m} / \mathrm{h}$ speeds. In welding of edge joints this value can decrease to $15 \mathrm{~J} / \mathrm{mm}$ and lower. In this case the use of microplasma constituent in hybrid process allows decreasing the emission power in ratio of about 1:1 due to heat mechanism of increasing the absorption ability of the base metal, thus significantly reducing the equipment cost.

In microplasma welding of aluminium alloys of up to $1.5 \mathrm{~mm}$ thickness the weld sagging in case of complete penetration, tendency to forma-

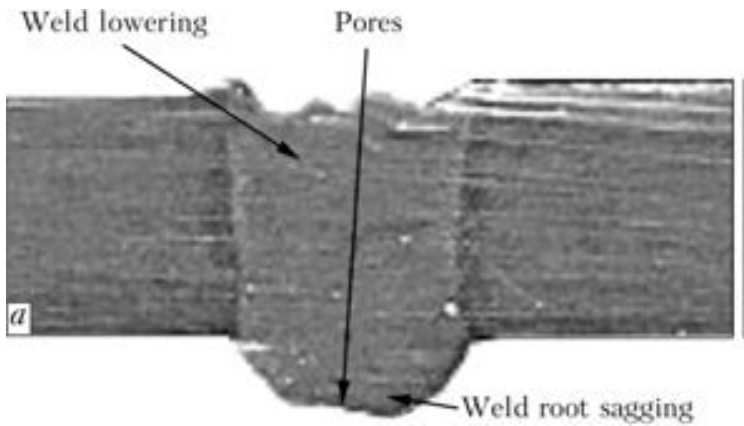

tion of undercuts at current above $30 \mathrm{~A}$, decrease in process stability with increase in speed above $40 \mathrm{~m} / \mathrm{h}$ are observed. The main drawback of laser welding of aluminium alloys by continuous emission is the need in power increase for producing a stable penetration, leading to increase in cost of welding equipment. One of methods of elimination of these drawbacks is the combination of microplasma and laser processes.

The HLMP welding of aluminium alloys of up to $1.5 \mathrm{~mm}$ thickness is characterized by stability of process at speeds above $60 \mathrm{~m} / \mathrm{h}$, decreased width of welds (by 1.5-2 times as compared with microplasma welding), significant reducing of residual deformations, and also by possibility of producing quality joints at comparatively low energy inputs (of about $12-15 \mathrm{~J} / \mathrm{mm}$ for edge joints and about $30 \mathrm{~J} / \mathrm{mm}$ for butt ones), absence of spattering. Typical defects of laser-

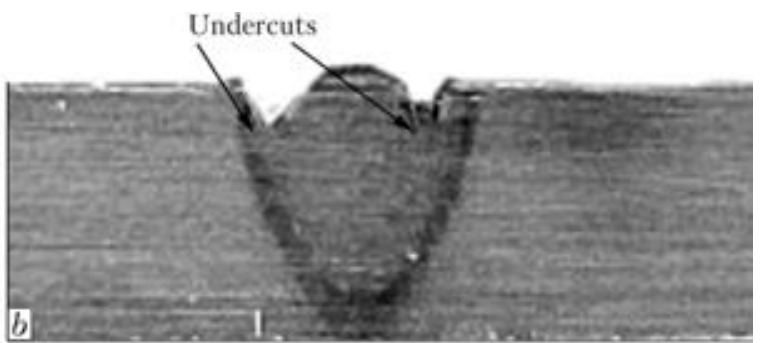

Figure 11. Macrostructure $(\times 20)$ of AMg5 alloy welded joints $(\delta=1.5 \mathrm{~mm})$ at $v_{\mathrm{w}}=420 \mathrm{~m} / \mathrm{h}$ 
microplasma welding of aluminium alloys include sagging of welds, welded without backing, formation of undercuts and inner pores of $0.1-$ $0.2 \mathrm{~mm}$ diameter. The main ways of elimination of these defects can considered the following: feeding of filler metal (for example, in the form of wire); use of steel backings (including those with grooves for lower bead formation); welding along raised edge (by edge welds); overlap welding (requires careful preparation of surfaces); decrease in energy input from microplasma constituent at conservation of general level of energy being input; applying of welding modes with high-frequency modulation of emission power.

The optimum values of parameters of $\mathrm{CO}_{2}$-laser welding are the power of $3.0-3.5 \mathrm{~kW}$ at $180-$ $300 \mathrm{~m} / \mathrm{h}$ speed, i.e. range of energy inputs of $36-70 \mathrm{~J} / \mathrm{mm}$. Reduction in energy input leads to lack of penetration of metal, while its increase - to hot cracks formation. At optimum parameters of the process a small porosity of welded joint is observed (pores of $0.1-0.2 \mathrm{~mm}$ diameter), which is considered as admissible. It should be noted that a small porosity is observed also in base metal.

The detailed study of structures of metal of welds made by plasma, hybrid and laser welding showed that in all the cases the structure is rather equiaxial, dense, without visible defects and has a dendritic nature. The most coarse-dispersed structure is observed in plasma welding, the most fine-dispersed structure - in laser welding. Dendritic parameter is about $4 \mu \mathrm{m}$ for plasma welding and approximately 3 times decreased for laser welding. In hybrid welding the more fine-dispersed structure is observed in edge joint, that is due to increase in welding speed, which became possible by improvement of laser emission absorption in narrow non-through gap formed by a raised edge.

1. Paton, B.E., Gvozdetsky, V.S., Dudko, D.A. et al. (1979) Microplasma welding. Kiev: Naukova Dumka.

2. Paton, B.E., Gvozdetsky, V.S., Krivtsun, I.V. et al. (2002) Hybrid laser-microplasma welding of thin sections of metals. The Paton Welding J., 3, 2-6.

3. Bondarev, A.A., Bondarev, Andr. A. (2001) Laser welding of aluminium alloys (Review). Ibid., 12, 19-25.

4. Krivtsun, I.V., Shelyagin, V.D., Khaskin, V.Yu. et al. (2007) Hybrid laser-plasma welding of aluminium alloys. Ibid., 5, 36-40.

5. Afonin, Yu.V., Golyshev, A.P., Ivanchenko, A.I. et al. (2004) Generation of radiation with quality of TEM00 mode in continuous $\mathrm{CO}_{2}$-laser of $8 \mathrm{~kW}$ power. Kvant. Elektronika, 31(4), 307-310.

6. Rabkin, D.M. (1986) Metallurgy of fusion welding of aluminium and its alloys. Kiev: Naukova Dumka.

7. Kovalenko, V.S. (1981) Metallographic reagents: Refer. Book. 3rd ed. Moscow: Metallurgiya.

Received 07.02.2014 


\title{
DEVELOPMENT OF TECHNOLOGIES OF REPAIR BY ARC WELDING OF OPERATING MAIN PIPELINES IN UKRAINE
}

\author{
V.S. BUT and O.I. OLEJNIK \\ E.O. Paton Electric Welding Institute, NASU \\ 11 Bozhenko Str., 03680, Kiev, Ukraine. E-mail: office@paton.kiev.ua
}

\begin{abstract}
In order to lower material-financial and ecological losses inherent to classical method of main pipeline repair, associated with their stopping, methods allowing main lines to be repaired without taking them out of service, are applied worldwide. The paper deals with the directions of development at PWI of technologies of restoring the load-carrying capacity of defective sections of the main pipelines under pressure with arc welding application. Analysis of the features of arc welding application on pipelines under pressure has been performed and ways to eliminate the unfavourable factors have been determined. Influence of welding heat on strength characteristics of pipe metal is shown, and safe conditions of welding-up corrosion defects are established, depending on thermophysical properties of the transported product and internal pressure magnitude. The paper presents an original design-technological approach to performance of repair operations with arc welding application, which is implemented on operating mail pipelines of Ukraine. Experimental-theoretical assessment of the advantages of application of overlap-butt welded joints over traditional joints with fillet welds is given. Results of investigations by polarization-optical method of stress concentration factors in the points of deposited metal transition to base metal are presented for various kinds of loading of simulation samples. Application of overlap-butt joints allows expansion of heat input range in arc welding; controlling the dimensions, structure and properties of HAZ metal; lowering concentration in the points of circumferential weld transition to the pipeline and thus improving the fatigue limit of welded joints of reinforcing structures at repeated static load. Normative-technical documents have been developed and introduced, which specify repair of the main pipelines under pressure with application of arc welding, and cases of practical application of the most effective design solutions are shown. 23 Ref., 10 Figures, 1 Table.
\end{abstract}

Keywords: main pipelines, arc welding, overlapbutt joints, pressure, safe welding conditions, heat input, strength characteristics, stress concentration factor, reinforcing structural elements, fatigue limit

Modern main pipelines are expensive facilities from low-alloyed higher-strength steels, designed for long-term operation of not less than 30 years. Therefore, high requirements are made to their reliable operation all over the world.

Safe operation of main pipelines (MP) is ensured by respective measures and means both at the stage of design and in operation. Among inservice measures, highly important is appropriate organization of periodical technical diagnostics of the state of MP elements and repair of detected inadmissible defects.

Classical repair of a pipeline, including its stopping, cleaning and replacement of defective sections, requires large material and financial expenses, and is also accompanied by considerable ecological damage. In this connection, technologies of MP repair without taking them out of service and, primarily, focused on arc welding processes, began to be developed at the end of the 20th century.

Features of arc welding application on pipelines under pressure. It is known that an arcwelded joint is the most readily made and reliable in operation. However, during welding operation performance on an operating pipeline there is the risk of through-thickness penetration or excess overheating of pipe wall by the welding arc that may lead to its rupture under inner pressure.

Results of testing conducted in the laboratory of British Gas Company showed that favourable conditions for pipe wall rupture under internal pressure during welding with low-hydrogen electrodes, are created at sufficiently high heat input [1]. So, in deposition of circumferential welds on a pipe with $4.7 \mathrm{~mm}$ wall thickness and with circumferential stresses $\sigma_{\theta}$ on the level of $0.72 \sigma_{\mathrm{y}}$ acting in it, fracture occurred at welding heat input not higher than $2.62 \mathrm{~kJ} / \mathrm{mm}$. With reduction of pipe wall thickness to $3.2 \mathrm{~mm}$, the probability of its rupture rises even at a small heat input (less than $1.51 \mathrm{~kJ} / \mathrm{mm}$ ), and in the case of making the weld along the generatrix it is less than $0.52 \mathrm{~kJ} / \mathrm{mm}$. Here, a considerable scatter 


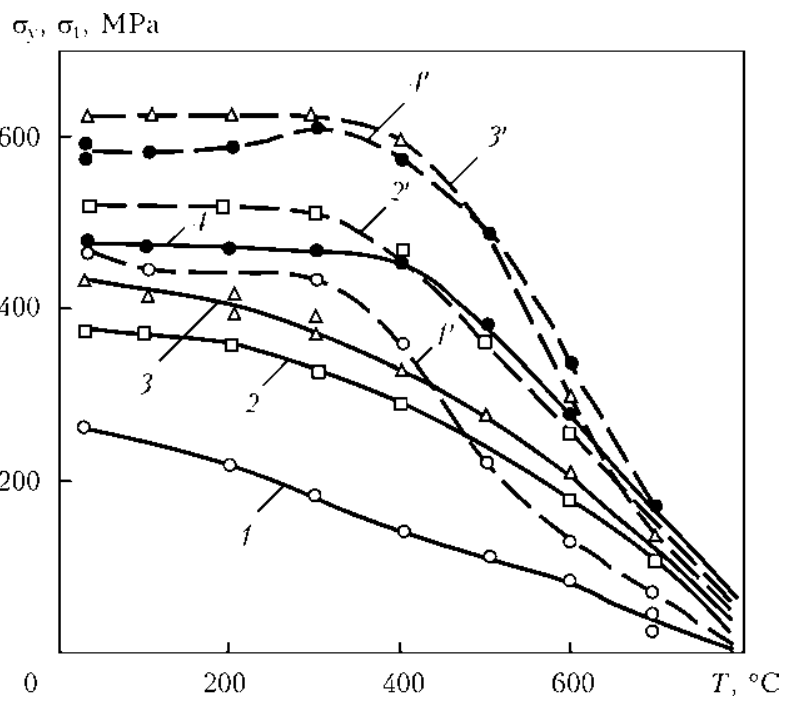

Figure 1. Influence of heating temperature on strength properties of studied steels: $1,1^{\prime}-$ steel $20 ; 2,2^{\prime}-14 \mathrm{KhGS}$; $3,3^{\prime}-17 \mathrm{G} 1 \mathrm{~S} ; 4,4^{\prime}-\mathrm{X} 60 ; 1-4-\sigma_{\mathrm{y}} ; 1^{\prime}-4^{\prime}-\sigma_{\mathrm{t}}$

of test results is recorded, particularly, when making longitudinal welds. All this is indicative of the high hazard of welding operation performance in pipelines under pressure.

Nature of variation of strength characteristics of some pipe steels, depending on heating temperature, as well as the possibility of arc welding performance on a pipeline at different parameters of internal pressure and heat input, have been quite well studied [2-4]. In the above-mentioned works it was found that heating of low-alloyed steels of $14 \mathrm{KhGS}, 17 \mathrm{G} 1 \mathrm{~S}, \mathrm{X} 60$ grades up to the temperature above $400{ }^{\circ} \mathrm{C}$ leads to an abrupt strength lowering, while at above $720{ }^{\circ} \mathrm{C}$, it becomes close to zero (Figure 1).

Obtained data are indicative of the fact that during welding on a pipe under pressure it is necessary to minimize its wall penetration and to reduce the zone of heating up to critical temperature. Admissible dimensions of the HAZ along the generatrix in arc welding on various diameter pipelines have been determined [5, 6]. It is found that with increase of pipeline diameter critical dimensions of the zone of heating up to limit temperature become larger. On the whole, however, these dimensions are small (Figure 2) that limits the capabilities of arc welding at metal deposition along the pipeline generatrix.

In [5] the procedure of calculation of pipes with surface corrosion damage was applied in determination of load-carrying capacity of a pipe under pressure during arc welding along the generatrix [7], as the nature of pipe rupture is identical in both the cases. The only question was what parameters of the zone of heating by the welding arc can be taken as the dimensions of the conditional surface defect, oriented along the

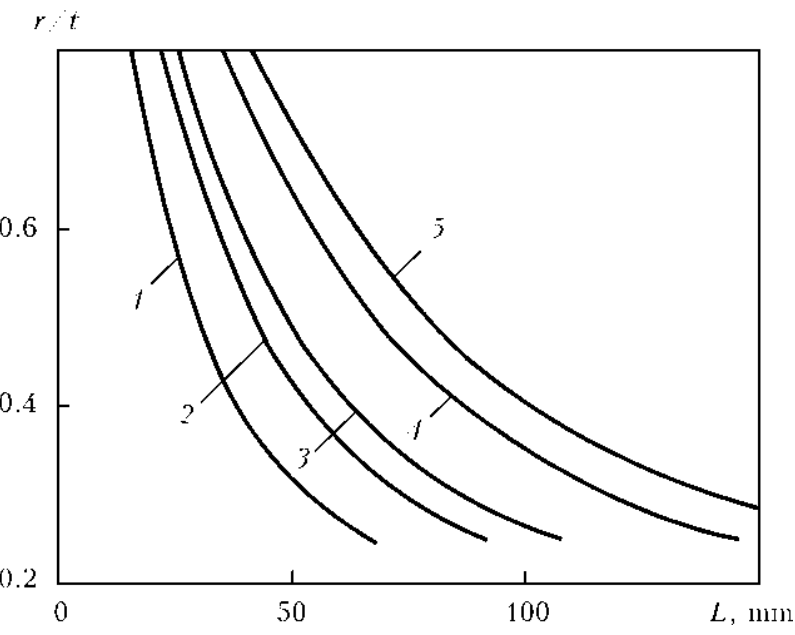

Figure 2. Admissible dimensions $L$ of zone of heating up to critical temperature in welding along generatrix for pipe with dimensions, $\mathrm{mm}: 1-325 \times 8 ; 2-530 \times 9 ; 3-$ $720 \times 9 ; 4-1020 \times 12 ; 5-1220 \times 12 ; r-$ maximum depth of the zone of pipe wall heating up to $720{ }^{\circ} \mathrm{C} ; t-$ pipe wall thickness

pipe generatrix. In one case it was possible to take the size of the zone of pipe wall heating up to melting temperature (weld pool size), and in another case - up to temperature above $720^{\circ} \mathrm{C}$, at which the metal strength characteristics are on a very low level. Moreover, what is important in practice is that this zone is readily determined visually on macrosections through the HAZ. Conducted testing showed that experimental data (Figure 3) are located much lower that the calculated values derived for a surface defect with weld pool parameters and somewhat higher than the values obtained for defects with dimensions of the zone of heating up to $720{ }^{\circ} \mathrm{C}$. And as was

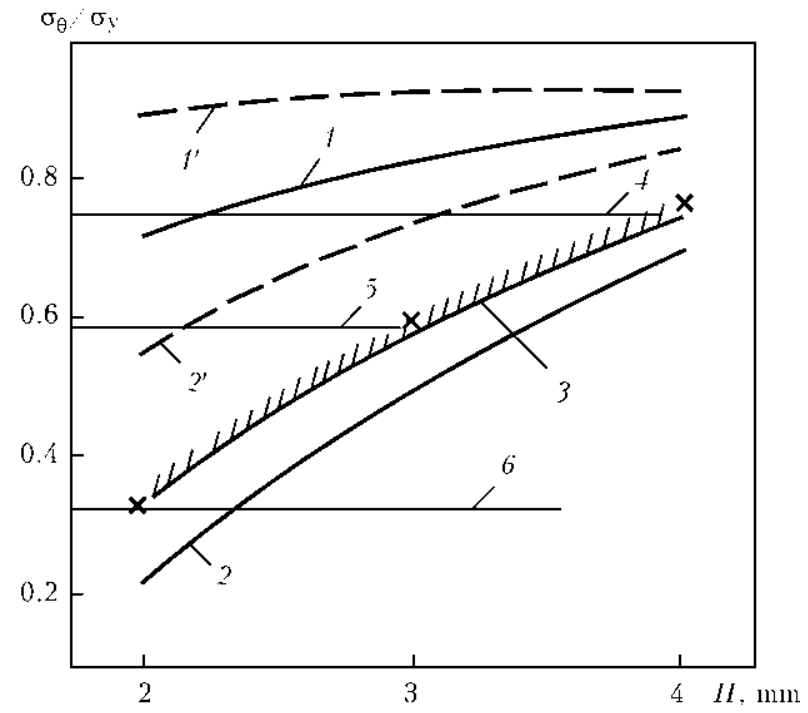

Figure 3. Relative level of breaking outer stresses $\sigma_{\theta} / \sigma_{\mathrm{y}}$ depending on thickness of unmelted bridge $H: 1,1^{\prime}-$ conditional defect of weld shape; $2,2^{\prime}-$ conditional defect with section of the zone of heating up to $700{ }^{\circ} \mathrm{C} ; 3-$ experimental data; $4-6-$ at $P=12,9.2$ and $5.3 \mathrm{MPa}$; $1-6-$ defect shape coefficient $C=1 ; 1^{\prime}, 2^{\prime}-C=2.3$ 
established, addition of the respective correction coefficient for deviation of heating zone longitudinal section from a rectangular shape allows obtaining a good agreement of experimental data with calculated values.

It should be also noted that the tendency to perform arc welding at low currents contradicts the requirements of producing HAZ metal of an acceptable hardness. As is known from [8] there is a high probability of cold cracking in welded joints with HAZ metal hardness above $H V 350$. In many countries a number of normative documents $[7,9,10]$ specify performance of multilayer fillet welds at mounting of sleeve fittings and branch pipes on operating pipelines. Here maximum HAZ metal hardness is achieved at external welds on the pipe as a result of cooling action of the transported product. And this hardness is the higher, the higher the speed of product pumping and the higher the pipe metal carbon equivalent $\mathrm{C}_{\mathrm{eq}}$. In [11] it is established that at gas pumping $\left(170,000 \mathrm{~m}^{3} / \mathrm{h}\right)$ through a pipeline from steel with $\mathrm{C}_{\mathrm{eq}}=0.4$, metal hardness in the HAZ reached $H V 415$, whereas at zero discharge it was $H V 285$.

In addition, the problem of making fillet circumferential welds is associated with inducing a rigid stressed state in the areas of branch pipe connection to the pipeline. In the presence of internal pressure these welded joints become vulnerable under the impact of mechanical deformations.

During circumferential welding, the evolving heat is quickly removed by the transported product, and this may lead to formation of quenching structures of martensite type in the HAZ metal. Therefore, it is necessary to apply additional heat to the welding zone for a long time. Manual propane torches are most often applied in practice, which preheat limited pipe sections up to $250{ }^{\circ} \mathrm{C}$. Welding is conducted until the temperature in the heating zone drops to $100{ }^{\circ} \mathrm{C}$. Then - heating again and subsequent welding.

Experimental investigations by Kiefner [12] confirm the probability of appearance of underbead cracks in fillet welded joints as a result of formation of quenching structures in the HAZ metal, presence of tensile stresses and diffusible hydrogen. To lower the risk of cold cracking, Kiefner proposes application of preheating and concurrent heating, as well as low-hydrogen electrodes.

Considering the very short period of heated pipeline sections staying in the range of acceptable temperatures (about $2-5 \mathrm{~min}$ ) at application of flame heating [12], other heat sources began to be actively introduced recently, such as electric heaters and inductors. Induction heating method and electric heaters have been tried out in nu- merous experiments and are successfully applied during repair operations on MP under pressure, allowing welding to be performed under the conditions of continuous heating [13].

In order to increase the safety of welding in operating pipelines and to be able to control the structure and properties of HAZ metal, as well as improve the reliability and performance of welded joints of reinforcing structural elements with pipelines, the authors of $[6,14]$ proposed a new design-technological approach with application of overlap-butt joints. Substantiation of such an approach will be given below.

Substantiation of the need for development of Ukrainian normative documents on repair of operating main pipelines. Already at the end of 1980s academician Boris E. Paton appreciated the urgency and attractiveness of development of repair technologies based on application of arc welding for restoring the load-carrying capacity of MP linear part and ensuring safe and undisturbed operation of transportation system. The first step in this direction were experimental investigations to determine the safe conditions of welding performance on a pipe with inner pressure [5].

In addition, in those years there was an urgent problem of gas supply to villages and urban-type villages located near the earlier constructed transit main gas pipelines, gas transportation through which could not be interrupted even for a minute. The problem posed for PWI staff was successfully solved owing to development and introduction first of the method of joining branchpipes to MP, based on application of explosion energy and bimetal transition piece [15], and then of a simpler and more reliable process of branchpipe connection by arc welding [5].

After USSR disintegration, Ukraine inherited a ramified network of pipelines for transportation of gas, oil and petroleum products. Total length of just the main pipelines, which are managed by company «Naftogaz Ukrainy», is more than $42,000 \mathrm{~km}$. Their main component is MP (more than $36,000 \mathrm{~km}$ ).

Considering the prolonged terms of pipeline operation, the problem of ensuring an effective and undisturbed operation of pipeline transportation is becoming ever more urgent. Its realization requires, primarily, improvement of currently available and development of new and reliable processes of work performance at MP repair and maintenance. To avoid financial-material losses and ecological damage, inherent to classical method of MP repair, techniques of repair without taking them out of operation are being developed all over the world. Such methods are 

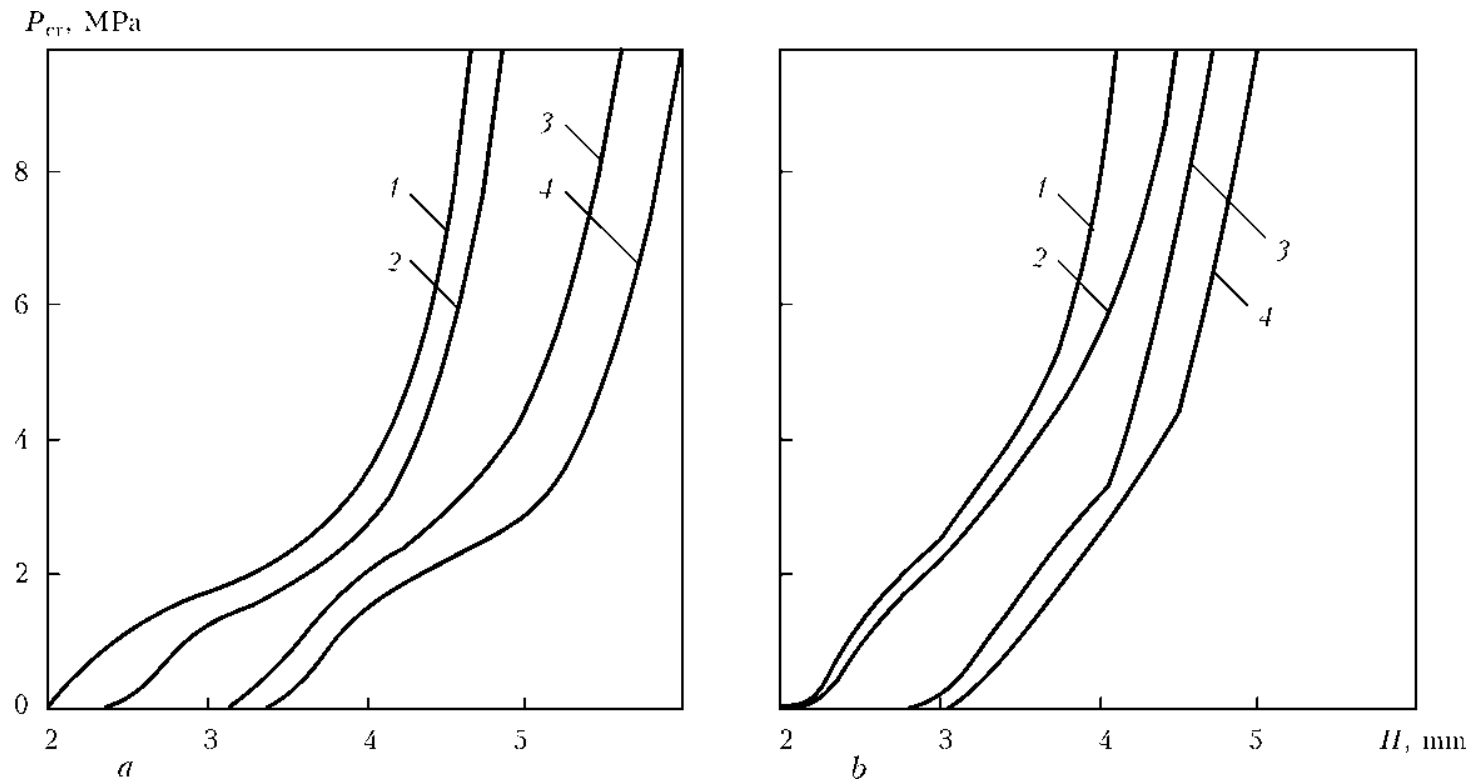

Figure 4. Dependence of critical pressure $P_{\text {cr }}$ on bridge thickness $H$ in welding-up cavities of $d=20(a)$ and $12(b) \mathrm{mm}$ in oil pipeline pipe of $1020 \times 11 \mathrm{~mm}: 1,2-I_{\mathrm{w}}=90 ; 3,4-140 \mathrm{~A} ; 1,3-$ oil transportation speed $W=6 ; 2,4-2 \mathrm{~m} / \mathrm{s}$

particularly important for Ukraine, considering the high concentration of population in the zone of main gas pipeline location, high gas price, and need for unconditional fulfillment of contractual obligations of gas supply to users both inside the country and abroad.

Moreover, now there is the need to develop a national normative document, which allows systematizing the approach to performance of repairreconditioning operations on MP under pressure with fulfillment of safety conditions and protection of environment, as well as ensuring the high quality, promptness and high standards of production cycle in keeping with the modern technology level.

Diagnostics of technical condition of main pipelines of Company «Ukrtransgaz», conducted using the intelligent pig of Rozen Company, showed that the largest number of detected de-

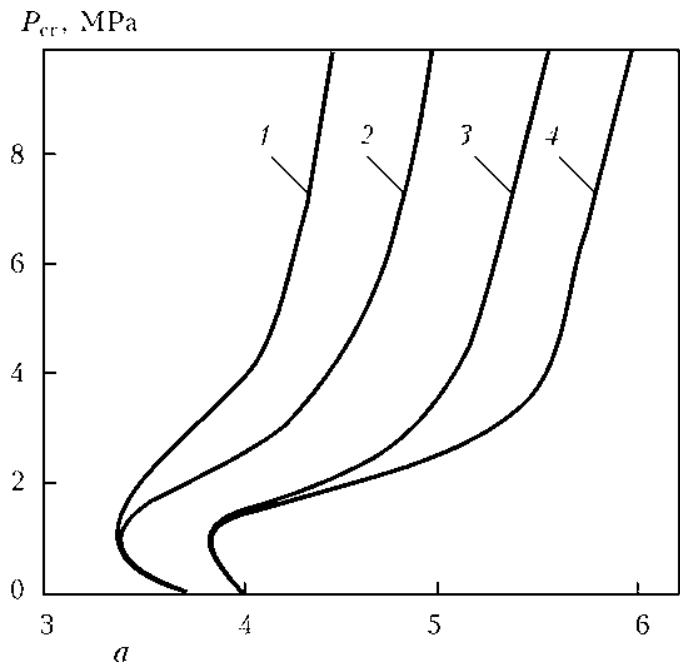

fects belong to surface corrosion damage of pipeline wall of «metal loss» type. So, metal losses of more than $60 \%$ of pipe wall thickness are equal to $0.9 \%$; 41-60\% - $5 \%$; 20-40\%$45.5 \%$. Defects of circumferential welds are equal to $10.8 \%$, surface defects - $11 \%$, longitudinal $-7 \%$, spiral $-0.9 \%$; base metal defects are $11.1 \%$, unclassified $-7 \%$, and anomalous kinds of defects are $0.8 \%$ [16]. In circumferential butt welded joints defects inadmissible, according to VSN 006-89 and VSN 012-88 requirements, were found, which were not detected during MP construction. Their number is more than $11 \%$ of all the detected defects. A multitude of surface defects in welds $(12 \%)$ and inner defects of delamination type $(11 \%)$ in base metal were found.

Proceeding from analysis of the nature and geometrical parameters of detected defects a comprehensive approach was proposed to develop-

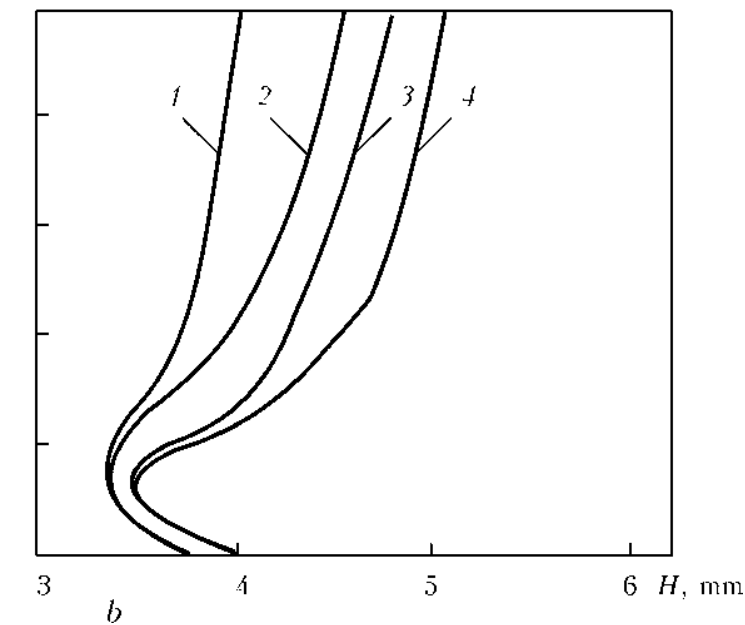

Figure 5. Dependence of $P_{\mathrm{cr}}$ on $H$ in welding-up cavities of $d=20(a)$ and $12(b) \mathrm{mm}$ in gas pipeline pipe of $1420 \times$ $\times 18 \mathrm{~mm}$ (designations are the same as in Figure 4) 
ment of technologies of restoration of the loadcarrying capacity of linear part of main gas pipelines (LPMGP) under pressure with arc welding application [14, 17]. Repair techniques were grouped by defect kinds and their purpose. For each group safe conditions of arc welding performance on MP under pressure are determined, allowing for working parameters and thermophysical properties of the transported product. Then conditions of ensuring the technological and structural strength of welded joints of the proposed reinforcing structures are the established.

Experimental-analytical evidence base of the advantages of proposed design-technological
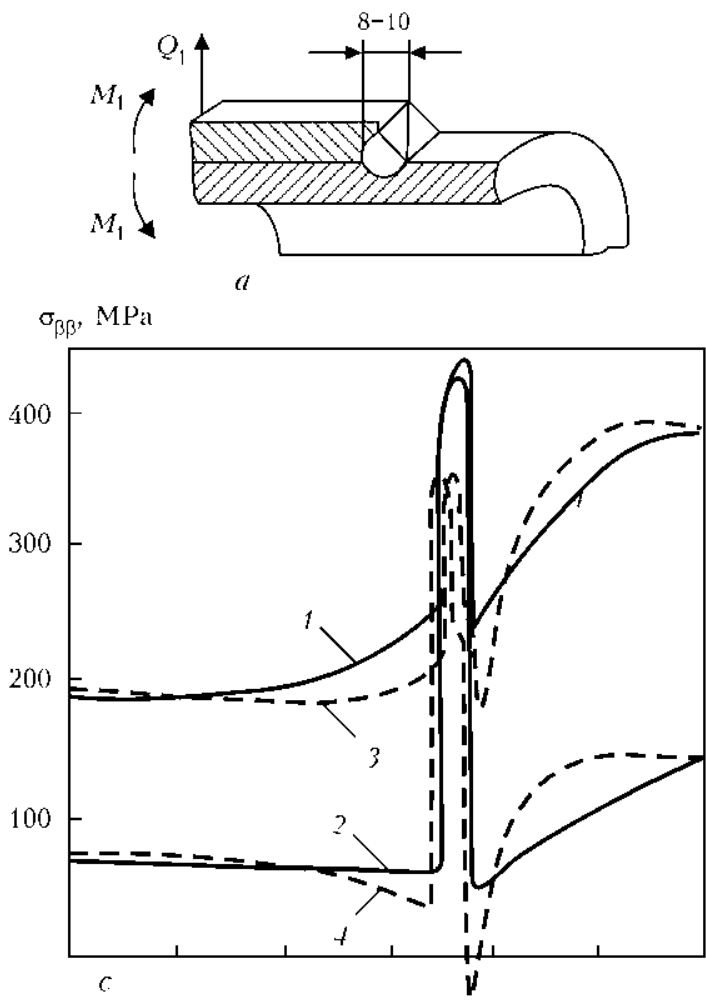

$\sigma, \mathrm{MPa}$

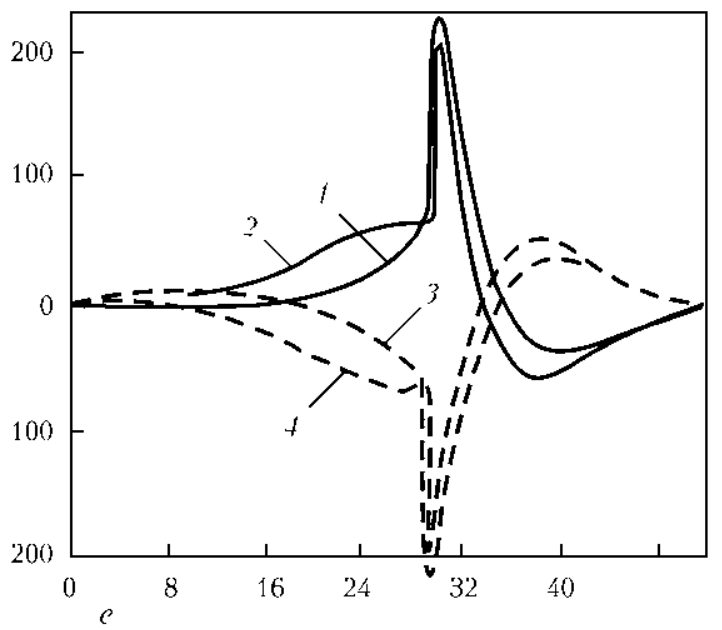

solutions. As was mentioned earlier, almost half of the detected defects on LPMGP are surface corrosion damage of a local nature. And, naturally, building-up by arc process is the simplest and most effective method to eliminate such individual defects. To provide mathematical substantiation of safe conditions of performance of building-up by arc process on pipelines under pressure, a nonstationary problem of heat conductivity [18] allowing for convective heat exchange on pipe wall inner surface depending on transported medium (gas, oil), was solved. Results of calculation of critical values of failure pressures for pipes from $17 \mathrm{G} 1 \mathrm{~S}$ steel of different
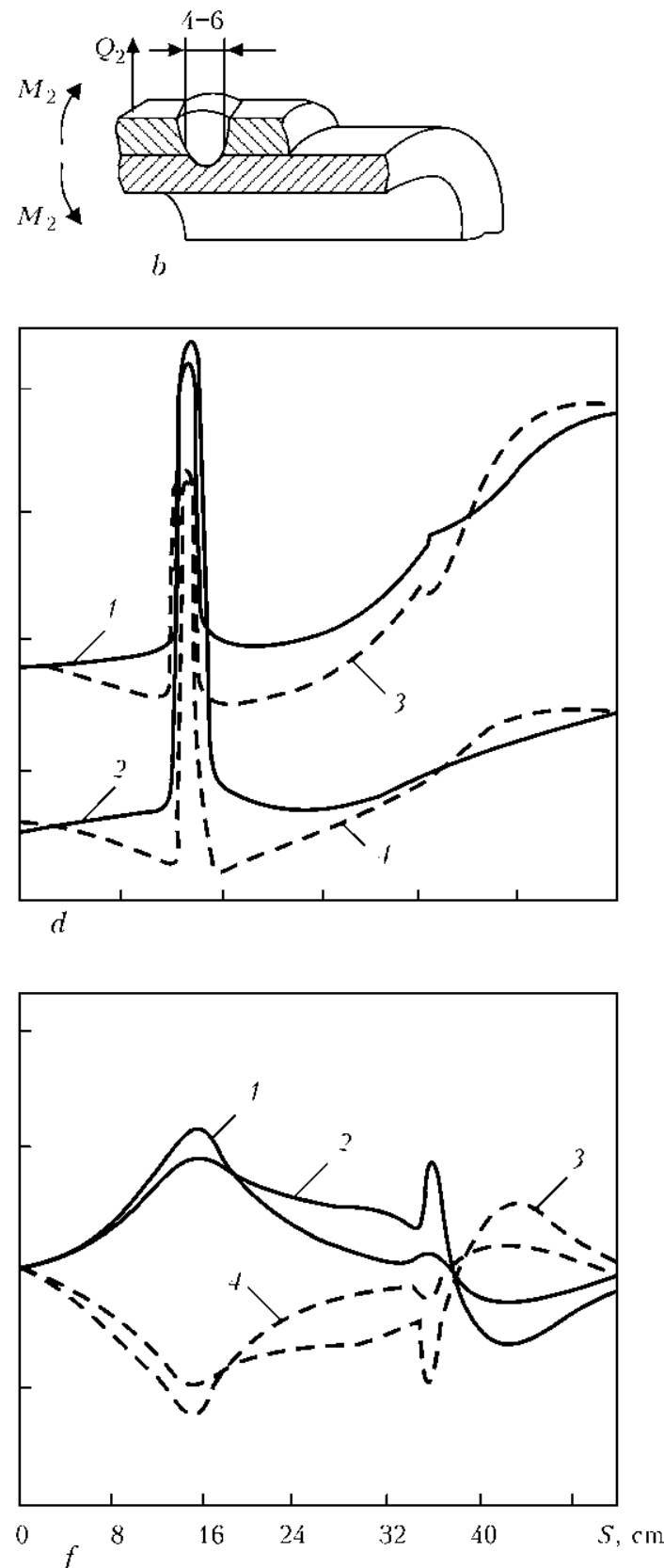

Figure 6. Influence of geometry on stress-strain state of welded joint: $a-$ with fillet weld; $b-$ overlap-butt; $c, d-$ distribution of longitudinal residual welding stresses $\sigma_{\beta}$ at internal pressure of $2.0(2,4)$ and $5.5(1,3) \mathrm{MPa} ; e, f-$ distribution of similar transverse stresses $\sigma_{s s} ; 1,2$ - outer surface of pipe wall; 3,4 - inner surface; $S$ - length of studied section 
diameter are presented in the form of graphical dependencies (Figures 4 and 5). These data show that for oil pipeline (Figure 4) the value of failure pressure rises monotonically with increase of metal thickness in the welding area up to certain limits, above which the considered failure mechanism (plastic instability) is not realized, as mean temperature across the thickness of the above-mentioned bridge is reduced abruptly. Reduction of welded up cavity diameter leads to reduction of bridge admissible thickness at the same pressure.

A similar situation is observed for gas pipelines (Figure 5). Here, however, the process is made more complicated by the high intensity of heat exchange between the wall and transported medium at low pressures, leading to nonmonotonic change of critical failure pressure, depending on bridge thickness.

Thus, it follows from the above-said that at welding up individual corrosion defects on MP under pressure the probability of bridge breaking up depends, primarily, on metal thickness in the welding area, as well as on transported product speed and its thermophysical properties, and internal pressure magnitude.

In order to restore the load-carrying capacity of LPMGP with extensive corrosion damage, crack-like defects, inadmissible defects in welds, design solutions were proposed, which are based on application of a new type of welded joint overlap-butt one [6]. As shown by investigations, a new original design approach to performance of repair operations in MP under pressure allows a considerable increase of welding heat input, with preservation of safe conditions of it performance. Only through-thickness burn of the wall can lead to depressurizing of the pipeline that is improbable in practice, as circumferential welds of reinforcing sleeves are made in pipeline sections with not less than $5 \mathrm{~mm}$ wall thickness [1].

Application of additional technological rings in overlap joints of sleeve with pipeline owing to reinforcing effect allows optimization of stressstrain state of welded joints, both under the impact of inherent welding stresses and of internal pressure (Figure 6). Load-carrying capacity and overall performance of welded joints under repeated-static loading depend on the level and nature of distribution of stresses in them.

Investigations of stress-strain state of samples of fillet and overlap-butt joints using polarization optical method at different kinds of loading [19] showed that in all the cases a higher stress concentration is observed in the areas of deposited metal transition to base metal in fillet welds ( $\mathrm{Ta}-$ ble). Obtained data correlate well with the results of testing simulation samples with different
Results of calculation of stress concentration $\alpha_{\sigma}$

\begin{tabular}{||l|c|c|}
\hline \hline \multicolumn{1}{|c|}{ Kind of sample loading } & Fillet joint & Overlap-butt joint \\
\hline Tension & $2.0-2.3$ & $1.8-2.0$ \\
\hline Three-point bending & $1.6-1.8$ & $1.2-1.3$ \\
\hline Cantilevered bending & $2.5-3.0$ & $1.2-1.5$ \\
\hline
\end{tabular}

weld geometries for fatigue resistance at repeated-static off-center tension [5]. Application of overlap-butt joints allows improvement of fatigue limit of welded samples 1.5 times compared to fillet weld joints (Figure 7).

In addition to the above-said, welding operation performance on pipelines under pressure using overlap-butt joints allows controlling HAZ dimensions, structure and properties. This reduces the probability of cold cracking and HAZ metal proneness to brittle fracture. In this case, complete automation of arc welding at joining of reinforcing elements to operating pipelines is possible [17].

In connection with the above-said, a number of design-technological solutions are proposed for restoration of load-carrying capacity of LPMGP with extensive corrosion damage without interrupting product transportation [20, 21].

The most characteristic examples of application of overlap-butt joints in reinforcing structures are sealed and two-layer sleeves (Figure 8). The latter are applied for reinforcement of pipeline defective circumferential butt joints, the majority of which are closing butt-«overlap» joints in construction.

Special consideration should be given to a structure with application of self-hardening compound based on polyurethane adhesive ( $\mathrm{Fi}^{-}$

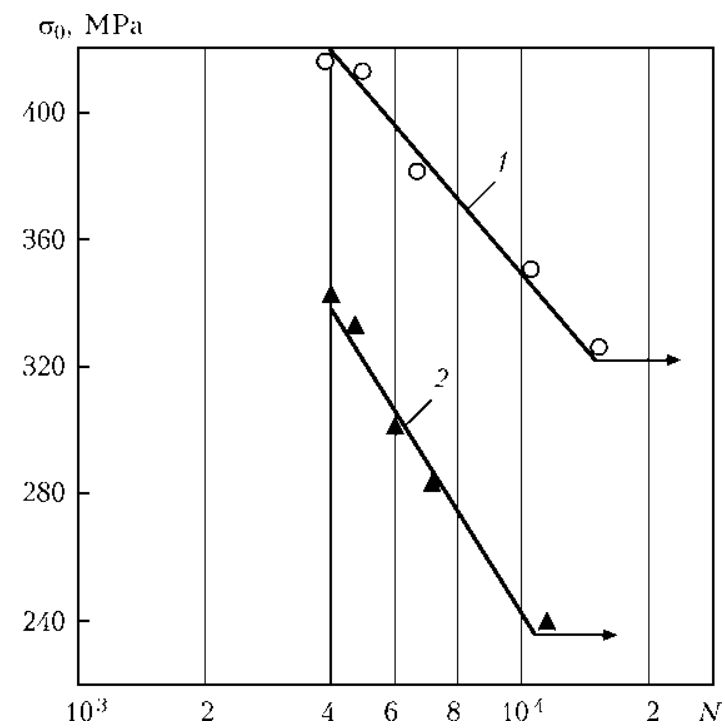

Figure 7. Results of testing welded samples at off-center repeated static loading: 1 - fillet; 2 - overlap-butt joints; $\sigma_{0}-$ sample fatigue limit; $N-$ cyclic fatigue life 

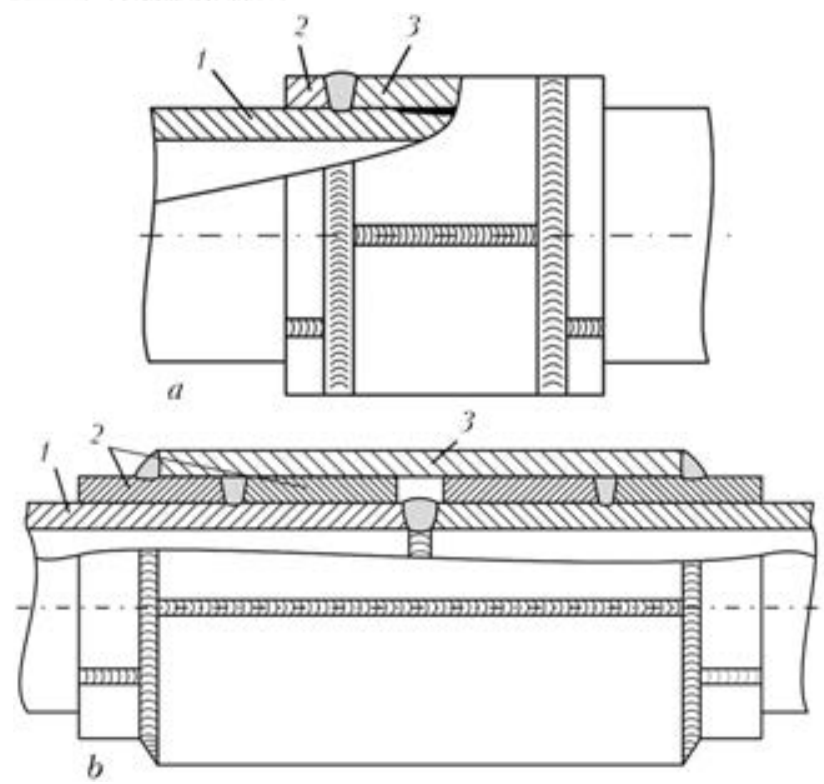

Figure 8. Design-technological schematics of MP repair under pressure using overlap-butt welded joints: $a$ - sealed $b$ - two-layer sleeve; 1 - pipeline; 2 - technological rings; 3 - sleeve

gure 9). In the authors' opinion, such an engineering solution is versatile and has considerable advantages over sealed sleeves, mounted directly on the pipeline and forming a sharp-angled stress raiser in the form of an interlayer gap between the sleeve and pipe in the circumferential weld area.

Application of additional thin-walled rings from flux-cored strip allows blunting the above stress raiser and thus lowering the stress level in

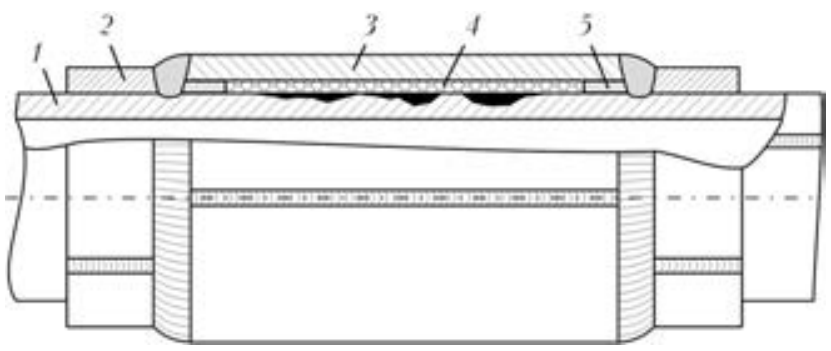

Figure 9. All-purpose bond-welded sleeve on thin backing: 1-3 - designations are the same as in Figure 8; 4 - adhesive composition; 5 - metal strip

the critical zone during formation of a circumferential weld. This results in lower probability of cold cracking in welds at the raiser. Moreover, application of thin-walled rings allows eliminating the need for making grooves on sleeve inner surface for pipeline longitudinal welds that simplifies the repair process and improves its quality, as well as lowers the probability of repaired structure failure. An essential advantage of the considered structure is the possibility of filling the undersleeve space by an adhesive self-hardening mixture under pressure, commensurate with working pressure in the pipeline. This allows lowering stress level in pipeline defective part, transferring the load to sleeve. Moreover, such an approach allows repairing extended MP sections due to mounting multisection weld-bonded sleeve [21] and can be advantageous, if it is required to increase the category of individual sections of operating gas pipeline.
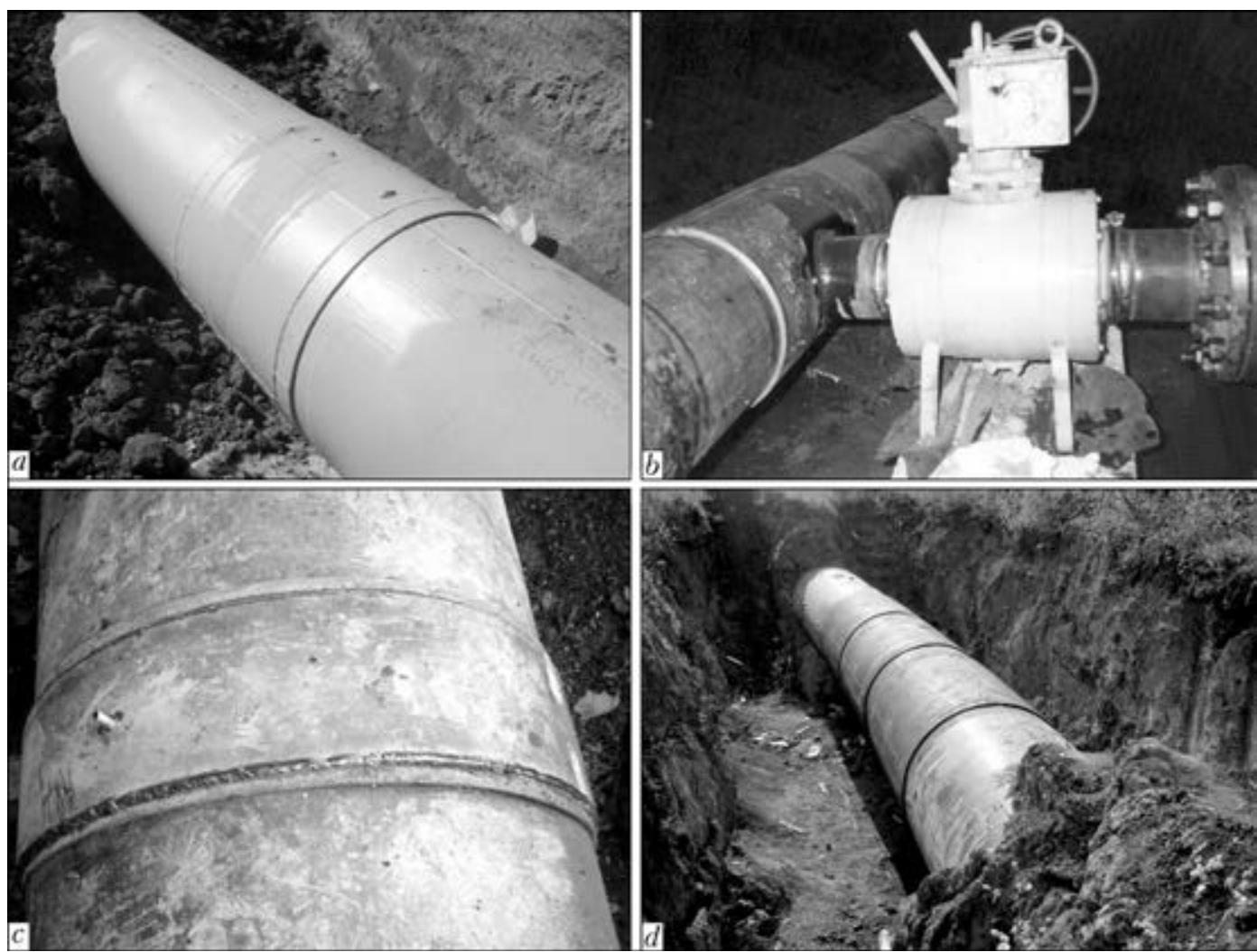

Figure 10. Mounting of sealed sleeve $(a)$, branchpipe $(b)$, two-layer sleeve $(c)$ and bond-welded sleeves $(d)$ on MP 
Practical experience of developed technology application. Groundwork on experimentaltheoretical substantiation of design-technological solutions application for repair of operating $\mathrm{MP}$, first in a smaller volume, was the basis for normative document VBN V3.1-0001374107:2007 for oil pipelines [20]. And later on, it was more completely incorporated into GBN B.3.1-00013741-12:2011 for gas pipelines [21]. In order to unify the approach to manufacturing reinforcing structural elements, TU U 27.219305558-001:2007 were developed [22].

For training and certification of personnel performing repair operations, respective programs were developed, both for welders and for welding operation supervisors, as well as training manual on repair techniques with application of arc welding on pipelines under pressure [23].

During the period of wide application (20012012) of the developed technologies in the facilities of «Ukrtransgaz» the following operations were performed: 326 two-layer sleeve fittings were mounted on defective butts of the main pipelines, 52 branchpipes were joined to the main line for connection of new consumers, more than $800 \mathrm{sec}-$ tions with considerable corrosion damage were repaired, using weld-bonded sleeves. Figure 10 gives examples of practical realization of the developed technologies. Overall economic effect from their introduction was greater than UAH $188 \mathrm{mln}$.

Successful cooperation of «Ukrtransgaz» and PWI teams allowed receiving more than 50 patents of Russia and Ukraine for a number of engineering solutions. Achievements in the field of systemic approach in development of technologies of repair of operating main pipelines have been rewarded by State Prize of Ukraine in the field of science and technology for 2008.

\section{Conclusions}

1. Analysis of the features of arc welding application in MP under pressure was performed and ways to eliminate the impact of adverse factors have been determined.

2. In order to extend MP safe operation, as well as considering the high population density in the zone of main line running and the need to ensure an undisturbed supply of energy carriers to users, industrial normative-technical documents have been developed on MP repair by arc welding in operation.

3. Advantages of the new design-technological approach at restoration of load-carrying capacity of defective areas of LPMGP in operation have been demonstrated. Application of overlap-butt joints allows widening heat input range in arc welding; controlling the dimensions, structure and properties of HAZ metal; lowering stress concentration in the area of circumferential weld transition to the pipeline and, thus, increasing the fatigue limit of welded joints of reinforcing structures at repeated static loading.

1. Bruce, W.A., Mishier, H.D., Kiefner, J.F. (1993) Repair of pipelines by direct deposition of weld metal. AGA Pipeline Res. Com. Project PR-185-9110. Edisson Weld. Inst.

2. But, V.S., Gretsky, Yu.Ya. (1997) On problem of joining of branchpipes to main pipelines in service conditions. Avtomatich. Svarka, 6, 25-33.

3. But, V.S., Gretskii, Yu.A. (2001) Repair of the main pipelines under pressure using arc welding. In: Proc. of Int. Conf. on Pipeline Repairs (Australia, 5-6 March, 2001).

4. Makhnenko, V.I., But, V.S., Kozlitina, S.S. et al. (2010) Risk of fracture of pressurised main pipeline with defects of the type of wall thinning during repair. The Paton Welding J., 1, 7-10.

5. But, V.S. (1991) Joining of branchpipes to main oil pipelines under pressure using arc welding. In: Petrol. Industry. Series Transport and oil storing. Moscow: VNIIOENG.

6. But, V.S., Rozgonyuk, V.V., Gretsky, Yu.Ya. et al. (2001) Validation of new approach to performance of welding operations on pipelines under pressure. Naft. i Gaz. Promyslovist, 4, 33-39.

7. (2007) ASME B31.8: Gas transmission and distribution piping system. Amer. Soc. of Mech. Eng.

8. Hrivnak, I. (1984) Weldability of steels. Moscow: Mashinostroenie.

9. (2007) CSA Z662-07: Oil and gas pipeline system. Canadian Stand. Assoc

10. (2006) BS EN ISO 16708: Petroleum and natural gas industrials. Pipeline transportation systems. Reliability-based limit state methods.

11. Phelps, B., Cossie, B.A., Evans, N.H. (1986) Welding onto live natural gas pipelines. J. Metal Construction, 8, 350-354.

12. Kiefner, J.F., Maxey, W.A. (1989) Test validate pipeline sleeve repair technique. Oil and Gas J., 8, 47-52.

13. Korolkov, P.M. (1996) Heat treatment of pipeline welded joints in field conditions. Montazhn. i Spets. Raboty v Stroitelsve, 11/12, 21-24.

14. Bekker, M.V., But, V.S., Govdyak, R.M. et al. (2008) Repair of main pipelines under pressure. Kyiv: Kyj.

15. Dobrushin, L.D. (1981) Development and investigation of the technology of welding branchpipes of main gas pipelines under pressure using explosion energy: Syn. of Thesis for Cand. of Techn. Sci. Degree. Kiev.

16. But, V.S., Gretsky, Yu.Ya., Drogomiretsky, M.M. et al. (1998) Evaluation of corrosion damages and application of arc welding for repair of operating pipelines. Naft. $i$ Gaz. Promyslovist, 6, 44-47.

17. But, V.S., Olejnik, O.I. (2007) Main trends in technology for repair of active pressurized main pipelines. The Paton Welding J., 5, 30-35.

18. Makhnenko, V.I., But, V.S., Velikoivanenko, E.A. et al. (2001) Mathematical modelling of pitting defects in active oil and gas pipelines and development of a numerical method for estimation of permissible parameters of arc welding repair of defects. Ibid., 11, 2-9.

19. But, V.S., Velikoivanenko, E.A., Pochinok, V.E. et al. (1988) Investigations of stress-strain state and prediction of serviceability of welded joints of structural elements with pipeline. In: Improvement of control and service systems of main oil transportation: Transact. Ufa: VNIISPTneft, 189-196.

20. $V B N$ V.3.1-00013741-07:2007: Main oil pipelines. Methods of repair of defective zones. Valid 01.01.07. Kyiv: Ministry of Fuel and Energy of Ukraine.

21. GBN V.3.1-00013741-12:2011: Main gas pipelines. Repair using arc welding in service conditions. Valid 06.09.11. Kyiv: Ministry of Energy and Coal Industry of Ukraine.

22. TU U 27.2-19305558-001:2007: Reinforcing structural elements of pipelines. Valid 03.07.07.

23. But. V.S. (2003) Construction and repair of operat ing main gas pipelines. Manual for supervisors of welding operations on main pipelines under pressure. Kiev: PWI ITCC. 


\title{
ASSESSMENT OF EFFECTIVENESS OF RESIDUAL STRESS LOWERING IN CIRCUMFERENTIAL JOINTS OF PIPES AFTER POSTWELD EXPLOSION TREATMENT
}

\author{
A.G. BRYZGALIN \\ E.O. Paton Electric Welding Institute, NASU \\ 11 Bozhenko Str., 03680, Kiev, Ukraine. E-mail: office@paton.kiev.ua
}

\begin{abstract}
It is established that at application of earlier developed procedure of calculation of explosion treatment modes for pipe circumferential joints the extent of residual stress lowering depends on their initial level. In particular, at explosion treatment of pipes without the circumferential weld the induced compressive stresses are essentially lower than welding stresses, whereas the latter are practically completely relieved at treatment of welds of similar pipes by the same modes. Scatter of induced compressive stresses in pipes of different typesizes did not exceed the measurement error. Dependence of explosion treatment effectiveness on the magnitude of initial welding stresses was determined, which is of a nonlinear nature. Presence of such a dependence allows prediction of treatment results and correction of modes depending on requirements made of treatment results. Fundamental difference of the mechanisms of residual stress lowering at heat treatment and explosion treatment is shown. 9 Ref., 2 Tables, 4 Figures.
\end{abstract}

Key words: effectiveness, explosion treatment, heat treatment, residual stresses, deformations, circumferential weld, pipelines

Reaching a zero stress level in the weld, being, as a rule, the weakest point of the structure, can be regarded as the optimum result of lowering residual stresses (RS) by postweld treatment. As shown in [1], application of calculation method to determine the modes of explosion treatment (ET) allows sufficiently effective lowering of RS in pipes of various typesizes. It is of interest to find out how close the calculated modes are to optimum ones, and to assess the possibilities of their correction when solving various practical problems. With this purpose additional verification of the calculation method was conducted on one-piece seamless pipes with the following typesize: $115 \times 4$ (steel 20$), 115 \times 10$ (steel $17 \mathrm{G} 1 \mathrm{~S}), 160 \times 6($ steel $17 \mathrm{G} 1 \mathrm{~S}), 216 \times 7 \mathrm{~mm}$

Table 1. Residual stresses at ET of seamless pipes

\begin{tabular}{||c|c|c|c||}
\hline \hline $\begin{array}{c}\text { Pipe typesize } \\
(2 R \times h), \mathrm{mm}\end{array}$ & $\sigma_{\mathrm{y}}, \mathrm{MPa}$ & $\sigma_{\mathrm{f}}, \mathrm{MPa}$ & $\Delta \sigma, \mathrm{MPa}$ \\
\hline $115 \times 4$ & 240 & -50 & 50 \\
\hline $115 \times 10$ & 350 & -70 & 70 \\
\hline $160 \times 6$ & 350 & -70 & 70 \\
\hline $216 \times 7$ & 240 & -60 & 60 \\
\hline
\end{tabular}

(steel 20). This allowed eliminating experimental error introduced by making the weld.

Explosive charges were mounted on pipe samples symmetrically relative to a certain diametral section plane, simulating the geometry of ET of pipes with finished circumferential welds. Calculation of experimental modes was conducted as it was done before for pipes with a weld, the center of which was conditionally located in the above section plane. Circumferential stresses after ET were measured in the same plane on the pipe outer surface.

Measurement results are given in Table 1. Initial RS values are equal to zero $\left(\sigma_{\text {in }}=0\right)$, and final stresses after ET are equal to $\sigma_{f}$ values in the respective column of Table 1. ET effectiveness $\Delta \sigma=\sigma_{\text {in }}-\sigma_{\mathrm{f}}=-\sigma_{\mathrm{f}}$.

Scatter of $\Delta \sigma$ value is on the level of RS measurement error. Table 2 gives the results of RS measurement in circumferential pipe welds, published in [1].

Effectiveness of ET of circumferential pipe welds depends on a multitude of factors, the most significant of which are as follows: pipe geometrical parameters (radius $R$, wall thickness $h$ ), pipe material strength $\sigma_{\mathrm{y}}$, initial $\mathrm{RS} \sigma_{\text {in }}$, pipe internal pressure $P$, pipe material temperature at the moment of treatment $T$.

It should be noted that stress measurement results which are presented in Tables 1 and 2, were derived when performing ET on pipes without internal pressure and at small variation of 
ambient temperature $\left(25 \pm 10{ }^{\circ} \mathrm{C}\right)$, therefore, these factors did not influence ET effectiveness.

Of all the significant parameters, $\sigma_{\text {in }}$ parameter, which was not taken into account in development of mode determination procedure, remained unconsidered. An essentially smaller $\Delta \sigma$ value in seamless pipes, compared to $\Delta \sigma$ in pipes with circumferential welds, is indicative of the presence of a dependence between initial RS and their lowering value in the case of selection of ET modes in keeping with the developed procedure. Let us analyze the derived experimental results.

Value of initial RS for different pipes (see Table 2) varies from 150 up to $300 \mathrm{MPa}$. After ET final RS values fell within the range of $\pm 50 \mathrm{MPa}$, i.e. despite the different level of initial $\mathrm{RS}$, a quite stable result for $\sigma_{\mathrm{f}}$ was achieved, even though for different pipes of both groups (with and without circumferential welds) thickness differed by 4.3 times, diameter -6 times, and diameter-to-thickness ratio -6.6 times.

To assess the influence of initial RS on treatment effectiveness, let us present the data of all the experiments on ET graphically in the form of a family of points in the co-ordinate plane $\left(\sigma_{\text {in }}\right.$, $\Delta \sigma)$ (Figure 1).

Linear correlation coefficient between $\sigma_{\text {in }}$ and $\Delta \sigma$ values is equal to 0.97 that is indicative of availability of a functional link between these parameters, close to a linear one. Let us present this dependence in the form of a straight line, flowing through point (0.63), which corresponds to mean value of stress variation at ET of seamless pipes. Selection of this point as the basic one for drawing a straight line relies on the fact that for seamless pipes errors of measurement of RS from welding are eliminated that determines its essential significance. Equation of a straight line defining the dependence between $\sigma_{\text {in }}$ and $\Delta \sigma$ for this experimental series, becomes

$$
\Delta \sigma=0.72 \sigma_{\text {in }}+63[\mathrm{MPa}]
$$

Presence of such a dependence enables predicting RS level after ET, and mode correction if required, and subsequent precising of the procedure of explosion impact parameter calculation in order to control RS value in welds. On the whole, it can be assumed that ET is an effective method to control RS in circumferential pipe welds.

Other methods to lower welding stresses are well-known [2-4]. All of them are based on running of plastic deformations, compensating shrinkage welding stresses. RS create in the
Table 2. Circumferential residual stresses in pipe welds, MPa

\begin{tabular}{||c|c|c|c||}
\hline $\begin{array}{c}\text { Pipe typesizes } \\
(2 R \times h), \mathrm{mm}\end{array}$ & $\sigma_{\text {in }}, \mathrm{MPa}$ & $\sigma_{\mathrm{f}}, \mathrm{MPa}$ & $\Delta \sigma, \mathrm{MPa}$ \\
\hline $115 \times 4$ & 150 & -30 & 180 \\
\hline $160 \times 5$ & 200 & -50 & 250 \\
\hline $115 \times 8$ & 200 & -20 & 220 \\
\hline $150 \times 8$ & 250 & 0 & 250 \\
\hline $530 \times 7$ & 300 & 50 & 250 \\
\hline $530 \times 9$ & 300 & 50 & 250 \\
\hline $168 \times 14$ & 250 & 0 & 250 \\
\hline \multicolumn{4}{|l|}{ Note. All the given stress values are for pipe outer surface. } \\
\hline
\end{tabular}

welded joint a margin of internal elastic energy, owing to which such a joint is in the condition of unstable energy equilibrium. Realization of the process of elastic deformation transition into plastic deformations requires an energy «impulse» from an external source. Such a source can be heating (heat treatment), explosion (ET), vibrational, electric-pulse treatment, etc. However, in order to remove RS in circumferential pipe welds, local heat treatment is applied as the most effective of the above-mentioned ones. Tempering temperature for carbon and low-alloyed steels is usually assigned to be $680-720{ }^{\circ} \mathrm{C}$ with 60-120 min soaking time, depending on pipe wall thickness. This mode is applied both in local industry [5], and abroad (British standard B 33511961, Standard USA I B 37.1.0).

However, heat treatment involves high labour and energy consumption. It is known that duration of heat treatment of circumferential pipe welds in the field is 3-4 times longer than the welding time [6]. Moreover, heat treatment effectiveness is essentially lowered with greater pipe wall thickness, as this is accompanied by an increase of temperature gradient through wall thickness. And, finally, in connection with ap-

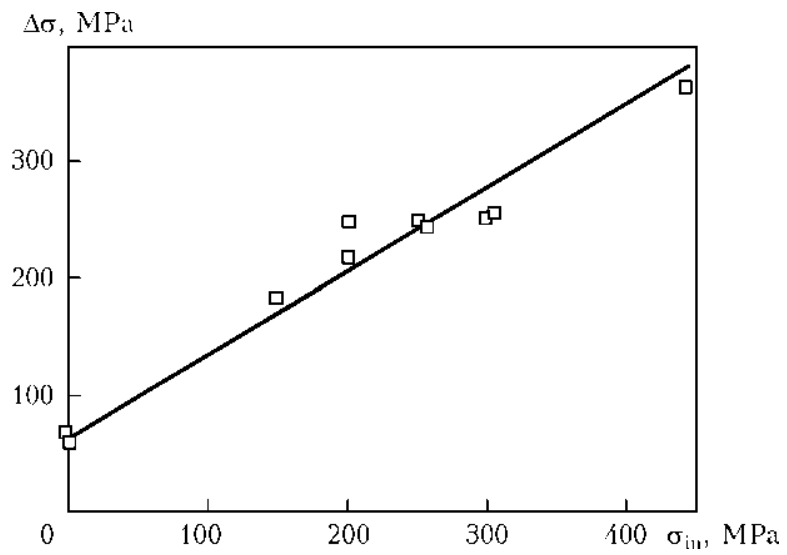

Figure 1. Dependence of the magnitude of residual stresses lowering on their initial value 

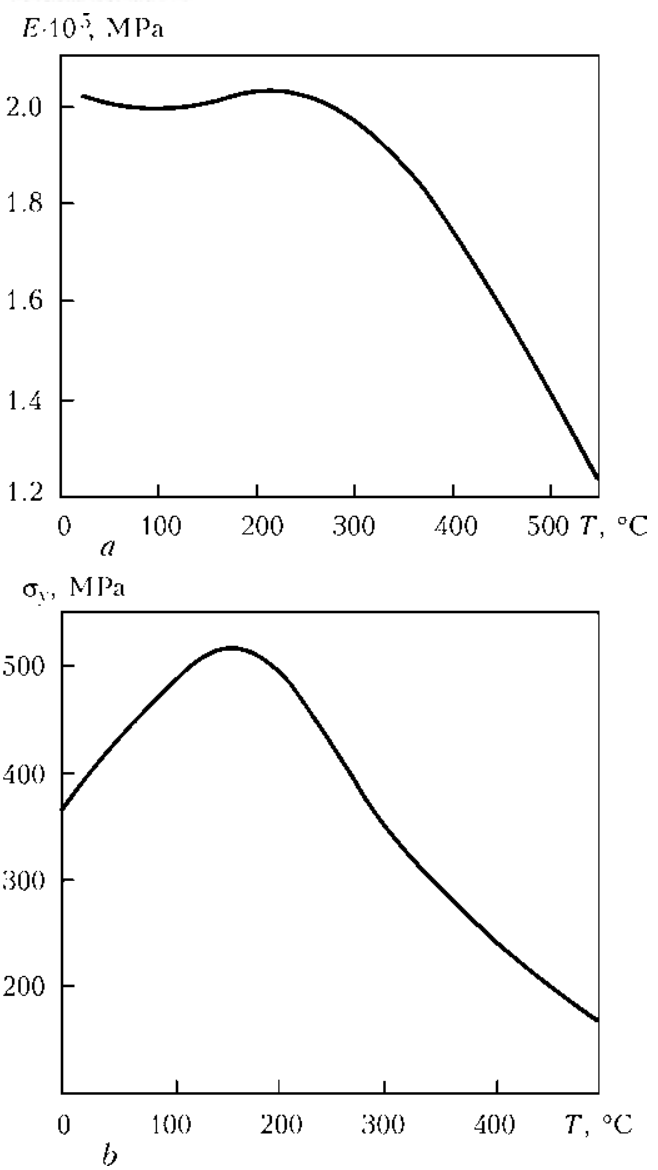

Figure 2. Dependence of modulus of elasticity $(a)$ and yield point $(b)$ of carbon steel on temperature

plication of pipes from higher strength steels (for instance, controlled-rolled steels), the risk of their softening as a result of overheating becomes higher.

It is known that ET is not inferior to heat treatment as to its effectiveness [7]. On the other hand, it is obvious that both the processes have completely different mechanisms of impact on welded joint, consideration of the principles of which (without allowing for diverse factors, af-

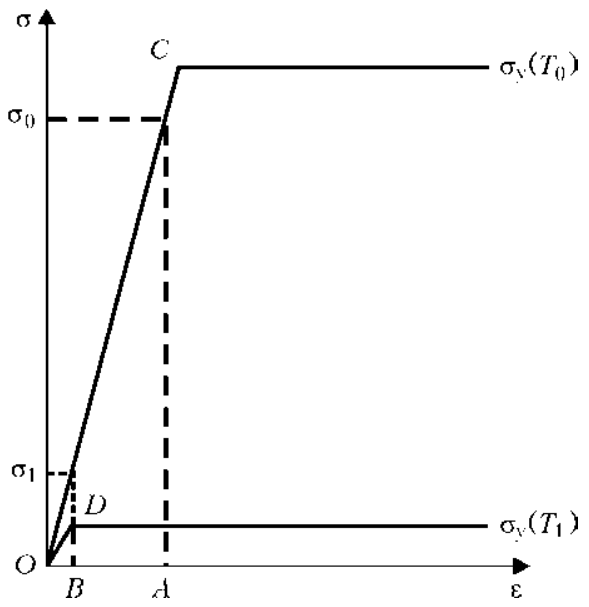

Figure 3. Ideal elastoplastic $\sigma^{-\varepsilon}$ diagram for steel at different temperatures fecting their effectiveness, but not changing the essence of the processes) appears to be rational.

Heat treatment. At uniform heating, thermal deformations are uniform over the entire metal volume, and in themselves they cannot lead to RS lowering. Heat treatment effect is achieved owing to the property of steel to change its yield point and modulus of elasticity with temperature change. Figure 2, $a$ gives dependencies of modulus of elasticity, and Figure 2, $b$ - those of yield point of carbon steel on temperature [8].

At heating of welded joint from $T_{0}$ up to $T_{1}$ (Figure 3) $E$ and $\sigma_{\mathrm{y}}$ decrease. Elastic deformations $\varepsilon_{1}$ corresponding to steel $\sigma_{\mathrm{y}}$ at temperature $T_{1}$ are shown in Figure 3 by section $O B$. The rest of deformation, which was elastic at $T_{0}$, will go into plastic deformation ( $B A$ section).

After welded joint cooling to $T_{0}$, modulus of elasticity will increase up to initial value, while elastic deformations will remain the same as at $T_{1}$. Then the stresses after heat treatment will be equal to

$$
\sigma_{1}=\varepsilon_{1} E_{0} .
$$

As we can see, after overall heat treatment RS are independent on the magnitude of their initial value. It should be noted that during soaking at heat treatment temperature further lowering of RS takes place through their relaxation by the diffusion mechanism. At local heat treatment the principle of RS lowering will remain the same.

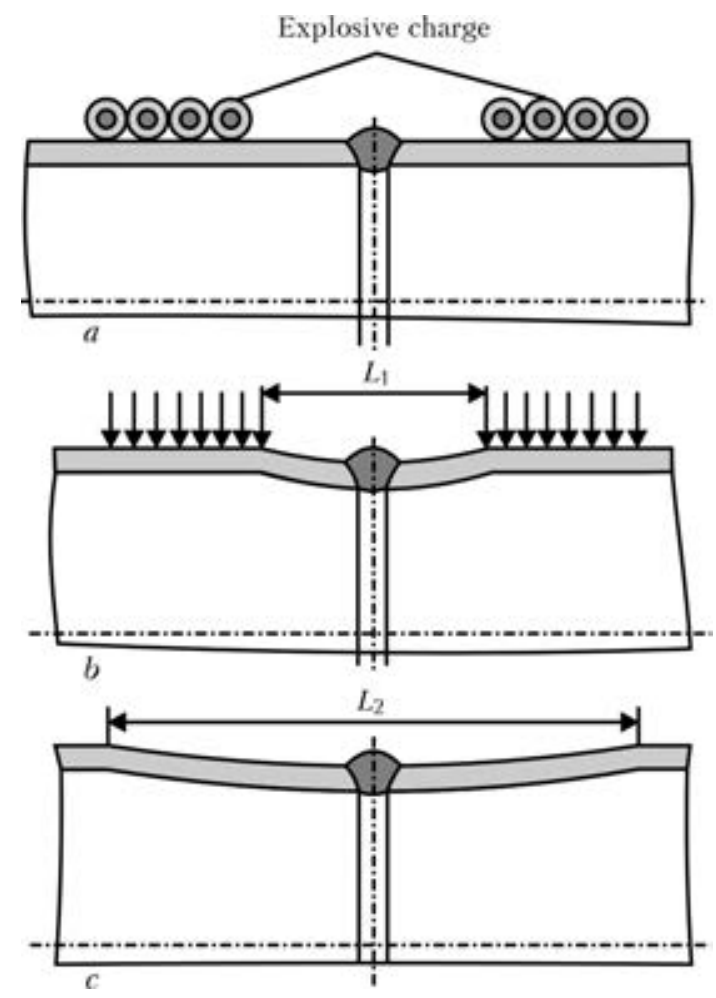

Figure 4. Schematic of ET process: $a$ - charge arrangement; $b$ - load application; $c$ - pipe wall deformation after ET 
However, additional RS of negligible magnitude will develop as a result of non-uniform thermodeformational cycle.

Explosion treatment. As a result of a complex thermodeformational process in welding, the circumferential weld and a certain zone of base metal adjacent to it have smaller radius than the rest of the pipe body [9]. The mechanism of RS lowering at ET of circumferential pipe welds by external charges consists in inducing plastic deformations, reducing the pipe radius in the section directly adjacent to the zone of plastic deformations of shrinkage due to welding. In this case RS are redistributed over a wider pipe section that leads to an essential lowering or complete elimination of peak tensile stresses in the weld (Figure 4).

At sufficiently extensive explosive loading such deformations can be induced in the pipe wall, that its radius under the charge is smaller than that of the circumferential weld. In this case the weld develops compressive stresses. Unlike heat treatment, ET performance does not affect weld metal structure (either positively or negatively). Numerous studies and experience of ET application show that the induced dynamic loads do not lead to development of defects present in the welded joint and base metal in the form of lacks-of-penetration, pores, undercuts, foreign inclusions, etc.
Conducted analysis shows that expansion of ET technological capabilities can be achieved by prediction and regulation of its results.

1. Bryzgalin, A.G. (2013) Calculation of parameters of explosion treatment for reduction of residual stresses in circumferential welds of pipelines. The Paton Welding J., 8, 31-36.

2. Zubchenko, A.S., Koloskov, M.M., Amelianchik, A.V. et al. (2002) Investigation of effect of deformation treatment on residual stresses in circumferential welds. Ibid., 1, 2-9.

3. Kasatkin, B.S., Prokhorenko, V.M., Chertov, I.M. (1987) Stresses and strains in welding. Kiev: Vyshcha Shkola.

4. Lobanov, L.M., Pavlovsky, V.I., Lysak, V.V. (1989) Application of preliminary elastic deformation for control of stress-strain state in welding of thin-sheet structures from aluminium alloys. In: Welding of non-ferrous metals. Kiev: Naukova Dumka, 52-56.

5. SNiP III-42-80: Rules for performance and acceptance of works. Main gas pipelines. Moscow: Strojizdat.

6. Perunov, B.V., Kushnarenko, V.M. (1983) Corrosion prevention as a guarantee of efficiency. Chelyabinsk: YuUKI.

7. Dobrushin, L.D., Effendiev, E.E., Bryzgalin, A.G. (1985) Investigation of comparative efficiency of residual stress relaxation in circumferential welds of pipes from controlled rolling steel using explosion treatment. In: Application of explosion energy in welding technique. Kiev: PWI, 90-94.

8. Rabotnov, Yu.N. (1963) Strength of materials. Moscow: Fizmatgiz.

9. Makhnenko, V.I. (1976) Stress state in zones of circumferential butt joints of pipes during explosion treatment. In: Calculation methods for examination of kinetics of welding stresses and strains. Kiev: Naukova Dumka, 291-296. 


\section{The Evgeny Paton Prize Winners of 2013}

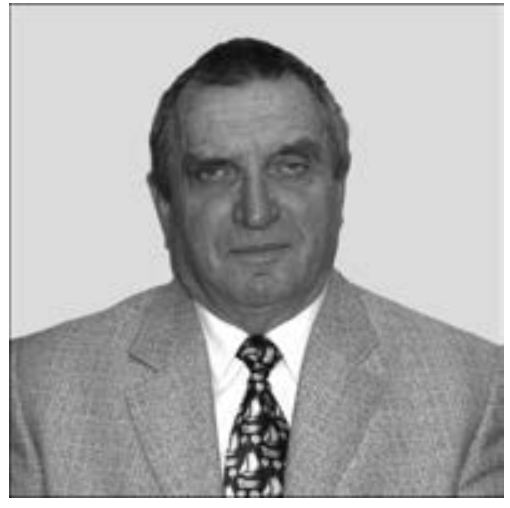

O.K. Nazarenko

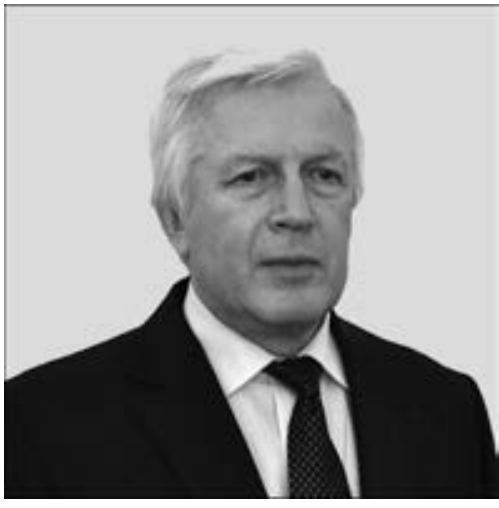

V.M. Nesterenkov

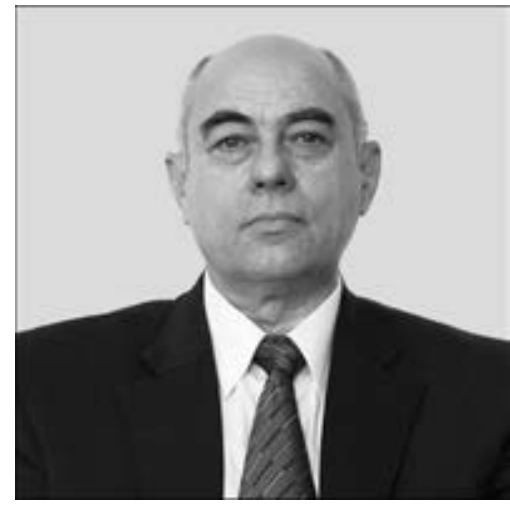

A.L. Majstrenko
The results of scientific achievements of 2013 were summarized at general meeting of the NAS of Ukraine from April 3, 2014. Simultaneously, grand presentation of the awards and prizes named after prominent scientists of Ukraine took place. In particular, the honour of wining of the Evgeny Paton Prize has a joint of researchers of Department of Physical Processes, Technology and Equipment for EBW of the E.O. Paton Electric Welding Institute, namely O.K. Nazarenko, Corresponding member of the NAS of Ukraine, Dr. of Tech. Sci., Professor, Head of Department; V.M. Nesterenkov, Corresponding member of the NAS of Ukraine, Dr. of Tech. Sci., Senior scientist, Deputy of head of department; and A.L. Majstrenko, Corresponding member of the NAS of Ukraine, Dr. of Tech. Sci., Head of department of the V.N. Bakul Institute for Superhard Materials, for series of works on the subject «Development of technology and computerized equipment for EBW in the aircraft, power machine building and metallurgy branches of industry».

It is a well-known fact that EBW in vacuum has wide technological capabilities allowing joining per one pass metals and alloys from 0.5 to $200 \mathrm{~mm}$ thickness. EBW is carried out at 5-15 times smaller rate of energy input than in arc welding, providing minimum deformations of welded parts and significantly reducing cost for their final mechanical treatment. This method of welding provides unique capability for producing of full-strength joints from high-strength alloys, which are used in key branches of industry.
The series of works, performed by the authors, represents the scientific results of research investigations, summarized experience of development and application of technology and equipment for EBW in aircraft, power machine building and metallurgy. All these works were carried out under the leadership and with the participation of Prof. Boris E. Paton. The list of achievements includes development of technological measures on providing of high stability of weld formation; application of EBW pre-modification of the edges for prevention of crack in the joints of highstrength difficult-to-weld aluminum alloys, used in manufacture of airplane wings at «Airbus» Company; production of around 30 modern machines for EBW with multi-coordinate traveling of welding gun and part; wide implementation of EBW technologies at «Zaray-Mashproekt» and «Motor-Sich» associations; development of technological processes and equipment for manufacture of pylons from titanium alloys for Russian aircraft SSI-100; manufacture of special equipment for space industry in India; for aircraft industry and production of drill bits for gas and oil-refining industry in USA; manufacture of capsules with granulated material in China; designing of structures of hard-alloy kubonit and steel operating tools for welding of plates and modifying of structure of nonferrous metals and alloys using friction stir methods for structure refinement.

Editorial Board of the Journal 